Portland State University

PDXScholar

Fall 12-4-2017

\title{
Investigation of Aerosol Optical and Chemical Properties Using Humidity Controlled Cavity Ring- Down Spectroscopy
}

Xijing Zhu

Portland State University

Follow this and additional works at: https://pdxscholar.library.pdx.edu/open_access_etds

Part of the Chemistry Commons

Let us know how access to this document benefits you.

Recommended Citation

Zhu, Xijing, "Investigation of Aerosol Optical and Chemical Properties Using Humidity Controlled Cavity Ring-Down Spectroscopy" (2017). Dissertations and Theses. Paper 4032.

https://doi.org/10.15760/etd.5916

This Dissertation is brought to you for free and open access. It has been accepted for inclusion in Dissertations and Theses by an authorized administrator of PDXScholar. Please contact us if we can make this document more accessible: pdxscholar@pdx.edu. 
Investigation of Aerosol Optical and Chemical Properties Using Humidity Controlled

\title{
Cavity Ring-Down Spectroscopy
}

\author{
by
}

Xijing (Jenny) Zhu

\begin{abstract}
A dissertation submitted in partial fulfillment of the requirements for the degree of
\end{abstract}

\author{
Doctor of Philosophy \\ in \\ Chemistry
}

\author{
Dissertation Committee: \\ Dean B. Atkinson, Chair \\ Reuben H. Simoyi \\ Robert Strongin \\ Andrew Rice
}

Portland State University

2017 


\begin{abstract}
Scientists have been observing a change in the climate since the beginning of the $20^{\text {th }}$ century that cannot be attributed to any of the natural influences of the past. Natural and anthropogenic substances and processes perturb the Earth's energy budget, contributing to climate change. In particular, aerosols (particles suspended in air) have long been recognized to be important in processes throughout the atmosphere that affect climate. They directly influence the radiative balance of the Earth's atmosphere, affect cloud formation and properties, and are also key air pollutants that contribute to a variety of respiratory and cardiovascular diseases. Despite their importance, aerosol particles are less well-characterized than greenhouse gases with respect to their sources, temporal and spatial concentration distribution, and physical and chemical properties. This uncertainty is mainly caused by the variable and insufficiently understood sources, formation and transformation processes, and complex composition of atmospheric particles. Instruments that can precisely and accurately measure and characterize the aerosol physical and chemical properties are in great demand. Atmospheric relative humidity $(\mathrm{RH})$ has a crucial impact on the particles' optical properties; the RH dependence of the particle extinction coefficient is an important parameter for radiative forcing and thus climate change modeling. In this work a Humidity-Controlled Cavity Ring-Down (HC-CRD) aerosol optical instrument is described and its ability to measure $\mathrm{RH}$ dependent extinction coefficients and related hygroscopicity parameters is characterized.
\end{abstract}

The HC-CRD is capable of simultaneously measuring the aerosol extinction coefficient at three wavelengths $(\lambda=355,532$, and $1064 \mathrm{~nm})$ and three different RHs (typically $20 \%$, 
$50 \%$, and $80 \%$ ). A range of chemicals and their mixtures were used to produce laboratory generated aerosols. Three mixture systems include one inorganic salts mixture system consisting of $\left(\mathrm{NH}_{4}\right)_{2} \mathrm{SO}_{4}, \mathrm{NH}_{4} \mathrm{HSO}_{4}, \mathrm{Na}_{2} \mathrm{SO}_{4}, \mathrm{NaHSO}_{4}$ serve as surrogates of the ionic salts found in the atmosphere. Two organic mixture systems were investigated: mixtures of $\mathrm{NaCl}$, D-glucose, sucrose, and glycine are benchmarks for compounds emitted from biomass burning. Finally, mixtures of $\left(\mathrm{NH}_{4}\right)_{2} \mathrm{SO}_{4}$ (ammonium sulfate, $\left.\mathrm{AS}\right)$ with a series of dicarboxylic acids including malonic acid, adipic acid, and azelaic acid are used as benchmarks to mimic urban pollutants.

The extinction coefficients were obtained as a function of RH from the HC-CRD measurements, from which optical growth factors $\mathrm{f}(\mathrm{RH})$ and $\gamma(\mathrm{RH})$ values can be determined to examine their dependence on chemical composition. A volume mixing rule was used to calculate the effective refractive index of the binary substrate mixtures, since both size and composition change during water uptake. The SDA/FMC algorithm developed by O'Neill, et al. 2005 is used to extract the van de Hulst phase shift parameter ( $\left.\rho_{\text {eff }}\right)$ from three-wavelength measurements of extinction. The fine mode fraction of extinction $(\eta)$ and fine mode effective radius $\left(\mathrm{R}_{\text {eff }}\right)$ of laboratory generated aerosol particles can be then determined. An iterative algorithm was developed to retrieve the change in refractive index of particles as function of $\mathrm{RH}$. The calculated $\mathrm{R}_{\mathrm{eff}}$ of aerosols at different RHs were used to obtain the physical size growth factor (gf), and $\kappa(\mathrm{RH})$. The size changes as a function of water uptake describe the dependence of aerosol optical properties on chemical composition. 
This work demonstrates the capability of conducting aerosol optical measurements using HC-CRD to determine the RH dependence of aerosol optical properties. The HC-CRD measurements combined with the SDA/FMC method to retrieve aerosol size for laboratory generated aerosols establish the connection between the optical properties and the aerosol particles' chemical compositions. It also underlines the importance and need for future investigation on the hygroscopic properties of atmospheric aerosols. This work is successfully developed a method that enables using the aerosols optical measurements to predict the compositions; it will greatly contribute to the atmospheric aerosol measurement and global climate modelling. 
Dedication

To my family...mom, dad, and grandma

To my advisor Dean Atkinson, he is a Godsend gift for me

To my big family, Uncle Dr. Zhao Qiang Fang and Dr. Zhao Ben Fang, cousins Min Fang, Leiyah Shan, and Bin Fang.

To my father figures, Dr. Mike Panigot, Dr. Reuben H. Simoyi and Dr. Vern Bissell

To Jackie Slack, Lyndsey Rush, thanks for me as my extended families

To the memory of my grandpa Zong Dai Fang, although he was my inspiration to pursue my doctoral degree, he was unable to see my graduation. This is for him. 


\section{Acknowledgements}

Life was like a box of chocolate. You never know what you're going to get. (Forest Gump)

The act itself becomes the destination. It is not just that there's no finish line; it's that you define the finish line. ...just keep going. Don't stop. Don't even think about stopping until you get there, and don't give much thought to where "there" is. Whatever comes, just don’t stop. (Phil Knight, 2016)

For I know the plans I have for you," declares the Lord, "plans to prosper you and not to harm you, plans to give you hope and a future. Jeremiah 29:11 (NIV)

The American Dream takes me to the journey of graduate schools. This dissertation is a combination of science, work and emotions at Portland State University. From my first number one in the chemistry exam, I knew my life was going to be filled with chemistry.

To my Godsend advisor Dr. Atkinson, I could not have asked a better advisor to work. You are the gift from God. Thanks for being part of the journey

To my family, mom, dad, and grandma, I am grateful to receive the support from you all.

To my friend, Jackie Slask (This is also for you), Tharuka Jayathilaka (also for your father), Joshua Murray, Lisa Sablan, Laurie Tull, Janell Lum, Dr. Lei Wang

And the reminder of God: Baby Paul 
Table of Contents

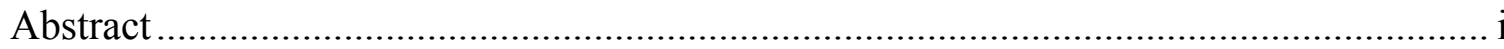

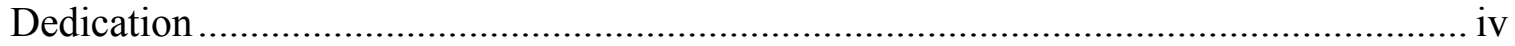

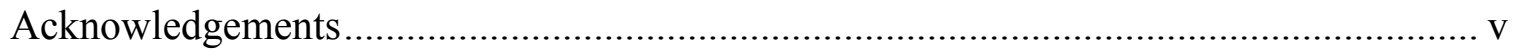

List of Tables ..................................................................................................... viii



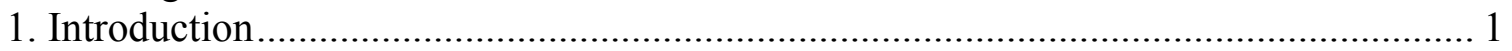



1.2 Greenhouse gases $(\mathrm{GHG})$ and climate change.................................................... 2

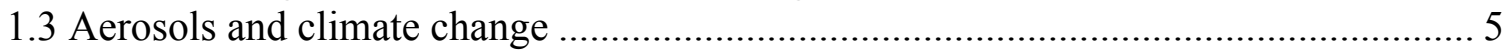



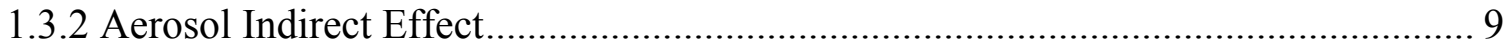

1.3.3 Semi-direct Effect ...................................................................................... 10

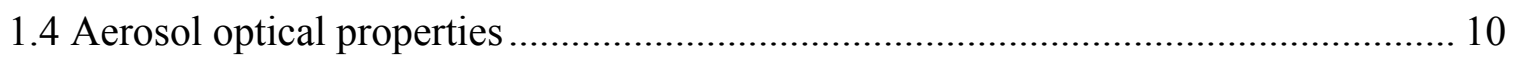

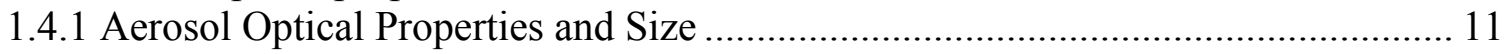

1.4.2 Aerosol Optical Properties and Chemical Composition ...................................... 13

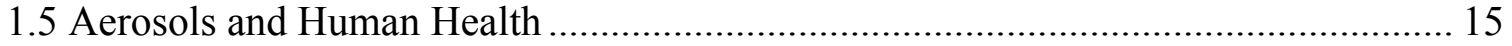

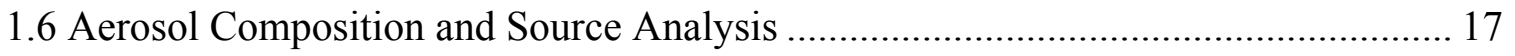

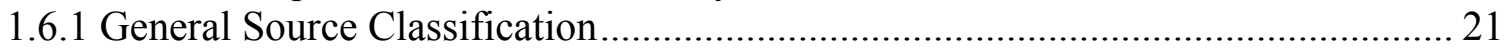

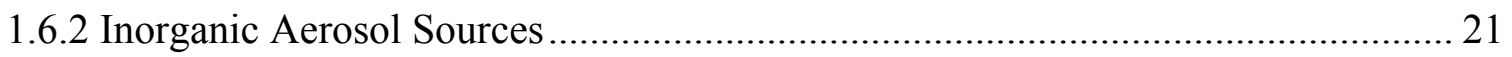

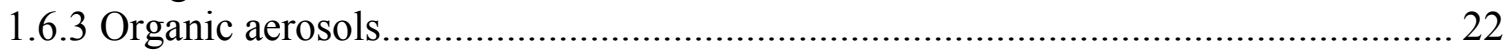

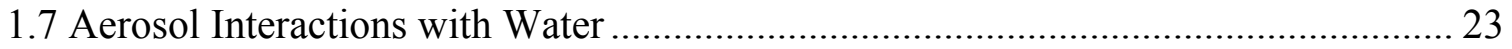

1.8 HC-CRD Laboratory Measurements of Hygroscopic Growth ................................ 34



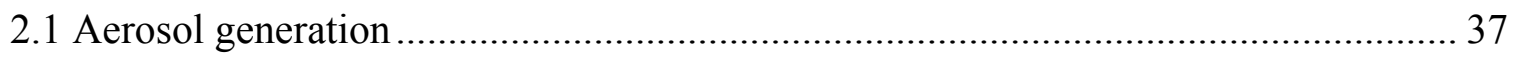

2.2 Humidity-Controlled Cavity Ring-Down (HC-CRD) ......................................... 38

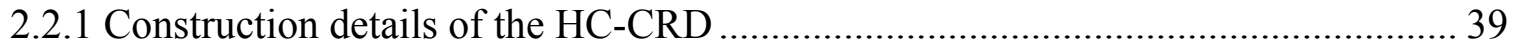

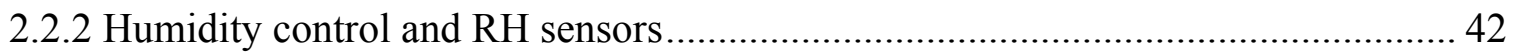

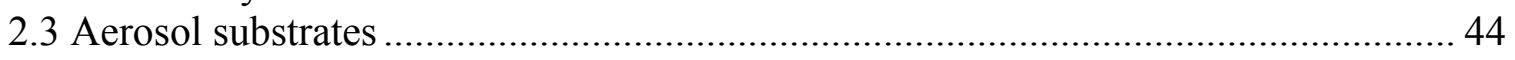

2.4 Derivation of particle size information from extinction coefficients at three

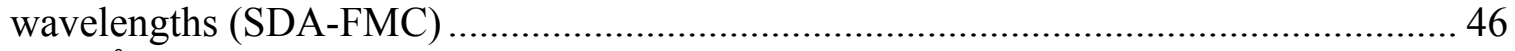

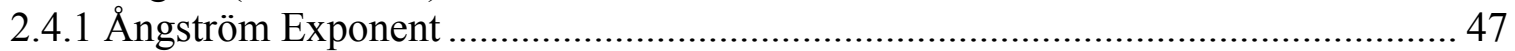

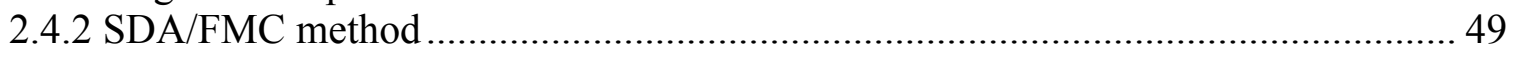

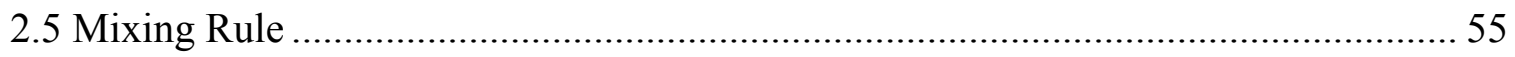

2.5.1 Determination of the effective refractive index for humidity controlled channels.. 57

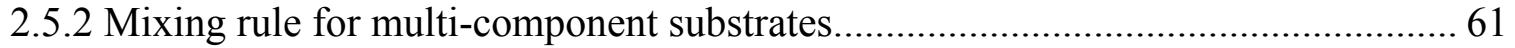

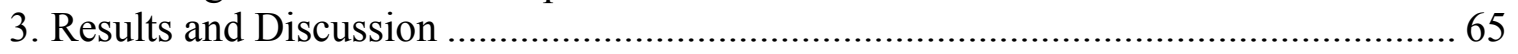

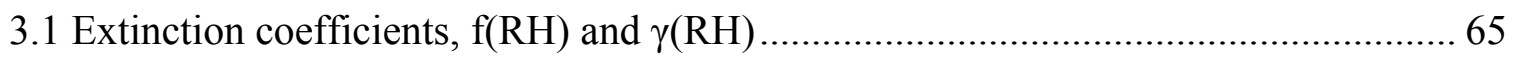

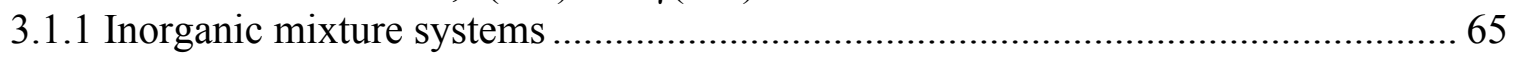

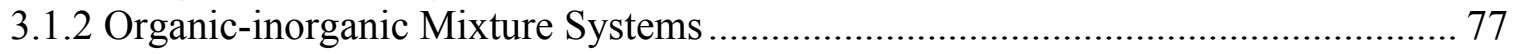

3.1.2.1 Organic-inorganic Mixture Systems: $\mathrm{NaCl}$ vs Organic systems ........................ 77

3.1.2.2 Organic-inorganic Mixture Systems: Dicarboxylic acids ................................. 80

3.2 Determination of the effective refractive indices and effective radius $\left(\mathrm{R}_{\mathrm{eff}}\right) \ldots \ldots \ldots \ldots . . . .84$ 
3.2.1 The effective refractive indices, $\mathrm{R}_{\mathrm{eff}}$, growth factors $(\mathrm{gf}), \mathrm{K}(\mathrm{RH})$ and WUP values

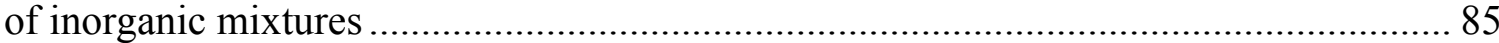
3.2.2 The effective refractive indices, $\mathrm{R}_{\mathrm{eff}}$, growth factors $(\mathrm{gf}), \mathrm{K}(\mathrm{RH})$ and WUP values of inorganic/organic mixtures 92

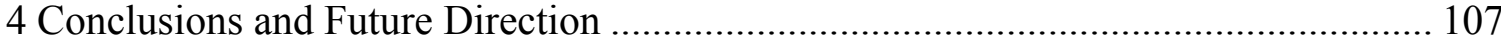

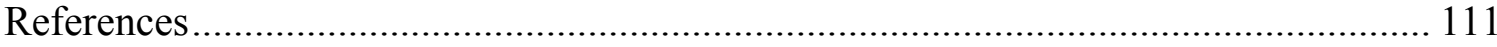


List of Tables

Table Title $\quad$ Page

Table 1-1 Air quality standards for PM 16

Table 2-1 Substrates analyzed in this study 45

Table 3-1 DRH and CRH for the substrates of sulfate and bisulfate system 66

Table 3-2 The extinction coefficients at three different humidity conditions 67

for the $\left(\mathrm{NH}_{4}\right)_{2} \mathrm{SO}_{4}-\left(\mathrm{NH}_{4}\right) \mathrm{HSO}_{4}$ mixture system

Table 3-3 $\mathrm{f}(\mathrm{RH})$ and gammas at three different humidity conditions for the 68 $\left(\mathrm{NH}_{4}\right)_{2} \mathrm{SO}_{4}-\left(\mathrm{NH}_{4}\right) \mathrm{HSO}_{4}$ mixture system

Table 3-4 The extinction coefficients, $\mathrm{f}(\mathrm{RH})$ and gammas at three different 72 humidity conditions for the $\mathrm{Na}_{2} \mathrm{SO}_{4}-\mathrm{NaHSO}_{4}$ mixtures system

Table 3-5 $\mathrm{f}(\mathrm{RH})$ and gammas at three different humidity conditions for the 73 $\mathrm{Na}_{2} \mathrm{SO}_{4}-\mathrm{NaHSO}_{4}$ mixtures system

Table 3-6 The extinction coefficients, $\mathrm{f}(\mathrm{RH})$ and $\gamma(\mathrm{RH})$ at three different $\quad 78$ humidity conditions for mixed sucrose and $\mathrm{NaCl}$ mixture aerosols

Table 3-7 The extinction coefficients, $\mathrm{f}(\mathrm{RH})$ and gammas at three different 79 humidity conditions for glycine and $\mathrm{NaCl}$ mixtures system

Table 3-8 The extinction coefficients, $\mathrm{f}(\mathrm{RH})$ and gammas at three different $\quad 80$ humidity conditions for glucose and $\mathrm{NaCl}$ mixtures system

Table 3-9 The extinction coefficients and pair-wise $\mathrm{f}(\mathrm{RH})$ and $\gamma(\mathrm{RH})$ at $\quad 81$ three different humidity conditions for malonic acid (MA) and ammonium sulfate (AS) mixtures

Table 3-10 The extinction coefficients, $\mathrm{f}(\mathrm{RH})$ and $\gamma(\mathrm{RH})$ at three different

humidity conditions for adipic acid (AA) and ammonium sulfate (AS) mixtures

Table 3-11 The extinction coefficients, $\mathrm{f}(\mathrm{RH})$ and $\gamma(\mathrm{RH})$ at three different humidity conditions for azelaic acid (AzA) and ammonium sulfate (AS) mixtures

Table 3-12 The refractive index and effective radius for three different 86 relative humidity conditions, and the derived growth factor, $\kappa$ $(\mathrm{RH})$ and WUP for the $\left(\mathrm{NH}_{4}\right)_{2} \mathrm{SO}_{4}-\left(\mathrm{NH}_{4}\right) \mathrm{HSO}_{4}$ mixtures

Table 3-13 The derived growth factor, $\kappa(\mathrm{RH})$ and WUP for the $\left(\mathrm{NH}_{4}\right)_{2} \mathrm{SO}_{4}$ 87 $\left(\mathrm{NH}_{4}\right) \mathrm{HSO}_{4}$ mixtures

Table 3-14 $\quad \kappa(\mathrm{RH})$ values obtained from this work and the literature 
Table 3-15 The refractive index and effective radius at three different $\mathrm{RH} \quad 90$ conditions, for the $\mathrm{Na}_{2} \mathrm{SO}_{4}-\mathrm{NaHSO}_{4}$ mixtures

Table 3-16 The derived growth factor, $\kappa(\mathrm{RH})$ and WUP for the $\mathrm{Na}_{2} \mathrm{SO}_{4^{-}} \quad 91$ $\mathrm{NaHSO}_{4}$ mixtures

Table 3-17 The effective refractive index and effective radius at three 92 different $\mathrm{RH}$ conditions, for the sucrose and $\mathrm{NaCl}$ mixtures

Table 3-18 The derived growth factor(gf), $\kappa(\mathrm{RH})$, and WUP for the glycine 95 and $\mathrm{NaCl}$ mixtures

Table 3-19 The effective refractive index and effective radius at three different $\mathrm{RH}$ conditions, and the derived growth factor(gf), $\kappa(\mathrm{RH})$, and WUP for the glucose and $\mathrm{NaCl}$ mixtures

Table 3-20 The effective refractive index and effective radius at three different $\mathrm{RH}$ conditions, and the derived growth factor(gf), $\kappa(\mathrm{RH})$, and WUP for malonic acid *(MA) and ammonium sulfate (AS) mixtures

Table 3-21 The effective refractive index and effective radius at three different $\mathrm{RH}$ conditions, and the derived growth factor(gf), $\kappa(\mathrm{RH})$, and WUP for adipic acid *(AA) and ammonium sulfate (AS) mixtures

Table 3-22 The effective refractive index and effective radius at three different $\mathrm{RH}$ conditions, and the derived growth factor (gf), $\kappa(\mathrm{RH})$, and WUP for azelaic acid *(AzA) and ammonium sulfate (AS) mixtures system

Table 3-23 summarizes the $\kappa(\mathrm{RH})$ values for single substrates obtained from 105 this work and compares them to literature values 


\section{List of Figures}

Figures Caption $\quad$ Page

Figure 1-1 Main drivers of climate change. 2

Figure 1-2 The greenhouse gas concentrations over the last 2000 years 4

Figure 1-3 Radiative forcing estimates in 2011 relative to 1750 and 7 aggregated uncertainties for the main drivers of climate change

Figure 1-4 Size and wavelength dependence of the light scattering 13 efficiency

Figure 1-5 Interdependence and feedback between atmospheric aerosol composition, properties, interaction and transformation, climate and health effects and source categories.

Figure 1-6 Growth factors (particle size change) as a function of relative 26 humidity for a series of sulfate containing aerosols

Figure 1-7 (a)growth curves for $\mathrm{NaCl}$ and $\left(\mathrm{NH}_{4}\right)_{2} \mathrm{SO}_{4}$ of same dry sizes; (b) 27 growth curve for $\mathrm{NaCl}$ of different dry sizes

Figure 1-8 Critical supersaturation as a function of the particle dry diameter 30 for different compounds and mixtures along with $\kappa$ parameterization

Figure 1-9 Measured $\mathrm{f}(\mathrm{RH})$ with scanning relative humidity nephelometry from pure (a) $\mathrm{NaCl}$ and (b) $\left(\mathrm{NH}_{4}\right)_{2} \mathrm{SO}_{4}$ with deliquescence and crystallization RH.

Figure 2-1 Aerosol generation and dilution system and HC-CRD operation 36

Figure 2-2 An experimental diagram showing the essential features of CRD 40 experiment

Figure 2-3 The parabolic equation generated curves and "ada"plot 53

Figure 2-4 The simulation plots of the (a, top) Angström exponent and (b, 54 bottom) curvature for the monomodal lognormal aerosol size distributions with varying effective radii.

Figure 2-5 Schematic representation of the iterative algorithm 58

Figure 3-1 $\mathrm{f}(\mathrm{RH})$ at three different humidity conditions for the $\left(\mathrm{NH}_{4}\right)_{2} \mathrm{SO}_{4^{-}} \quad 68$ $\left(\mathrm{NH}_{4}\right) \mathrm{HSO}_{4}$ mixture system

Figure 3-2 $\quad \gamma(\mathrm{RH})$ (Gammas) at three different humidity conditions for the 69 $\left(\mathrm{NH}_{4}\right)_{2} \mathrm{SO}_{4}-\left(\mathrm{NH}_{4}\right) \mathrm{HSO}_{4}$ mixture system

Figure 3-3 $\quad \mathrm{f}(\mathrm{RH})$ at three different humidity conditions for the $\mathrm{Na}_{2} \mathrm{SO}_{4^{-}} \quad 73$ $\mathrm{NaHSO}_{4}$ mixtures system 
Figure 3-4 $\quad \gamma(\mathrm{RH})$ (gammas) at three different humidity conditions for $\mathrm{Na}_{2} \mathrm{SO}_{4}-\mathrm{NaHSO}_{4}$ mixtures system

Figure 3-5 SEM images of spherical pure ammonium sulfate particles, irregular particle of AA:AS= 3:1 mixture and pure adipic acid

Figure 3-6 Schematic drawing of the process resulting in an inverse Kelvin 102 effect

Figure 3-7 Some comparison between literature $\kappa(\mathrm{RH})$ values vs HC-CRD 105 measured values

Figure 4-1 Anatomy of a mobile air pollution detection lab 


\section{Introduction}

\subsection{Climate and climate change}

Weather and climate have a great impact on human life on Earth, affecting food production and health and well-being. The weather is loosely defined as the fluctuating state of atmospheric conditions that occur locally over a short period, as characterized by temperature and relative humidity, wind speed and direction, precipitation, cloudiness, etc. Climate, which comes from the ancient Greek "klima" meaning 'slope, area/zone' is commonly defined as the weather pattern experienced over a longer finite period for a particular region. The Earth's climate and weather is powered by solar radiation (Figure 1-1). The climate of the Earth depends on the amount of solar energy retained by the land, ocean and atmosphere and how the system responds to changes in this retention. The Earth's climate has natural variability and has constantly changed over decades, centuries, and millennia. Climate change is distinguished from weather as a significant variation of the mean state of the system's characteristics persisting for a decade or longer. Climate forcing (e.g., radiative forcing) is used to quantitatively describe induced changes in the atmospheric state, such as the radiative balance. Radiative forcing is defined as the change in the net radiative flux at the top of the atmosphere due to a change in an external factor or "driver", an example being the concentration of carbon dioxide. A positive forcing causes warming, while the negative forcing produces cooling of the climate (IPCC $\left.5^{\text {th }} \mathrm{WG} 1\right)$. 


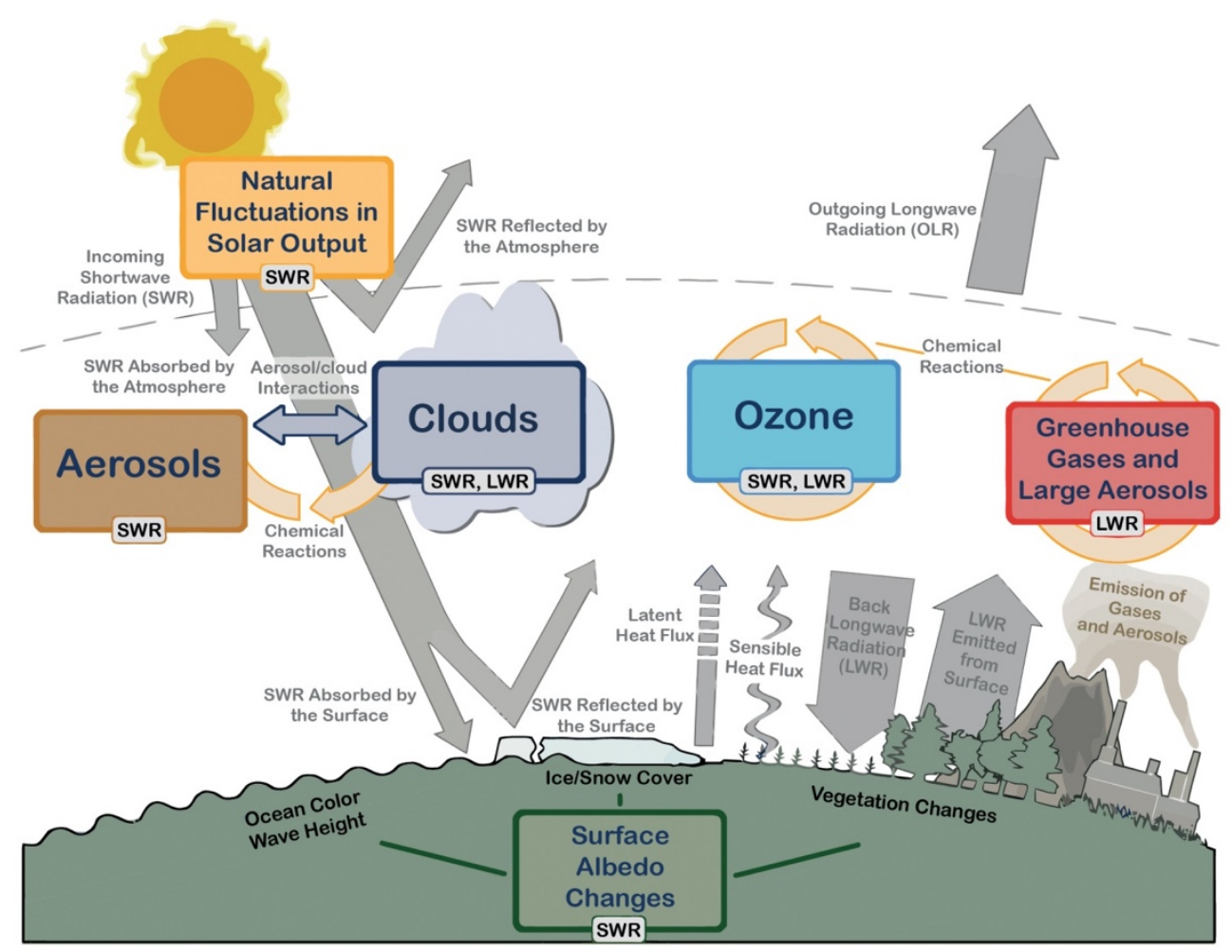

Figure 1-1: Main drivers of climate change. The radiative balance between incoming solar shortwave radiation (SWR) and outgoing longwave radiation (OLR) is influenced by global climate 'drivers' (From IPCC $5^{\text {th }}$ report Fig1-1)

\subsection{Greenhouse gases $(\mathrm{GHG})$ and climate change}

The latest report of the International Panel on Climate Change (IPCC AR 5) defines the climate as a complex system consisting of five major interacting components comprising the atmosphere, hydrosphere, cryosphere, land surface, and biosphere. The climate system is influenced by many sources of external forcing with solar radiation as the most significant driver. Human activities have undeniably had a direct effect on the climate system but the magnitude of the anthropogenic forcing(s) is less well-characterized.

The atmosphere is the most unstable component of the climate system and its composition has shifted with the evolution of the Earth. The modern-day dry atmosphere 
is a mixture of $78.1 \%$ nitrogen $\left(\mathrm{N}_{2}\right), 20.9 \%$ oxygen $\left(\mathrm{O}_{2}\right)$ and $0.93 \%$ argon $(\mathrm{Ar})$; all of which are transparent in the visible and infrared regions of the spectrum and relatively stable against photolysis by the balance of the solar radiation except at the outer edge where the most energetic ultraviolet radiation is absorbed. In contrast, trace gas species such as carbon dioxide $\left(\mathrm{CO}_{2}\right)$, methane $\left(\mathrm{CH}_{4}\right)$, nitrous oxide $\left(\mathrm{N}_{2} \mathrm{O}\right)$ and ozone $\left(\mathrm{O}_{3}\right)$, all present at less than $1 \%$ by volume, absorb strongly in the infrared and thus play a crucial role in the Earth's radiation budget. These species are collectively known as greenhouse gases (GHGs) because their radiative effect is similar to that of the windows in a greenhouse. The atmosphere contains a highly variable amount of water vapor, which is also a greenhouse gas. Current life on Earth relies on the energy coming from the sun, amplified by the natural GHGs. Approximately half of the sunlight reaching Earth's atmosphere passes through the air and cloud to the ground, where it is absorbed and then re-radiated in the infrared (as heat). Much of the heat is absorbed by the greenhouse gases and radiated back to the surface, creating a suitable environment for life.

Before the industrial revolution in the 1700 s, the climate was primarily governed by natural influences. Recent climate change, especially the observed warming since the mid- $20^{\text {th }}$ century (shown in Figure 1-2) is due at least in part to human activities. Global monitoring and modeling efforts have provided solid evidence that human activities such as the burning of fossil fuel, agriculture development, waste generation, synthetic chemical production, biomass burning and changes in land use are significantly altering the level of radiatively- and chemically-active gases and aerosols in the atmosphere.(Hewitt, C.N,2009) The increases in the concentration of anthropogenic 
GHGs are changing the Earth's natural heat balance and causing global warming. The greenhouse gases' effect on climate and the mechanisms of the effects have been intensively studied in the past few decades. Best scientific estimates of the anthropogenic impact and the response of our current climate system are documented in the recent $5^{\text {th }}$ IPCC report.

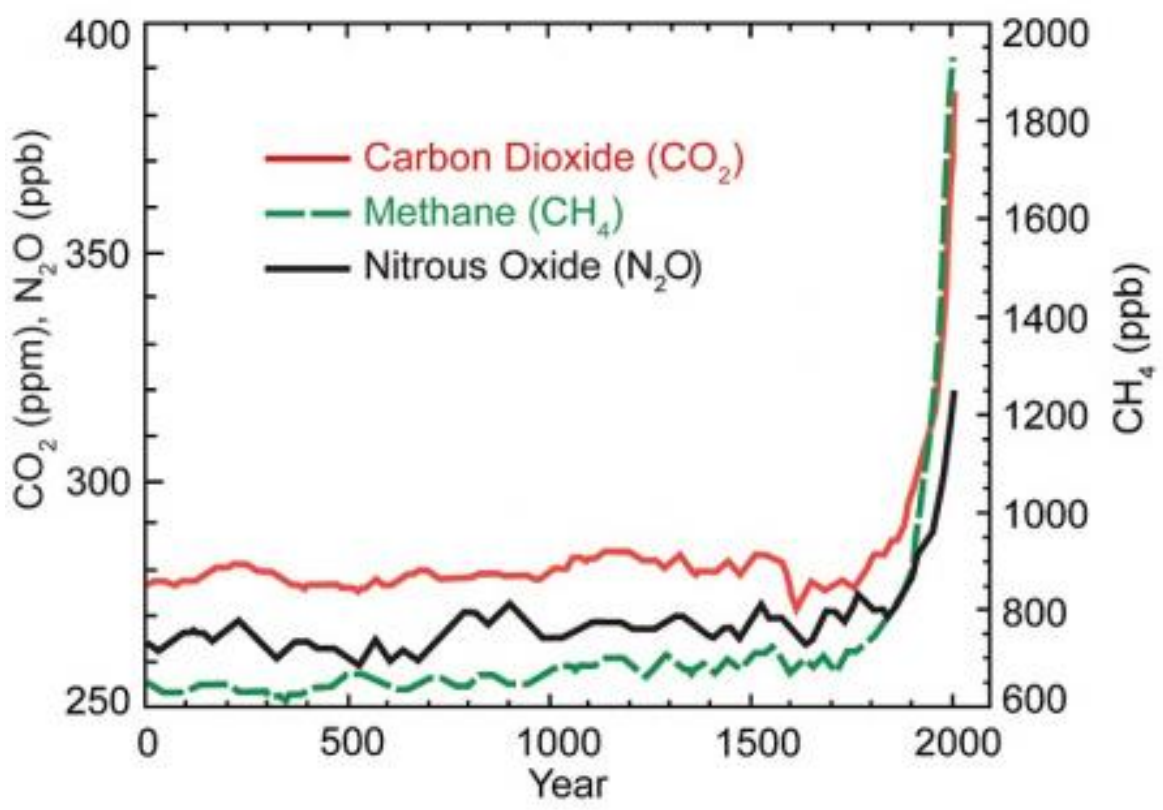

Figure 1-2: The graph shows the greenhouse gas concentrations over the last 2000 years: the rapid concentration increases since 1975 can be clearly observed. Source: U.S. National Climate Assessment (2014) 


\subsection{Aerosols and climate change}

In addition to the gases that are the majority constituents, the atmosphere also contains suspended solid and liquid particles (aerosols) and clouds - technically large water aerosols, but so important to the atmosphere that they are regarded as a separate entity. In the IPCC report, atmospheric aerosols are defined as suspensions of small solid or liquid particles with sizes between a few nanometers and ten micrometers $(\mu \mathrm{m}$, sometimes called microns) in diameter that reside in the atmosphere for at least several hours. The particles within an aerosol, often referred to interchangeably as the aerosol, can be categorized according to their physical properties: size, chemical composition, water content, etc. and/or their origin. (IPCC $5^{\text {th }}$ report WG1) Aerosol particles in the Earth's atmosphere arise from both natural sources and anthropogenic activities. Typical troposphere aerosols exhibit number concentrations varying from tens to hundreds of particles per cubic centimeter $\left(\mathrm{cm}^{-3}\right)$ in remote locations to over $10^{4} \mathrm{~cm}^{-3}$ at polluted urban sites. Their mechanism of formation is also characterized as primary or secondary: primary aerosols are emitted directly from a source, whereas secondary aerosols are formed from gaseous precursors via nucleation and/or condensation. Natural aerosol sources include mineral dust from the desert, sea salt aerosols from the ocean, dust and ash from volcanic eruptions, biogenic debris consisting of viruses, fungi and spores as well as smoke from the unplanned burning of biomass (forest fires). Anthropogenic aerosol sources include industrial emissions, resuspension of roadside dust, fossil fuel combustion, and intentional burning of waste and biomass. After emission of primary (or nucleation of secondary) aerosols, various physical and chemical interactions and 
transformations involving $\mathrm{SO}_{2}, \mathrm{NO}_{\mathrm{x}}$, volatile organic compounds (VOCs), and other chemicals emitted from both natural and anthropogenic activities (Seinfeld and Pandis, 2006) result in evolution of the particle's size, structure, and composition. In addition to nucleation and condensation of gaseous species, the particles also undergo coagulation and interact with clouds leading to both scavenging and evaporation effects.

The radiative effects of aerosols are complex and some are still not well-understood. Aerosol direct effects are reasonably well-characterized, referring to the interaction of the particles with the incoming solar radiation especially during clear-sky (non-cloudy) conditions. For many atmospheric conditions scattering is dominant over absorption and part of the incoming solar radiation is redirected back into space producing negative radiative forcing. The aerosol indirect effect is related to changes in the radiative forcing of clouds brought about by interactions between the aerosol particles and clouds. Despite their small fractional composition in the atmosphere; aerosol particles have a profound influence on climate through these processes. 




Figure 1-3: Radiative forcing estimates in 2011 relative to 1750 and aggregated uncertainties for the main drivers of climate change. (From 5th IPCC WGR-1 Figure SPM.5 report, 2013)

Figure 1-3 shows best scientific estimates of the total amount of radiative forcing caused by natural substances and human activities between 1750 and 2010. The magnitude of each driver is quantified as radiative forcing calculated in watts per square meter $\left(\mathrm{W} \mathrm{m}^{-2}\right)$ representing the size of the energy imbalance in the atmosphere due to that effect. The colored bar represents the magnitude of the net radiative forcing, while the black diamond shape with the thin black bar (i.e., the error bar) represents the corresponding uncertainty. Short error bars indicate that the effect is better understood and obtains a higher level of confidence. As shown by the red bars near the bottom of the Figure, the total radiative forcing is positive, with a 2011 magnitude that is $+2.29 \mathrm{~W} \mathrm{~m}^{-2}$ above the 
pre-industrial level. The forcing is also increasing more rapidly now than in the past as shown by the 1950 and 1980 results. The radiative forcing from the GHGs produces the majority of the total positive forcing and the contribution from these drivers has a relatively high level of confidence. This confidence is the result of a well-established observation system and adequate knowledge of the mechanism of the forcing.

The climate effect of aerosols depends on their atmospheric distribution, hygroscopicity, optical properties and ability to serve as $\mathrm{CCN}$ and IN, with particle number size distribution, chemical composition, mixing states and morphology all affecting the aerosol optical properties and aerosol-cloud interactions. The spatio-temporal distributions and properties are related in a complicated way to sources, atmospheric transformations, and removal mechanisms for the various aerosol types. The measurement capability of many of the key aerosol properties is not comparable in detail or spatial scope to the current GHG observation system and as a result, the effect of aerosol on climate is often highly simplified in models. These simplifications and errors related to the imprecise knowledge of the aerosol loadings are then propagated into the total radiative forcing calculations, generating substantial uncertainties in the climate response. Thus the error bars on the total radiative forcing estimates near the bottom of Figure 1-3 come mainly from the uncertainties in the aerosol effects. In order to be more confident in our ability to predict future climate effects there is still a need to improve aerosol models, and to continue laboratory and field studies with advanced instruments like the one used in this dissertation. 


\subsubsection{Aerosol Direct Effect}

The direct effect depends on the size distribution and amount of aerosol that the light interacts with, but is also dependent on single scattering albedo (SSA) the ratio of scattering to extinction. Whereas sulfate and sea salt aerosols are mostly scattering in the visible spectrum $\mathrm{SSA} \approx 1.0$ at $500 \mathrm{~nm}$, black carbon aerosols are considerably more absorbing SSA $\approx 0.2$ at 500nm (Ramanathan et al., 2001) resulting in localized heating of the atmosphere, rather than generalized cooling. Nearly all aerosols are composed of an amalgamated mixture of several components with potentially different optical properties and the morphology of the particle can thus also affect the amounts of scattering and absorption produced. For example, particles with absorbing cores and transparent outer shells can enhance the absorption of the core due to lensing.

\subsubsection{Aerosol Indirect Effect}

Indirect effects of aerosols include their influence on the radiation balance and hydrology through their impact on cloud microphysical processes (first indirect effect) and amount (second indirect effect). (IPCC 5th) The first indirect effect, also known as the cloud albedo effect, is when as increased number concentration of particles results in a larger concentration of smaller cloud droplets, leading to formation of a brighter cloud and more cooling. The second indirect effect, the cloud lifetime effect, is when particles change the cloud's liquid water content and/or cloud height resulting in a change in the cloud's lifetime, potentially increasing or decreasing the cooling. The aerosol-cloud-precipitation process consists of many possible pathways that can amplify or dampen this effect. The 
indirect effects contribute significant uncertainty due to the complexity and variety of atmospheric interactions involved and the spatial scale on which they take place.

\subsubsection{Semi-direct Effect}

The semi-direct effect is when aerosols optical properties affect the lifetimes of clouds. For example, regardless of cloud type the presence of reflecting aerosols tends to brighten the cloud, resulting in prolonged cloud lifetime and less precipitation. Alternatively, aerosols containing $\mathrm{BC}$ from soot can cause localized warming resulting in cloud droplet evaporation and decreased cloud lifetime and extent. Absorbing aerosols also affect the static stability characteristics of the atmosphere and the surface energy budget. Therefore the semi-direct effect can induce positive or negative changes in the net radiative flux at the top of the atmosphere (TOA) and/or changes in the global mean net shortwave radiation at the surface. (Claudo Tomasi, Sandro Fuzzi, and Alexander Kokhanovsky, 2017)

\subsection{Aerosol optical properties}

The aggregate effect of all of the particle's scattering and absorption of the radiation is collectively referred to as the aerosol optical properties. When light strikes a particle, its electric charges are excited into an oscillatory motion. The excited electric charges reradiate energy in all directions in a process called scattering. Alternatively, the particles may absorb the light and convert part of the radiation into thermal energy. The combination of scattering and absorption is referred to as extinction. The extinction $\left(\mathrm{b}_{\mathrm{ext}}\right)$ scattering $\left(b_{\text {scat }}\right)$ and absorption $\left(b_{\text {abs }}\right)$ coefficients are the directly measured aerosol 
optical properties representing the loss of light as it travels through the aerosol defined through the Beer-Lambert equation $\mathrm{I}=\mathrm{I}_{0} \mathrm{e}^{-\mathrm{bl}}$. The relationship described above can be written as

$$
b_{\text {ext }}=b_{\text {scat }}+b_{a b s}
$$

where $b_{\text {ext }}, b_{\text {scat }}, b_{a b s}$ are the extinction, scattering and absorption coefficients respectively, all expressed in units of inverse length $\left(\mathrm{m}^{-1}, \mathrm{Mm}^{-1}\right.$, or $\left.\mathrm{cm}^{-1}\right)$.

\subsubsection{Aerosol Optical Properties and Size}

Particle size is one of the most important physical characteristics, affecting both lifetime and optical properties. Aerosol particles with effective diameters (the particles are generally imagined to be spherical and non-spherical shapes are often represented by an equivalent diameter that is an average of the actual dimensions) less than $2.5 \mu \mathrm{m}$ are called fine mode aerosols. Within the fine mode, particles are then separated into a nucleation mode, with diameters less than $100 \mathrm{~nm}$, and an accumulation mode, ranging from $100 \mathrm{~nm}$ to $2.5 \mu \mathrm{m}$. Coarse mode particles are those with diameters greater than 2.5 $\mu \mathrm{m}$ to approximately $10 \mu \mathrm{m}$ where the lifetime begins to shorten due to gravitational settling (Seinfeld and Pandis 1998, Mahowald, N. et al. 2011). Coarse mode particles are often primary aerosols of natural origin, while the anthropogenic aerosols occur mostly in the fine mode and have a significant contribution from secondary formation. The aerosol particles' size determines their life cycle and removal mechanisms. Particle lifetimes vary from hours to days, depending upon their size. The aerosol life cycle then determines the 
spatial and temporal distribution of the particles and thus the chemical, microphysical and optical properties observed at any given location and time.

All particles produce light scattering, but particles much smaller than the wavelength of light have lesser optical influence as they are not efficient light scatterers. Very large particles scatter a lot of light, but cannot stay in the atmosphere for long so they also have minimal impact. As Figure 1-4 shows, particles with diameters near the wavelength of the light scatter it most effectively. As the radiation passes the particle, the particle creates a "shadow" of area $\mathrm{C}_{\text {scat }}$ with units of area $\left(\mathrm{m}^{2}\right) .{ }^{4}$ This shadow can be larger or smaller than the geometric particle size. The efficiency with which an individual particle can scatter light is expressed as a ratio of a particle's effective cross section to its geometric cross section and is given the symbol $\mathrm{Q}_{\text {scat }}$

$$
C_{\text {scat }}=Q_{\text {scat }} \cdot A
$$

where $\mathrm{A}$ is the aerosol particle cross-sectional area and $\mathrm{C}_{\text {scat }}$ is the scattering cross section. $\mathrm{Q}_{\text {scat }}$ is thus a dimensionless scattering efficiency used as a per-particle version of the scattering coefficient. 




Figure 1-4 Size and wavelength dependence of the light scattering efficiency produced by the MiePlot (V.4211) program using the refractive index of $\mathrm{NaCl}$

(http://www.philiplaven.com/mieplot.htm)

In Figure 1-4, the scattering efficiency varies as a function of the particle size. The small particles are very inefficient at scattering light. As particle increases in size from $0.1 \mu \mathrm{m}$ to $1 \mu \mathrm{m}$, it becomes a more efficient light scatter. In particular, at a size that is close to the wavelength of the incident light, its scattering efficiency reaches a maximum and then drops off to a plateau value with periodic variations at the other size resonances.

\subsubsection{Aerosol Optical Properties and Chemical Composition}

The chemical composition of the aerosol particles determines the relative strength of the interaction with light, expressed as the refractive index. Refractive index is a dimensionless number that quantitatively describes how strongly light of a given wavelength is bent as it passes through a material and whether or not it is absorbed. The refractive index $\mathrm{m}$ is a complex number 


$$
m=n+i k
$$

where $\mathrm{n}$, the real part, represents the bending or scattering component; and $\mathrm{k}$, the imaginary part, is the absorbing component; both are functions of the wavelength $\lambda$. The "white" aerosol particles (e.g., ammonium sulfate) have small or zero $\mathrm{k}$ in the visible region of the electromagnetic spectrum and generally cause cooling while absorbing particles with non-zero $\mathrm{k}$ can also contribute to warming. The refractive index of particles with multiple species (internal mixture) is obtained by taking a weighted linear combination of the $\mathrm{n}$ and $\mathrm{k}$ values for the constituents. Mole fractions would be the most correct weighting, but volume fractions are sometimes used.

The chemical composition of the aerosol also determines the hygroscopicity of the particles, which plays a role in both the direct and indirect effect (the ability to take up water is responsible for aerosol cloud-seeding). In the simplest terms, the addition of water to a particle causes it to grow in size, increasing its scattering; but there are a number of more subtle and interrelated effects. The atmospheric aerosol contains mixtures of inorganic and carbonaceous types both between (external mixture) and within (internal mixture) the individual particles. Inorganic aerosols are composed of watersoluble ions like sulfate, nitrate, and ammonium, all quite hygroscopic. Carbonaceous aerosols are composed of molecules with a range of hygroscopicity from highly oxygenated organic carbon (OC) species like dicarboxylic acids, to very hydrophobic elemental carbon (EC, sometimes called black carbon $\mathrm{BC}$ ) particles. The presence of unsaturation and/or heteroatoms in OC can impart UV absorption producing "brown 
carbon" (BrC) particles. Most OC aerosol particles do not exhibit as much hygroscopic growth as inorganic aerosol particles, so their optical properties have an intermediate relative humidity dependence. The variability of the hygroscopic response of the particles, in addition to the difference in optical properties, makes even direct effect modeling more difficult.

\subsection{Aerosols and Human Health}

The evidence of the public health impact of airborne particulate matter (PM) consistently shows adverse effects at the exposure levels currently experienced by urban populations in both developed and developing countries (WHO air quality guide line 2006). Aerosol particles were included (as particulate matter "PM") in the six criteria pollutants of the National Ambient Air-Quality Standards (NAAQS) along with sulfur dioxide $\left(\mathrm{SO}_{2}\right)$, nitrogen dioxide $\left(\mathrm{NO}_{2}\right)$, carbon monoxide $(\mathrm{CO})$, ozone $\left(\mathrm{O}_{3}\right)$ and lead $(\mathrm{Pb})$. Enforcement of these regulations has resulted in a significant decrease in PM exposure in the US from mid to late $20^{\text {th }}$ century levels and similar regulations have resulted in comparable decreases in Europe. According to the World Health Organization (WHO), particulate matter (PM) pollution is still ranked 13th as a cause of mortality.

The ranges of health effects are broad, but are predominantly to the respiratory and cardiovascular systems. Established relationships between human health and PM (especially fine and ultrafine particle UFP modes) include mortality, morbidity, and hospital admissions with ambient levels. In particular, $\mathrm{PM}_{2.5}$ and especially the smaller UFP penetrate deeply into the lung reaching the alveoli, and are thus more likely to 
induce adverse health effects than larger particles. Combustion sources often produce polycyclic aromatic hydrocarbons PAHs and their derivatives and/or metals attached to small $(10$ to $100 \mathrm{~nm})$ EC cores, increasing their toxicity. The PM adverse health effects thus depend on a complex set of physicochemical characteristics including mass, size, number concentration, surface area, chemical composition and source all of which can change during atmospheric transport and in the body after inhalation.

Table 1-1: Air quality standards for PM

\begin{tabular}{|c|c|c|c|c|}
\hline Unit $\left(\boldsymbol{\mu g} / \mathbf{m}^{3}\right)$ & PM 2.5 (24hrs) & $\begin{array}{c}\text { PM 2.5 } \\
\text { (annual) }\end{array}$ & PM 10 (24hrs) & PM 10 \\
(annual)
\end{tabular}

The WHO (2013) and IARC on October 17, 2013 (Loomis et al., 2013), designated PM as a group 1 (known human) carcinogen. Current European air quality standards for human health and environment protection for PM (EC, 2008) are above the World Health Organization Air Quality Guidelines (WHO-AQG) that aim to protect public health. In

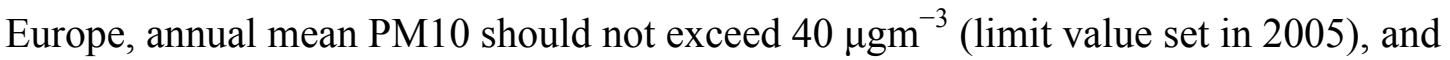
member states are requested to reduce exposure to $\mathrm{PM}_{2.5}$ in urban areas to below 20 $\mu \mathrm{gm}^{-3}$ by 2015 (legally binding value). This document compiled the results from 
numerous scientific studies and made a clear conclusion that exposure, at certain concentrations and lengths, to these pollutants endangers public health.

This conclusion is not wholly unexpected, since PAHs, a class of organic matter found in the aerosol particles, are known to be carcinogenic. People who are exposed to PM may also experience lesser symptoms including sore throat, persistent cough, burning eyes, shortness of breath, and tightness or pain in the chest. Those symptoms may trigger asthma and can lead to premature death, especially in the elderly or people with preexisting conditions. They result in more frequent medication use, decreased lung function, increases in hospital admission, E.R visits and ultimately increased mortality.

Aerosols also cause visibility degradation primarily because they scatter light as it moves through the atmosphere degrading image information. This was directly addressed as an air quality issue for National Scenic areas in 1977 (Ref 14). Impairment of visibility could also affect agricultural practices and transportation safety. Understanding the physical and chemical properties of the aerosol particles aids in characterizing their impact on human health as well as in the climate science that is that main emphasis of this dissertation.

\subsection{Aerosol Composition and Source Analysis}

As noted earlier in this Introduction, atmospheric aerosol particles are found in a wide range of sizes, with diameters from nanometers to tens of micrometers, and a variety of shapes, although some widely used theories (e.g., Mie scattering) are only strictly 
applicable to spheres. Chemical compositions and particle morphologies may vary with size, and even among the particles within a given size range. 


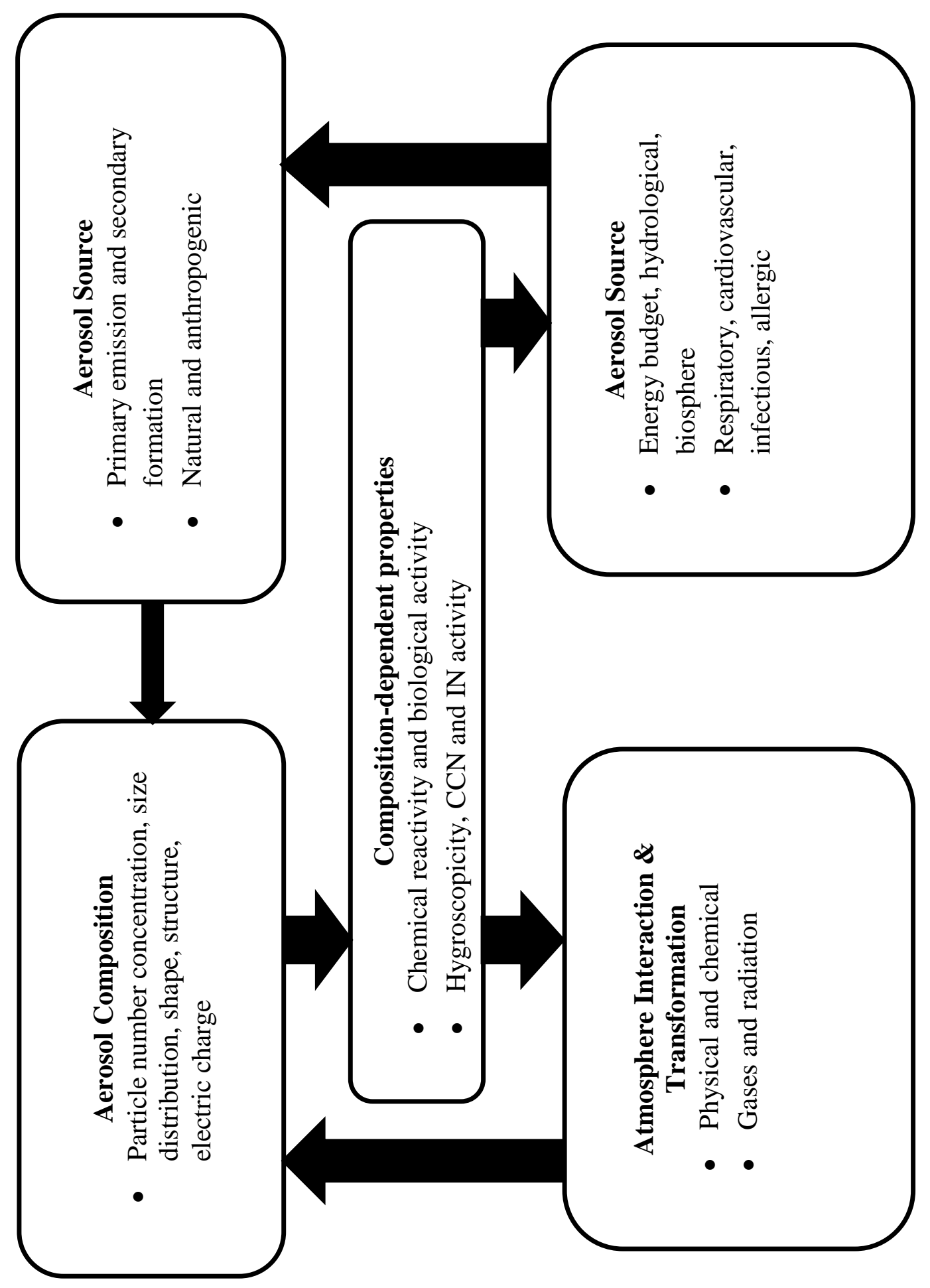


Figure 1-5: Interdependence and feedback between atmospheric aerosol composition, properties, interaction and transformation, climate and health effects and source categories.

A number of instrumental methods have been developed and deployed for the physical and chemical analysis of aerosols. Physical characterization methods/instruments include differential mobility analyzers (DMA) and particle counters, inertial separation (impaction, time of flight), scanning and transmission electron microscopy (SEM, TEM), and light scattering (Mie) for determinations of particle size, structure, and density; $\beta$-ray attenuation, gravimetry, and quartz crystal microbalances or oscillating tapers for particulate mass; spectrophotometry, photoacoustic spectroscopy, and nephelometry for absorption and scattering coefficients. Accurate determination of the chemical composition of atmospheric aerosols is a formidable task. Minute amounts of matter are sampled and are composed of a large number of chemical constituents, some of which are at trace levels. Within the samples the composition of individual particles can be uniform (internally mixed) or very different from the ensemble composition (externally mixed).

Linking observed composition to sources requires consideration of the atmospheric aging processes involved including coagulation, gas-particle partitioning, and other chemical reactions. Beside the primary chemical components, directly emitted by natural and anthropogenic sources, atmospheric aerosol also contains secondary chemical components that are formed by gas-phase reactions and subsequent gas-to-particle conversion or by chemical transformation of primary aerosol particles in the atmosphere. 


\subsubsection{General Source Classification}

Airborne atmospheric aerosol particles may be directly generated at the Earth's surface or through a combination of physical and chemical (and biological) process occurring in the atmosphere. There are three commonly cited source types: The first type is bulk-toparticle (B-to-P) conversion and examples include wind-generation of mineral dust aerosol, formation of maritime (sea salt) aerosols, and the production of plant debris and pollen; the second type is gas-to-particle (G-to-P) conversion where condensable vapor leads to nucleation of new particles or growth of existing particles; the third type is combustion which is a combination of first two in a high temperature environment.

\subsubsection{Inorganic Aerosol Sources}

Sea salt aerosols primarily consist of inorganic salts such as $\mathrm{NaCl}, \mathrm{KCl}, \mathrm{CaSO}_{4}$, and $\left(\mathrm{NH}_{4}\right)_{2} \mathrm{SO}_{4}$ but they can sometimes be coated with organic constituent. These particles are hygroscopic, as noted earlier in this Introduction, and thus can grow significantly as a function of RH (Posfal et al. 1998) and act as cloud condensation nuclei (CCN), affecting clouds and inducing indirect aerosol effects (O’Dowl et al., 1997).

The desert and semi-arid land surfaces are the dominant sources of mineral dust. During transport, dust particles can undergo reactions and mixing with other species that alters their chemical composition. The morphologies of dust particles are varied and largely depend on the geological location of their origins. Quartz, clay, calcite, gypsum, and iron oxide are commonly found from soil dust. The majority of atmospheric dust is less 
hygroscopic than sea salt aerosols and experiences less change in size, composition and scattering with RH.

\subsubsection{Organic aerosols}

Depending on source, OA can be primary or secondary. Primary organic aerosols (POA) are emitted from the source in the condensed phase (liquid or solid particles) or as an involatile vapor that condenses rapidly at ambient temperature. The sources of POA come from both natural and anthropogenic activities including biomass burning, fossil fuel combustion, biological materials (plant and animal debris, microorganism, pollen), and organic compounds on sea salt.

Secondary organic aerosols (SOAs) are formed by chemical reaction and g-to-p conversion of naturally and anthropogenically produced volatile, intermediate volatility, and semi-volatile organic compounds (VOC, IVOC and SVOC respectively) in the atmosphere. Oxidation processes lower the vapor pressure of organics, shifting the partitioning of mass from the gas-phase to the particle-phase. Condensation on existing particle is usually dominant (except under very clean conditions) and can be understood as equilibrium partitioning using Raoult's Law (Song et al. 2011).

Organic aerosols are abundant in the atmosphere; in a 1996 study they accounted for 10$40 \%$ of the fine particles and $30-50 \%$ in those in rural and remote locations. Despite the recognized importance of condensed phase organic species in the atmosphere, our understanding of the phase transitions that affect $\mathrm{OA}$ is still evolving and must be improved to properly simulate SOA in climate models. 
As an example. adipic acid (AA) is found in primary and aged biomass burning OA. Dicarboxylic acids are often used as surrogates for the highly oxidized organics detected in the atmosphere that have a high $\mathrm{O}: \mathrm{C}$ atom ratio and low vapor pressures, and $\mathrm{AA}$ is on the more organic end of the scale of these organic species. AA is sparingly soluble in water (2.5 g solute per $100 \mathrm{~g}$ water) and it was reported that pure AA particles do not absorb water even at RH up to $95 \%$ with a deliquescence point over $100 \%$ RH (Parsons, et al. 2004, Song et al. 2011).

\subsection{Aerosol Interactions with Water}

Relative humidity $(\mathrm{RH})$ is a key atmospheric parameter, determining cloud formation and precipitation, in addition to modifying aerosol properties. In this study, RH will always be presented in percentage form $(\% \mathrm{RH})$ representing 100 times the ratio of the partial pressure of water $\mathrm{P}_{\mathrm{w}}$, to its saturation vapor pressure $\mathrm{P}_{\mathrm{w}, 0}$ at the ambient temperature

$$
\% \text { Relative Humidity }=\frac{\mathrm{p}_{\mathrm{w}}}{\mathrm{p}_{\mathrm{w}, \mathrm{o}}} \times 100 \%
$$

An RH of $100 \%$ refers to saturation, one greater than $100 \%$ would indicate supersaturation, and below $100 \%$ is referred to as sub-saturated. Supersaturations are also sometimes presented as the excess beyond $100 \%$, i.e., $\mathrm{S}=100-\mathrm{RH}$ and at typical aerosol loadings, only a few percent will be metastable with respect to droplet formation. The saturation vapor pressure and thus RH (and S) are strongly temperature dependent.

Hygroscopicity is described as the phenomenon of attracting and holding water molecules from the surrounding gaseous environment. For most spherical particles, 
adsorption only adds a small volume of water until very high RH, so sub-saturated particle growth is usually the result of absorption/dissolution. Depending on chemical composition, the size of an aerosol particle can increase with relative humidity and the addition of water that causes this hygroscopic growth results in changes to the density, size and optical properties ( $m$ and $b_{\text {scat }}$ ). Thus the growth can be measured as a change in the size (using a DMA/CPC) or the scattering (using optical instruments) or some other property at multiple RHs. Aerosol particles that readily take up water (like inorganic salts) are hygroscopic, while those at the other extreme (e.g., EC) are classified as hydrophobic.

The change in size with RH can be described by a growth factor (gf)

$$
g f(R H)=\frac{D_{w e t}}{D_{d r y}}
$$

where the "dry" diameter is typically obtained by measuring size (or a related property like particle mobility) at RHs approaching zero and the "wet" diameter is that of the same particle after being exposed to the relevant relative humidity for sufficient time to equilibrate. Instruments that conduct direct particle size growth measurements of this type include the Hygroscopic Tandem Differential Mobility Analyzer (H-TDMA) and the Differential Aerosol Sizing and Hygroscopicity Spectrometer Probe (DASH-SP). Past investigations of $\mathrm{gf}(\mathrm{RH})$ for a number of aerosol types reveal some common features and some composition-specific behavior.

where the "dry" diameter is typically obtained by measuring size (or a related property like particle mobility) at RHs approaching zero and the "wet" diameter is that of the same 
particle after being exposed to the relevant relative humidity for sufficient time to equilibrate. Instruments that conduct direct particle size growth measurements of this type include the Hygroscopic Tandem Differential Mobility Analyzer (H-TDMA) and the Differential Aerosol Sizing and Hygroscopicity Spectrometer Probe (DASH-SP). Past investigations of $\mathrm{gf}(\mathrm{RH})$ for a number of aerosol types reveal some common features and some composition-specific behavior.

Tang et al. (1979) investigated the hygroscopicity of sulfate containing aerosols and the results are reproduced as Figure 1-4 below. The dry solid ammonium sulfate and ammonium bisulfate particles did not begin to grow immediately when exposed to increasing (from $0 \%$ ) relative humidity (gf remained near 1 ), but sulfuric acid liquid particles did experience modest growth with increasing but low RH. This difference was attributed to the change in state that occurs when the added water dissolves the particle at some sufficiently high RH. Above this relative humidity, the growth factor increases rapidly from 1 and all particles start to grow rapidly until the particle phase change has been completed (Kotchenruther, R. A et al. 1999). The RH where the transition begins to occur is defined as the deliquescence relative humidity DRH (Zieger, P. et al..2013; Zieger, P. et al. 2010; Fierz-Schmidhauser, R. et al. 2010). Some compounds like sulfuric acid exhibited a continuous monotonic increase in size with no clear DRH. Most salt particles behaved like ammonium sulfate where the particle size changes (growth factor) remained near 1 below the DRH and increased dramatically above it. 




Figure 1-6: Growth factors (particle size change) as a function of relative humidity for a series of sulfate containing aerosols (Tang et al. 1979)

The discontinuous change in size also occurs during the dehumidification process for salt particles; but as the RH decreases, particles do not recrystallize to the solid phase at the deliquescence point. Instead the rapid phase change begins at a lower humidity called the efflorescence or the crystallization RH (ERH or CRH). This hysteresis behavior varies between particles because each has unique physical/chemical characteristics that determine the DRH and ERH. Figure 1-7 shows both composition and size dependent differences: in sub-panel (a) both $\mathrm{NaCl}$ and $\left(\mathrm{NH}_{4}\right)_{2} \mathrm{SO}_{4}$ show hysteresis and the growth curves are distinguishable because $\mathrm{NaCl}$ has a lower DRH than $\left(\mathrm{NH}_{4}\right)_{2} \mathrm{SO}_{4}$ (the efflorescence isn't shown, but ERH is also lower); sub-panel (b) shows that for $\mathrm{NaCl}$ a smaller dry diameter requires a higher DRH to initiate the growth. In principle, this 
hysteresis behavior would make characterizing the size and optical property changes expected from aerosols under changing atmospheric conditions (RH and temperature) very difficult to determine, let alone predict. But, because ambient aerosol particles are usually polydisperse mixtures of different compositions (often both internal and external mixtures), the distinct DRH, ERH and clear hysteretic behavior is not usually observed; rather a more continuous water uptake like that shown for sulfuric acid is usually produced under humidification, especially for organic-containing aerosols.
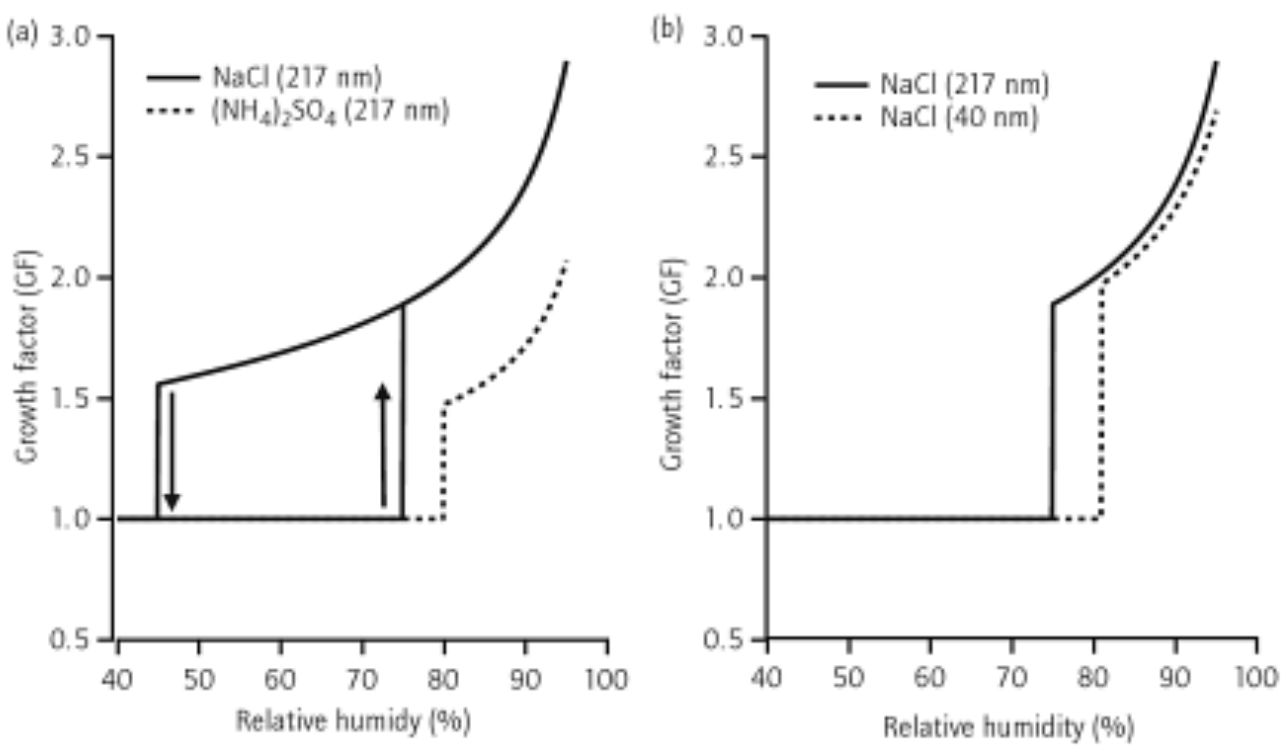

Figure 1-7: (a)growth curves for $\mathrm{NaCl}$ and $\left(\mathrm{NH}_{4}\right)_{2} \mathrm{SO}_{4}$ of same dry sizes; (b) growth curve for $\mathrm{NaCl}$ of different dry sizes (Hewitt et al. 2009)

The hygroscopicity of aerosol particles also determines the relationship between dry particle size and critical supersaturation $\left(\mathrm{S}_{\mathrm{c}}\right)$, the excess $\mathrm{RH}$ where spontaneous conversion to cloud droplets occurs, i.e., the cloud condensation nucleation $\mathrm{CCN}$ activities of aerosol particles. The Köhler equation (1-9) describes the equilibrium vapor 
pressure as a function of the droplet size and combines the effects described by Raoult's law (solute effects) and the Kelvin equation (curvature effects - most important for particles with diameters below $100 \mathrm{~nm}$ ) (Kohler et al. 1936). When describing the CCN behavior of aerosols, it is usually written as

$$
S=\alpha_{\omega} \exp \left(\frac{4 \sigma_{S / a} M_{\omega}}{R T \rho_{\omega} D}\right)
$$

where $\alpha_{\omega}$ is the activity of water in solution, $\rho_{\omega}$ is the density of water, $M_{\omega}$ is the molecular weight of water, $\sigma_{s / a}$ is the surface tension of the solution /air interface, R as the gas constant, $\mathrm{T}$ is the temperature in $\mathrm{K}$, and $\mathrm{D}$ is the diameter of the droplet.

Applying Köhler theory requires prior knowledge of the particle's dry mass, molecular weight, bulk density, number of dissociable ions, and activity coefficient. In order to parameterize the water activity and its dependence on the dry and wet particles' size, the hygroscopicity parameter " $\kappa$ " was introduced by Petters and Kreidenweis (2007) (Petters et al.2007). The hygroscopicity parameter describes the effect of the solute on the solution water activity

$$
\frac{1}{\alpha_{\omega}}=1+k \frac{V_{s}}{V_{w}}
$$

where $\mathrm{V}_{\mathrm{s}}$ is the volume of the dry particle, $\mathrm{V}_{\mathrm{w}}$ is the volume of water, and $\alpha_{\omega}$ is the activity of water in solution. Equation 1-9 can then be rewritten as the $\kappa-$ Köhler equation 


$$
S(D)=\frac{D^{3}-D_{d}^{3}}{D^{3}-D_{d}^{3}(1-\kappa)} \exp \left(\frac{4 \sigma_{s / a} M_{\omega}}{R T \rho_{\omega} D}\right)
$$

where $\mathrm{D}$ and $\mathrm{D}_{\mathrm{d}}$ are the wet and dry particle diameters. In practice, $\kappa$ can be determined by measurements of $\mathrm{gf}(\mathrm{RH})$ under sub-saturated conditions (for example with an $\mathrm{H}$ TDMA) or under supersaturated conditions. For the latter $\kappa$ is derived from Cloud Condensation Nuclei CCN counters, which measure the critical supersaturation where size-selected dry particles activate to cloud droplets. Experimentally-determined critical supersaturation as a function of dry particle diameter for different particles and mixtures are shown in Figure 1-6. Hygroscopic inorganic aerosols like ammonium nitrate have large $\kappa$ values (0.67) but a 3:7 organic: inorganic mixture has an appreciable $\kappa$ value of 0.63. Ambient EC produces $\kappa \sim 0$, while values closer 1 usually indicate the presence of inorganic species. Some water soluble organic aerosols have values from 0.033 to 0.21 indicating moderate hygroscopicity. 


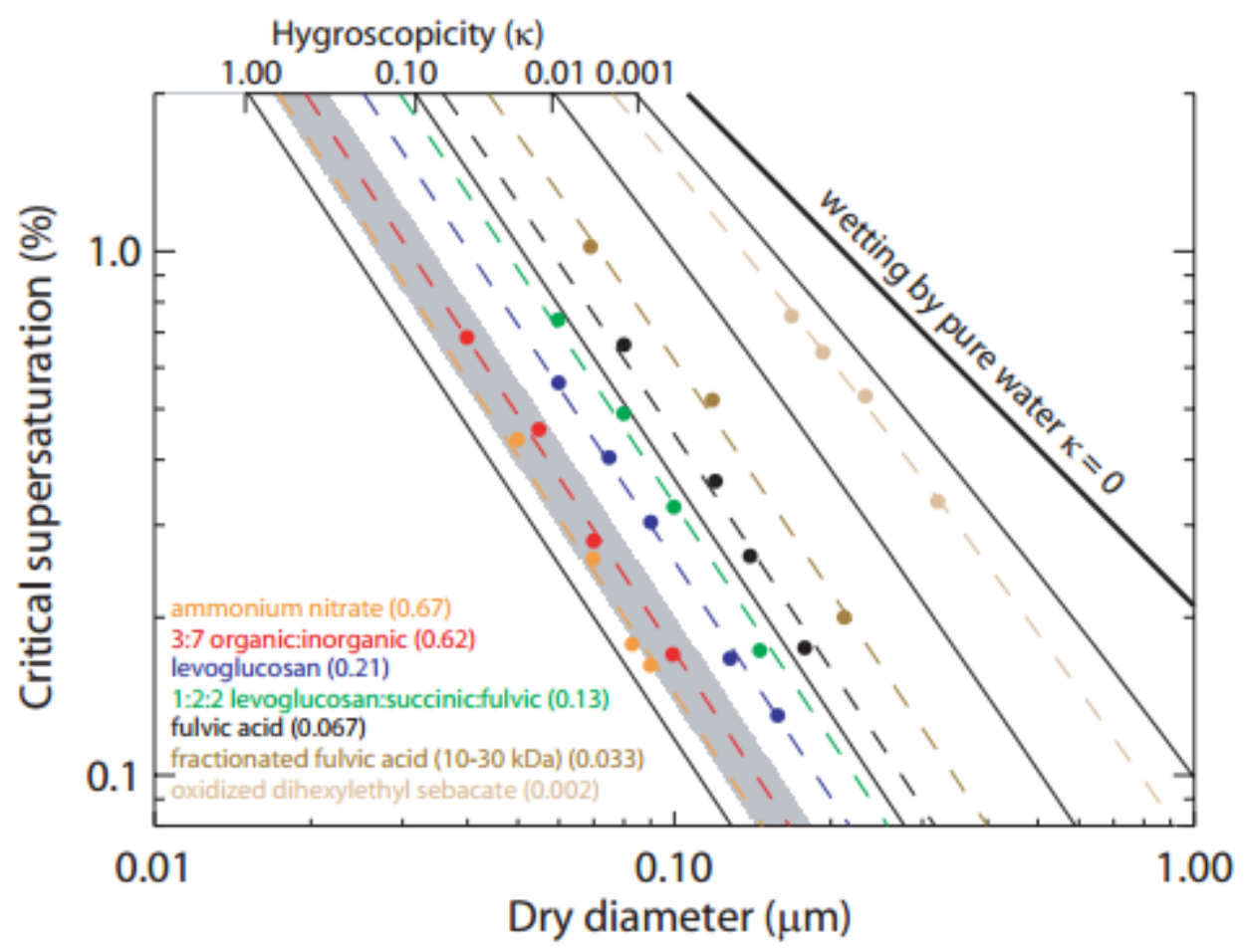

Figure 1-8: Critical supersaturation as a function of the particle dry diameter for different compounds and mixtures along with $\kappa-$ parameterization. (Figure 1 from Petters and Kreidenweis et al. 2007)

For multicomponent systems $\kappa_{\text {tot }}$ is calculated using a volume mixing rule, where $\varepsilon_{\mathrm{i}}$ and $\kappa_{\mathrm{i}}$ are the volume fraction and hygroscopicity parameter of pure component $\mathrm{i}$.

$$
\kappa_{t o t}=\sum_{i} \varepsilon_{i} \kappa_{i}
$$

Another implication of $\kappa$ is that with known chemical composition, sub-saturated aerosol particle size growth can be predicted via

$$
g f\left(a_{w}\right)=g f(R H)=\left(1+\kappa \frac{a_{w}}{1-a_{w}}\right)^{1 / 3}
$$


or the reverse procedure can be used to infer $\kappa$ from $\mathrm{gf}(\mathrm{RH})$ measurements. In some cases, $\kappa_{\text {tot }}$ determined by the two approaches agree, but in many cases they do not. This point is currently under investigation, so we seek an alternative method that can help resolve uncertainties regarding particle hygroscopicity.

In addition to measurements that obtain growth factor by measuring particle size, optical methods that measure the aerosol light extinction (or scattering) at different RHs have been used to describe the effect of water uptake. ${ }^{6}$ The scattering enhancement factor (or optical growth factor) $\mathrm{f}(\mathrm{RH})$ is the ratio of the extinction (or scattering) coefficients at a specified wavelength for the $\mathrm{RH}$ of interest over a reference $\mathrm{RH}$ (usually the dry $\mathrm{RH}$ )

$$
f(R H, \lambda)=\frac{b_{\text {ext }, \text { igh } R H, \lambda}}{b_{\text {ext, low } R H, \lambda}}
$$

where $b_{\text {ext, high } R H, \lambda}$ is the extinction coefficient at the RH of interest; and $b_{\text {ext, low } R H, \lambda}$ is the corresponding dry extinction coefficient. Measured $\mathrm{f}(\mathrm{RH})$ increases with $\mathrm{RH}$ away from unity, assuming the dry particles are the reference state. The $\mathrm{f}(\mathrm{RH})$ has been measured by scanning-RH nephelometer systems sometimes called humidographs, and the data is used to generate a humidogram. It should be noted that the refractive index of the particles also changes with water uptake, so the humidogram is not a direct representation of the changing size of the particles. However, the humidogram does capture the aerosol particles' growth and can obtain the hysteresis behavior expected from salt aerosols. In Figure 1-9 pure $\mathrm{NaCl}$ and ammonium sulfate (AS) were used as aerosol substrates and a nephelometer measured the scattering coefficient as the relative humidity was changed. From the humidogram, the $\mathrm{DRH}$ and $\mathrm{CRH}$ of $\mathrm{NaCl}$ is found to be $75 \%$ and $41 \%$ vs. $79 \%$ 
and $31 \%$ for AS. These results are in good agreement with Tang and Munkelwitz, et al. 1993 who reported DRHs for $\mathrm{NaCl}$ and $\mathrm{AS}$ at $298 \mathrm{~K}$ as $75.3+/-0.1 \%$ and $79.9+/-0.5$ and CRHs for $\mathrm{NaCl}$ and $\mathrm{AS}$ as $46-48 \%$ and $37-40 \%$ (Tang et al. 1993, 1996). These experiments have some drawbacks, including a need to cycle from low RH to the high $\mathrm{RH}$ and back to observe the lower and upper branches of the humidogram and the aforementioned convolution of the size information with the changing refractive index. The change in the optical property also depends on the dry size of the particle with larger changes in scattering for smaller particles and a similar water uptake.


Figure 1-9: Measured $\mathrm{f}(\mathrm{RH})$ with scanning relative humidity nephelometry from pure (a) $\mathrm{NaCl}$ and (b) $\left(\mathrm{NH}_{4}\right)_{2} \mathrm{SO}_{4}$ with deliquescence and crystallization $\mathrm{RH}$. (Carrico et al 2003) As noted earlier in this section, many ambient aerosol particles do not exhibit clear hysteresis behavior and thus their more continuous monotonic changes with $\mathrm{RH}$ can be measured and represented in a simpler way. One alternative to measuring or presenting a 
full humidogram is to parameterize the $\mathrm{f}(\mathrm{RH})$ dependence of the measured scattering or extinction using a presumed power-law growth of extinction with $\mathrm{RH}$

$$
f(\% R H)=\left(1-\frac{\% R H}{100}\right)^{\gamma}
$$

where $\gamma$ is the power and represents the particle hygroscopicity. This single-parameter expression can capture the magnitude of the scattering enhancement on the "wet" branch of an hysteresis curve and/or the full RH dependence for aerosols that do not exhibit hysteresis. It is sensitive to aerosol composition and size as expected. The modeling of $\mathrm{f}(\mathrm{RH})$ and $\gamma$ dates back to the work of Kasten in 1969 and several laboratory and field studies explored the dependence of $\mathrm{f}(\mathrm{RH})$ and $\gamma$ on aerosol chemical compositions (Kasten et al. 1969, Hanel et al. 1976). Typical $\gamma$ values range from 0.1 for nonhygroscopic species like OA to greater than 1.0 for very hygroscopic aerosols like sulfuric acid. Several studies show that $\gamma$ values less than 0.3 are applicable for dust and $\mathrm{BC}, 0.6$ to 0.8 for aged sulfate, 0.9 for the clean marine aerosol and pure sulfuric acid aerosols produce a $\gamma$ of 1.2 (Gasso et al. 2000, Massoli et al. 2009).

In practice two scattering or extinction coefficients at different RHs can be combined to obtain $\gamma$ from the following equation

$$
\gamma_{\text {High } R H / \text { Low RH }}=\frac{\log \frac{b_{\text {ext, High } R H}}{b_{\text {ext }, \text { Low }, R H}}}{\log \frac{100-R H_{\text {High }}}{100-R H_{\text {Low }}}}
$$

where the $b_{\text {ext,high,RH }}$ is the extinction coefficient at $532 \mathrm{~nm}$ with the relative humidity of interest (i.e., the higher $\mathrm{RH}$ ), and $\mathrm{b}_{\mathrm{ext}, \mathrm{low}, \mathrm{RH}}$ is the extinction at the reference relative humidity (i.e., the lower RH). In the work reported in this dissertation, the HC-CRD 
instrument described in the next section measured extinction coefficients at two or three controlled RHs. As an alternative to Eqn, 1-16, several extinction or scattering coefficients at different RH values can be subjected to a log-log plot to obtain $\gamma$. In some experiments reported in the Results section, three extinction coefficient measurements were made (humidified, untreated and dehumidified) and produced two different $\gamma(\mathrm{RH})$ values from pairs of measurements using Equation 1-16. In this case the different $\gamma(\mathrm{RH})$ values are able to capture the rate of extinction enhancement with $\mathrm{RH}$ on the log-log space. Non-hysteretic aerosols have similar values for the two $\gamma(\mathrm{RH}) \mathrm{s}$ while inorganic salt aerosols generated different values within the pair. This difference could be used in ambient sampling as an indicator of the presence of hysteresis/deliquescence/efflorescence, thus enabling coarse determination of the hysteresis behavior and nature of the aerosol being observed. The simplicity in the determination of $\gamma(\mathrm{RH})$ is the major advantage of this method and the results will be mainly qualitative.

\subsection{HC-CRD Laboratory Measurements of Hygroscopic Growth}

This dissertation used the above-referenced HC-CRD instrument to investigate the hygroscopic growth of a number of aerosol types, including a set of dicarboxylic acids that act as benchmarks for atmospheric OA. The instrument (comprehensive description in the second part of the Methods section) measures the extinction coefficients at three widely spaced wavelengths for laboratory generated aerosols that are then raised and lowered in RH to allow for water uptake and hygroscopic growth. A theoretical approach that is described in the first part of the Methods section is then used to determine the 
effective size of the particles at that RH. The changes in size with RH can then be used to determine the hygroscopicity parameter $\kappa$ and comparison with the literature provides validation of the combined experimental and theoretical method. In future work, the measurements of ambient aerosols should allow determination of their hygroscopity allowing inferences about composition, in addition to the size and optical property data products. 
2. Materials and Methods

A schematic of the experimental block diagram for measuring the optical extinction of laboratory-generated aerosol is shown in Figure 2-1. Particles were generated from aqueous solutions, subjected to two stages of drying and dilution, and passed into the humidity controlled-cavity ring-down (HC-CRD) instrument. The sections that follow provide more details on each of the sub-systems. Then a new way of obtaining growth factors and hygroscopic parameters for aerosols is described, including a previously published theoretical approach that is used to determine effective radii of the particle size distributions.

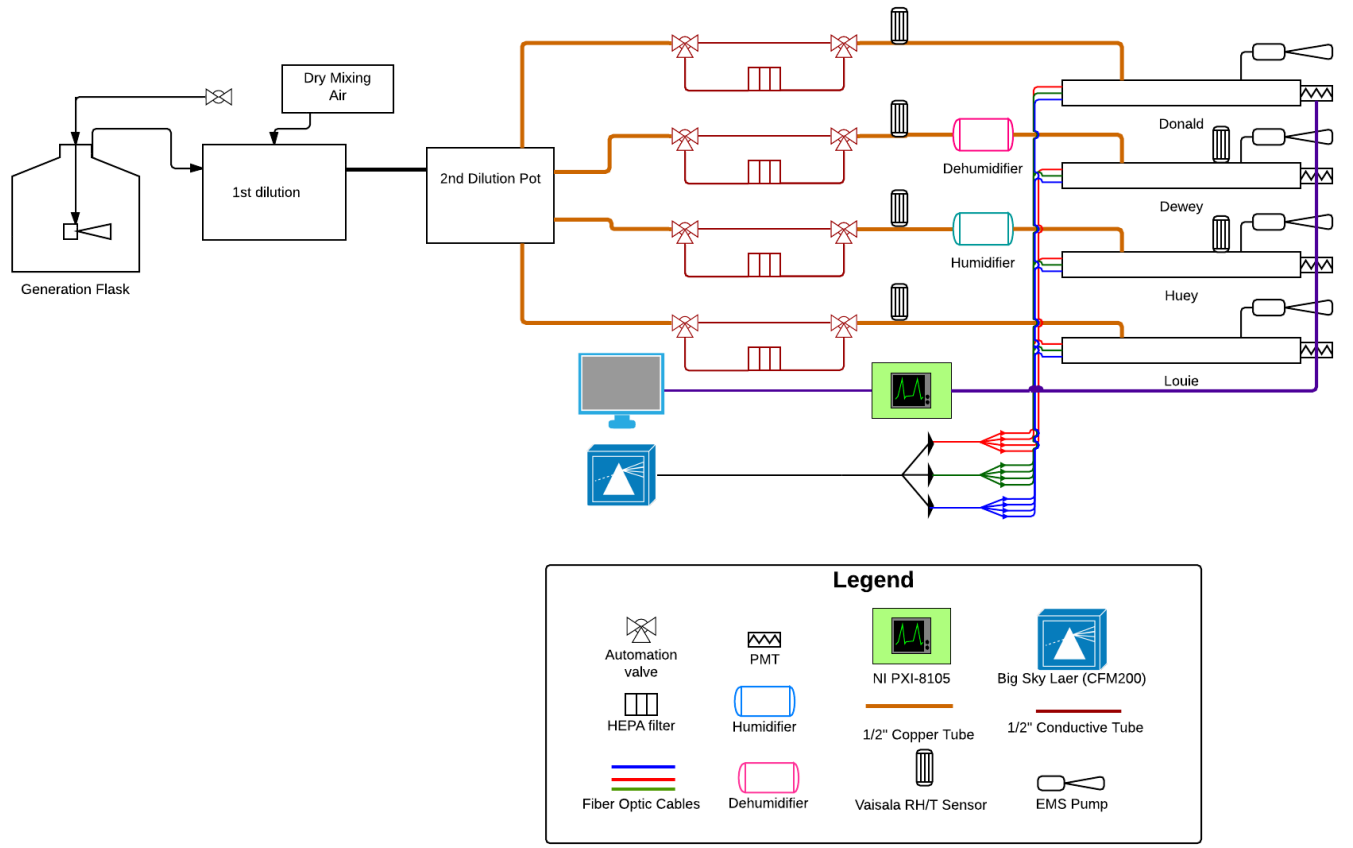

Figure 2-1: Aerosol generation and dilution system and HC-CRD operation 


\subsection{Aerosol generation}

The laboratory measurements required an aerosol source that could continuously produce particles with variable, but relatively high and stable number concentrations (particles-m ${ }^{-}$

${ }^{3}$ ). Filtered air (from the SRTC building compressed air system) was passed through an atomizer where an aqueous solution of the aerosol substrate contained in a large glass reservoir (4L sidearm flask) was nebulized and wet aerosol droplets/particles were formed. The aqueous solutions were prepared by the addition of known masses of primary reagent grade chemicals (e.g., ammonium sulfate) to the deionized water generated from an ion-exchange column connected to a distilled water tap. The concentrations of the solutions were typically in the range of 100 to $200 \mathrm{mg} / \mathrm{L}(100-200$ ppm). The wet particles produced by the atomizer entered the first $20 \mathrm{~L}$ aluminum dilution chamber where filtered air (from the same system as the nebulizer flow) was introduced on the opposite side from the aerosol. A swirling air flow and appropriately placed baffles made sure that the aerosol was well-mixed within the chamber. The output of the first mixing chamber was then sampled through a $1 / 4$ " copper tube from a manifold that led to an exhaust hood and this aerosol was directed to the second $20 \mathrm{~L}$ aluminum dilution chamber, creating a significant concentration drop, adjustable by adding another variable filtered air flow. The design of the secondary chamber only allows aerosols to exit the chamber by circulating through a set of flow baffles to one of four copper tubing exit fittings, resulting in a fully mixed and equilibrated aerosol sample flow. Finally, this aerosol flow was directed to the HC-CRD instrument inlet system. Large droplets from the atomizer were captured within the primary substrate reservoir, meaning that the only 
loss of aerosol solution was to the primary dilution chamber, so this setup produced aerosols with particle size distributions and concentrations that were stable for hours to days of continuous operation.

\subsection{Humidity-Controlled Cavity Ring-Down (HC-CRD)}

O'Keefe and Deacon (1988) is considered the seminal publication on cavity ring-down (CRD) spectroscopy. Since then, a large number of applications have been published and commercial instruments are available, based on the cavity ring-down (or cavity enhancement of absorption) concept. Cavity ring-down is based on the measurement of the decay rate (or time constant) of light escaping from an optical cavity. In the instrument used for this work, a laser light source was coupled into an optical cavity formed by two highly reflective planoconcave mirrors. The light was thus "stored" in the cavity for some number of microseconds with a small amount "leaking out" on each reflection. The decay of the light intensity is exponential, and the decay time (rate) is inversely (directly) proportional to the losses in the cavity. A photomultiplier tube (PMT) optical detector was placed at the opposite end of the cavity from the laser source to measure the exponential decay of the emerging light intensity. A fast digitizer coupled to a computer data system processed the signal from the detector and extracted the cavity decay rate, which was used to determine the extinction coefficient.

The intensity decay includes all losses, including leakage through and scattering from the mirrors, diffraction of the beam beyond the mirrors, and scattering and absorption (extinction) losses inside the cavity. The empty (no aerosol, filtered air) cavity was 
constructed of two mirrors with high reflectivity $(\mathrm{R})$, separated by a length L (about $1 \mathrm{~m}$ ) and the intensity decay may be expressed as

$$
I=I_{0} e^{-t / \tau}
$$

where $\mathrm{I}_{0}$ and $\mathrm{I}$ are the intensities of light entering and leaving the cavity, and $\tau$ is the empty cavity ring-down time $(\mathrm{s}), \tau=\mathrm{L} / \mathrm{C}(1-\mathrm{R})$, where $\mathrm{C}$ is the speed of light $(\mathrm{m} / \mathrm{s})$. When the aerosol sample flow was introduced to the cavity, the light decayed faster, yielding a shorter ring-down time ( $\left.\tau_{\text {aerosol }}\right)$; and the extinction coefficient of the aerosol sample was determined by the difference in the inverse of these ring-down time constants

$$
b_{\text {Ext }}=\frac{1}{C}\left(\frac{L_{\text {cavity }}}{L_{\text {aerosol }}}\right)\left(\frac{1}{\tau_{\text {aerosol }}}-\frac{1}{\tau_{\text {clean }}}\right)
$$

where $L_{\text {cavity }}$ is the mirror-to-mirror length of the cavity, $L_{\text {aerosol }}$ is the length of the aerosol-filled section of the cavity. and the ratio is necessary for practical CRD experiments because filtered air is generally flowed near the mirrors to keep them clean. The resulting units on $b_{\text {ext }}$ are inverse length, typically $\mathrm{Mm}^{-1}$ because the losses are generally in the parts-per-million.

\subsubsection{Construction details of the HC-CRD}

The Humidity Controlled Cavity ring-down instrument was custom-built and developed in the Atkinson lab to enable the simultaneous measurement of the extinction coefficients at three different wavelengths under four different flow conditions (for this work, three RHs). Thus there were up to 12 optical cavities used to measure extinction coefficients simultaneously; each of the four flow tubes contained three optical ring-down cavities 
that were formed by pairs of high reflectivity mirrors (Layertec, Germany) at $1064 \mathrm{~nm}$ (radius of curvature $\mathrm{r}=1000 \mathrm{~mm}$, reflectivity $\mathrm{R}>99.98 \%$ ), $532 \mathrm{~nm}(\mathrm{r}=1000 \mathrm{~mm}, \mathrm{R}>$ 99.98\%) and $355 \mathrm{~nm}(\mathrm{r}=1000 \mathrm{~mm}, \mathrm{R}>99.9 \%)$. The mirrors were mounted in ball-insocket adjustable gimbals on mirror mounting plates that attached to the ends of the aerosol flow tubes. The mirror holders (the ball in the ball-in-socket) were flange-shaped with cylindrical inner diameters where each mirror was embedded and glued, resulting in a reasonably leak-tight flow system. Each mirror socket was ringed with four evenly distributed \#0-80 screw threads and the balls had corresponding holes that allowed for insertion of screws to effect adjustment of the mirrors. The three mirror sockets formed a triangle on the mirror plate. The laser paths were parallel to one another through the flow system.

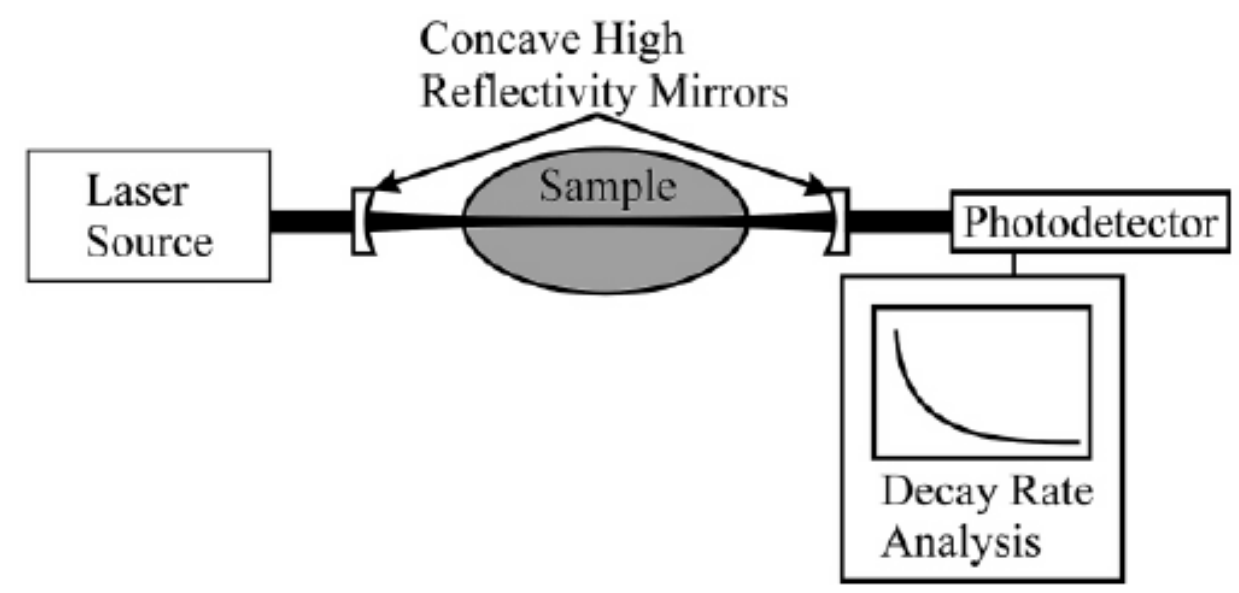

Figure 2-2: An experimental diagram showing the essential features of CRD experiment (Atkinson et al. 2003) 
The light source of the HC-CRD was a nanosecond pulsed Nd: YAG laser (Big Sky Laser CFR400 operating at $15 \mathrm{~Hz}$ ) with second and third harmonic generation and separation (producing separate $1064 \mathrm{~nm}, 532 \mathrm{~nm}$ and $355 \mathrm{~nm}$ outputs). The output laser pulses of the three different wavelengths impinged onto three separate fiber optic bundles. The bundle for each of the three wavelengths then split into four sub-bundles that were used to direct the laser pulses into the appropriate optical cavity for each flow tube using a pair of plano-convex focusing lenses and a bandpass filter (to block residual output of the other two wavelengths).

At the other end of the optical cavity, a set of three PMTs were positioned behind the output mirrors for each flow tube to record the intensity of the laser pulses transmitted through the mirrors on each round trip through the cavity. The electrical signals from the twelve PMTs were then digitized by two National Instruments NI-PXI-5105 (60MSa/s, $120 \mathrm{MHz}, 12-$-bits) high-speed 8-channel digitizers that were able to simultaneously convert the 12 analog data inputs at $60 \mathrm{MSa} / \mathrm{s}$. An NI PXI-1031 4-slot 3U PXI chassis contained the two NI PXI-5105 digitizers and an NI PXI-8105 embedded controller and facilitated the rapid data transfer necessary for real-time collection and processing of the ring-down (exponential) decays. The controller was equipped with an Intel 2.0GHz dualcore processor running a custom NI LabVIEW program that was used to process and store the data.

The aerosol sample entered (and exited) each HC-CRD flow tube through $1 / 2$ " I.D. inlets that connected to $1 / 2$ " copper tubing with a Swagelok connector. The inlets were 
positioned at a $45^{\circ}$ angle to the flow axis ensuring homogeneous mixing and even concentration of the flows. The main flow ( 3 standard liters per minute) in each flow tube was controlled individually by a linear pump (EMS MegaLite IAQ Pump, Model \# $6025 \mathrm{SE}-\mathrm{V}$ ) that connected to the $1 / 2$ " exit tube through a Swagelok reducing union leading to $3 \mathrm{~m}$ of flexible Teflon tubing. A double-headed peristaltic pump (Stenner 170DM5) provided filtered air circulation to inlet/exit ports between the mirror plates and the flow inlets/exits to minimize particle deposition on the cavity mirrors. The $1 / 2$ " copper tubing from the HC-CRD flow tube inlets terminated at a computer-controlled electromechanically-actuated three-way valve that alternately directed the incoming aerosol flow through a HEPA filter or a direct run to a second three way valve that connected to a final $10 \mathrm{~m}$ run of $1 / 2$ " copper sampling tubes. Two of the valve-to-HCCRD copper tubing connections also incorporated custom-built humidifier/dryers, as described in the next section. Cyclone impactors (URG Corp., URG-2000-30EQ) were used at the end of the $1 / 2$ " copper sampling tubes to limit the aerosol entering the instrument to particles below $2.5 \mu \mathrm{m}$ in aerodynamic diameter, i.e. $\mathrm{PM}_{2.5}$. The size selection is more important for ambient aerosol sampling during field studies than for laboratory studies where nearly all of the particles generated are smaller than $1 \mu \mathrm{m}$.

\subsubsection{Humidity control and RH sensors}

As noted in the previous section, among the four flow tubes in the HC-CRD instrument, two underwent humidity modification by directing the sample flow through a humidifier or dehumidifier before the ring-down measurement. The custom-built humidifier and dehumidifier used were inspired by the TSI 3062 diffusion dryer. The dehumidifier 
consisted of two concentric cylinders with silica gel desiccant (Fisher Scientific, Grade 48, 4-10 mesh, indicating) between them: the inner cylinder was 1" stainless steel with $1 / 8$ " holes every $1 / 4$ " wrapped with a stainless steel wire screen, while the outer was a 3 " PVC tube. The outer cylinder was sealed by two removable end caps fitted with inlet and outlet connectors (male $1 / 2$ " Swagelok connectors that mated to the $1 / 2$ O.D. copper tubing) that could be removed to recharge/replace the desiccant. The aerosol flow passed through the inner cylinder allowing water vapor to diffuse through the holes and wire mesh into the silica gel. This design minimized particle loss from contact between the aerosol particles and the silica gel desiccant and from static charging of the inner cylinder (which was grounded). The silica gel desiccant was regenerated by heating in a $120^{\circ} \mathrm{C}$ oven overnight. For ambient sample flows with $\mathrm{RH}=40-50 \%$ the dehumidifier lowered the $\mathrm{RH}$ to below $15 \%$ (when the desiccant was fresh) at a temperature of $20-25^{\circ} \mathrm{C}$.

The humidifier consisted of identical concentric cylinders (as the dehumidifier) with a water-saturated cotton wick replacing the desiccant, wrapped around the inner cylinder so that water vapor from the moist wick humidified the flow that passed through the inner cylinder. A water reservoir was attached to the outside of the humidifier and the end of the moist wick was submerged in the water so that capillary action continuously drew water in from the reservoir and rehydrated the wick inside the humidifier. Ambient sample flows with $\mathrm{RH}=40-50 \%$ could be humidified to $\mathrm{RH}=80-85 \%$ at a temperature of $20-25^{\circ} \mathrm{C}$. 
Six relative humidity/ temperature probes (Vaisala HMP50 RH/T) were used in the HCCRD flow system. These probes incorporated an INTERCAP ${ }^{\circledR}$ sensor based on changes in the capacitance of a thin polymer film as it absorbs or releases water. Two probes were placed before the HC-CRD flow tubes using Ultra-Torr vacuum fittings while four probes were placed on each sample flow exit of the HC-CRD using a modified Swagelok fitting. One of the unconditioned flows and the humidified flow had upstream and downstream probes enabling determination of sample RH before and after the HC-CRD instrument. The analog outputs of these sensors were digitized at $1 \mathrm{~Hz}$ using a Measurement Computing 24 channel $1 \mathrm{KHz}$ 12-bit A/D that used USB to send data to the NI PXI-8105 where it was stored along with the ring-down decays and valve state (sample or filtered air) for post-processing.

\subsection{Aerosol substrates}

Optimally, the aerosol substrates chosen for this study should occur naturally in the atmosphere. Additionally, the following criteria were desirable: the substrate must be chemically stable and moderately water soluble, commercially available with relatively high purity (>99\%), be of a known composition and have known optical properties (e.g., refractive index). For the purpose of this study strongly scattering, rather than strongly absorbing, substances were preferred. Table $2-1$ provides a summary of the main substrates that were used in this study and an ambient aerosol type that each could mimic. 
Table 2-1: Substrates analyzed in this study

\begin{tabular}{|c|c|c|c|}
\hline Substrate & Formula & Molecular Weight & Surrogate \\
\hline Sodium Chloride & $\mathrm{NaCl}$ & 58.44 & sea salt aerosol \\
\hline Ammonium sulfate & $\left(\mathrm{NH}_{4}\right)_{2} \mathrm{SO}_{4}$ & 132.14 & ag. + combustion \\
\hline Ammonium bisulfate & $\mathrm{NH}_{4} \mathrm{HSO}_{4}$ & 115.11 & ag. + combustion \\
\hline Sodium sulfate & $\mathrm{Na}_{2} \mathrm{SO}_{4}$ & 142.05 & sea salt aerosol \\
\hline Sodium bisulfate & $\mathrm{NaHSO}_{4}$ & 120.06 & sea salt aerosol \\
\hline D-Glucose & $\mathrm{C}_{6} \mathrm{H}_{12} \mathrm{O}_{6}$ & 180.16 & bio mass burning \\
\hline D-Fructose & $\mathrm{C}_{6} \mathrm{H}_{12} \mathrm{O}_{6}$ & 180.16 & bio mass burning \\
\hline Sucrose & $\mathrm{C}_{12} \mathrm{H}_{22} \mathrm{O}_{11}$ & 342.30 & bio mass burning \\
\hline Malonic Acid & $\mathrm{CH}_{2}(\mathrm{COOH})_{2}$ & 104.0615 & bio mass burning \\
\hline Adipic Acid & $\left(\mathrm{CH}_{2}\right)_{4}(\mathrm{COOH})_{2}$ & 146.1412 & bio mass burning \\
\hline Azelaic Acid & $\left(\mathrm{CH}_{2}\right)_{7}(\mathrm{COOH})_{2}$ & 188.22 & bio mass burning \\
\hline
\end{tabular}

Each substrate was weighed as a pure compound and dissolved in $1.0 \mathrm{~L}$ of DI water to produce a solution that was introduced to the aerosol generation system. The aerosol generation flows were established and allowed to stabilize for 15 to 30 minutes and then determination of the extinction coefficients ensued. The aerosol and dilution flows were adjusted to produce an unconditioned flow with an RH between 40 and $60 \%$ and a 532 $\mathrm{nm} \mathrm{b}_{\text {ext }}$ between 50 and $150 \mathrm{Mm}^{-1}$ (vs. the filtered air baseline measurement). These levels allow for significant increase and decrease in $\mathrm{RH}$ due to the humidifier and dehumidifier as noted in the previous section. The $b_{\text {ext }}$ chosen gives good signal-to-noise ratios for all three wavelengths and decreases the likelihood that the high $\mathrm{RH}$ measurements (especially the UV $355 \mathrm{~nm}$ one) will go outside of the linear dynamic range (upper limit $\sim 4000 \mathrm{Mm}^{-1}$ ) of the HC-CRD. (At very high extinctions, the ringdown decay takes place so quickly that the digitizer is only able to capture a few points, 
resulting in poor determinations of the ring-down time and thus $b_{\text {ext. }}$.) A robust data set is usually produced by running the fully automated instrument for 8 to 16 hours (often overnight). The data is then transferred to another PC for post processing, including the filtered air subtraction (the blank measurement) and averaging of the $15 \mathrm{~Hz}$ data to 1 to 10 min. intervals with substantially improved limits of detection ( $3 \sigma$ LoD $355 \mathrm{~nm}=3$ $\mathrm{Mm}^{-1}, 532$ and $1064 \mathrm{~nm}=1 \mathrm{Mm}^{-1}$ at $1 \mathrm{~min}$. averaging). This averaged data is then subjected to the SDA-FMC analysis to determine the effective radius, a measure of the average size, as described in the next section.

2.4 Derivation of particle size information from extinction coefficients at three wavelengths (SDA-FMC)

As discussed in the Introduction section, the traditional approach for investigating the change in optical properties upon alteration of the RH is simply to compare the extinction coefficients directly (optimally at a range of RH to produce a full humidogram). This approach is time-consuming, requires more control over the $\mathrm{RH}$ and must still be modeled to extract the increase in particle size because the $\mathrm{f}(\mathrm{RH})$ contains information about the changes in size and composition during water uptake. Also, because particle transmission differences in the humidifier and dehumidifier systems were suspected to be interfering with reliable measurements of the changes in aerosol extinction with relative humidity, a completely different approach is investigated in this dissertation (the first report of this application, to our knowledge). The measurements of extinction at three wavelengths in each flow tube were used to determine the effective radius of the particles in that aerosol. Then the growth factor could be derived by comparing the effective radii 
from the flows with different $\mathrm{RH}$ endpoints. The derivation of the radius from the multiwavelength extinction measurements is described first in this section.

\subsection{1 Ångström Exponent}

A power-law relationship has been used for decades to describe the spectral dependence of aerosol extinction coefficients; the wavelength exponent of the aerosol extinction is commonly known as the Ångström exponent. The Ångström exponent for aerosol optical depth AOD at wavelength $\lambda$ was defined as

$$
\alpha_{\lambda}=-\frac{d \ln \left(A O D_{\lambda}\right)}{d \ln \lambda}
$$

The Ångström exponent for the atmospheric aerosol can be measured in many ways, including using automated surface sunphotometry, multi-wavelength spectral measurements on airplanes and satellites or using in situ instruments like the HC-CRD. The remote measurements have enabled characterization of the aerosol particles from maritime sources, biomass burning, and urban sites on a nearly global scale. AOD is an analog to the extinction coefficient but measured along an atmospheric path, often from the top of the atmosphere to the ground (Gobbi et al. 2007). The HC-CRD version of Ångström exponent uses $b_{\text {ext }}$ instead of AOD

$$
\alpha_{\lambda}=-\frac{d \ln \left(b_{\text {ext }, \lambda}\right)}{d \ln \lambda}
$$


The numerical value of the Ångström exponent serves as a qualitative indicator of the aerosol particle size: fine-mode $(0.1-1.0 \mu \mathrm{m})$ aerosol particles have a value greater than 2, while $\alpha_{\lambda}<2$ usually indicates coarse-mode $(>1 \mu \mathrm{m})$ aerosol particles (Schuster at al. 2006).

The common practice when obtaining the Ångström exponent is to measure the extinction (or AOD) of atmospheric aerosol particles at two or more broadly spaced wavelengths, e.g., UV, visible and/or near IR. The Ångström exponent obtained in this form is the average slope of the wavelength dependence of the AOD or extinction coefficients in logarithmic coordinates (O'Neill, et al. 2001). Equations 2-5a and 2-5b below are the pair-wise formulas for AOD and extinction. The latter applies to measurements by the HC-CRD.

$$
\begin{aligned}
& \alpha\left(\lambda_{1}, \lambda_{2}\right)=-\frac{\ln \frac{A O D_{, \lambda 1}}{A O D_{\lambda 2}}}{\ln \frac{\lambda_{1}}{\lambda_{2}}} \\
& \alpha\left(\lambda_{1}, \lambda_{2}\right)=-\frac{\ln \frac{b_{\text {ext }, \lambda 1}}{b_{\text {ext }, \lambda, 2}}}{\ln \frac{\lambda_{1}}{\lambda_{2}}}
\end{aligned}
$$

If extinction coefficients or AODs at more than two wavelengths are measured, the spectral derivative and curvature (first and second derivatives of the logarithmic wavelength dependence) can be used instead of the Ångström exponent to derive a more 
quantitative estimate of the aerosol particles' size. The principles described above are the foundation of the expanded algorithm that will be discussed in the next section.

\subsubsection{SDA/FMC method}

O'Neill et al. $(2001,2003)$ developed the spectral deconvolution algorithm (SDA) that partitions the contributions of the fine and coarse modes to atmospheric AOD at a reference wavelength (typically $500 \mathrm{~nm}$ ) (O'Neill et al. 2001, 2003). The SDA separation is purely based on the spectral behavior of AOD, which is the advantage of this method. A validation of the SDA-FMC method used an extensive aerosol dataset collected during a smoke event in Quebec (O'Neill et al. 2005). It was found that the multi-wavelength AOD directly taken from sunphotometry can be used to derive the fine mode fraction of extinction $\eta$ and the Van de Hulst phase shift parameter $\rho_{\text {eff, }}\left(\mathrm{O}^{\prime} \mathrm{Neil}\right.$ et al. 2005, 2001). 
The van de Hulst phase shift parameter $\rho_{\text {eff }}$ is defined as

$$
\begin{array}{r}
\rho=2 x(m-1) \\
=\frac{2 \cdot(2 \pi r)}{\lambda}(m-1)
\end{array}
$$

where $\mathrm{x}$ is the size parameter $\mathrm{x}=\mathrm{kr}, \mathrm{k}$ is the wave number $\mathrm{k}=2 \pi / \lambda$ and $\mathrm{m}$ is the refractive index, and was originally developed by van de Hulst in 1957 (Van de Hulst, 1957). The fine mode Van de Hulst phase shift parameter $\rho_{\text {eff,f }}$ can then be used to retrieve the fine mode effective radius $\mathrm{R}_{\mathrm{eff}, \mathrm{f}}$ of the aerosol if the refractive index is known or assumed.

The effective radius was defined by Hansen and Travis (1974) (Hansen et al.1974).

$$
R_{e f f}=\frac{\int_{0}^{\infty} r \pi r^{2} \frac{d N}{d \ln r} d \ln r}{\int_{0}^{\infty} \pi r^{2} \frac{d N}{d \ln r} d \ln r}
$$

where $\mathrm{r}$ is the particle radius, $\mathrm{N}$ is the number density and $\mathrm{dN} / \mathrm{dln} r$ is the numberweighted size distribution for the aerosol - multiplying this by $\pi r^{2}$ as is done in Equation 2-7 converts this to the surface area-weighted size distribution. It may be described as the average radius weighted by the geometrical cross-sectional area, the applicable moment for optical studies.

The SDA-FMC algorithm used in this work begins by extracting the spectral derivative and curvature from the aerosol extinction coefficients vs. wavelength using a secondorder polynomial fit to the log-transformed data (Eck et al. 1999, Atkinson et al. 2010). 


$$
\ln b_{\text {ext } \lambda}=a_{0}+a_{1} \ln \lambda+a_{2}(\ln \lambda)^{2}
$$

where $a_{0}, a_{1}, a_{2}$ are coefficients determined by the fitting. The spectral derivative $\alpha_{\lambda}$ and the spectral curvature $\alpha_{\lambda}{ }^{\prime}$ are then obtained from the coefficients

$$
\begin{gathered}
\alpha_{\lambda}=\frac{-d \ln \left(b_{\lambda}\right)}{d \ln \lambda}=-a_{1}-2 a_{2} \ln (\lambda) \\
\alpha_{\lambda}^{\prime}=\frac{d a_{\lambda}}{d \ln (\lambda)}=\frac{-d \ln b_{\lambda}^{2}}{d \ln (\lambda)^{2}}=-2 a_{2}
\end{gathered}
$$

In the special case when $\mathrm{a}_{2}=0, \mathrm{a}_{1}=-\alpha$ as originally identified by Ångström. For many fine mode distributions (and many ambient aerosol observations) the spectral derivative is found to be wavelength dependent - i.e, there is measureable curvature, which this method exploits. Neither the AOD (or extinction) nor its spectral derivative vary much within the visible spectrum for coarse mode particles (values of $\alpha_{c}$ and $\alpha_{c}$, are close to zero) so at the reference wavelength of $500 \mathrm{~nm}, \alpha_{\mathrm{c}}$ and $\alpha_{\mathrm{c}}$ ' were set to constant values of 0.15 and 0.0 respectively (O’Neill, et al.2001). This allows extraction of the fine mode parameters $\left(\alpha_{\mathrm{f}}\right.$ and $\left.\alpha_{\mathrm{f}}{ }^{\prime}\right)$ and the fine mode fraction of the extinction.

Using the remote measurements from the Quebec smoke event, O'Neill et al. (2005) showed that the fine mode spectral curvature $\left(\alpha_{\mathrm{f}}{ }^{\prime}\right)$ is sensitive to the effective radius of the fine mode aerosol particles. The plot at the bottom left corner in Figure 2-3 demonstrates that the magnitude of $\alpha_{\mathrm{f}}$ increases as the $\mathrm{R}_{\mathrm{eff}}$ (actually $\rho_{\mathrm{eff}}$, but only $\mathrm{R}_{\mathrm{eff}}$ is allowed to vary) increases between $10 \mathrm{~nm}$ to $500 \mathrm{~nm}$, reversing direction once the $R_{\text {eff }}$ is greater than 500nm. Another view of this relationship is provided in Schuster, et al. (2006) as reproduced in Figure 2-4, which shows the Ångström exponent and curvature for a 
modeled monomodal lognormal aerosol size distribution with varying effective radius. The polar plot in Figure 2-3 shows the modeled dependence on both parameters as a function of size for several test cases.

The "ada" plot - in the two-dimensional space of $\alpha_{\mathrm{f}}$ and $\alpha_{\mathrm{f}}$ ' - is shown in Figure 2-4. The term "ada" comes from a concatenation of the Angstrom exponent " $\alpha$ " and its derivative "d $\alpha$ " $(\alpha, \alpha)$. The empirical observations were discretized and plotted on the $\left(\alpha, \alpha^{\prime}\right)$ space. The angle $\varphi$ from the $\alpha_{\mathrm{f}}$ axis subtended by a line of constant $\rho_{\text {eff, } \mathrm{f}}$ was used as the independent variable in a fit to the data. All of the lines of constant $\rho_{\text {eff }}$ intersect at an approximate origin of $\left(\alpha_{\mathrm{f}, 0} \alpha_{\mathrm{f}, 0}{ }^{\prime}\right)=(0.5,0.2)$ as shown in Figure 2-3b highlighted with the red box. 


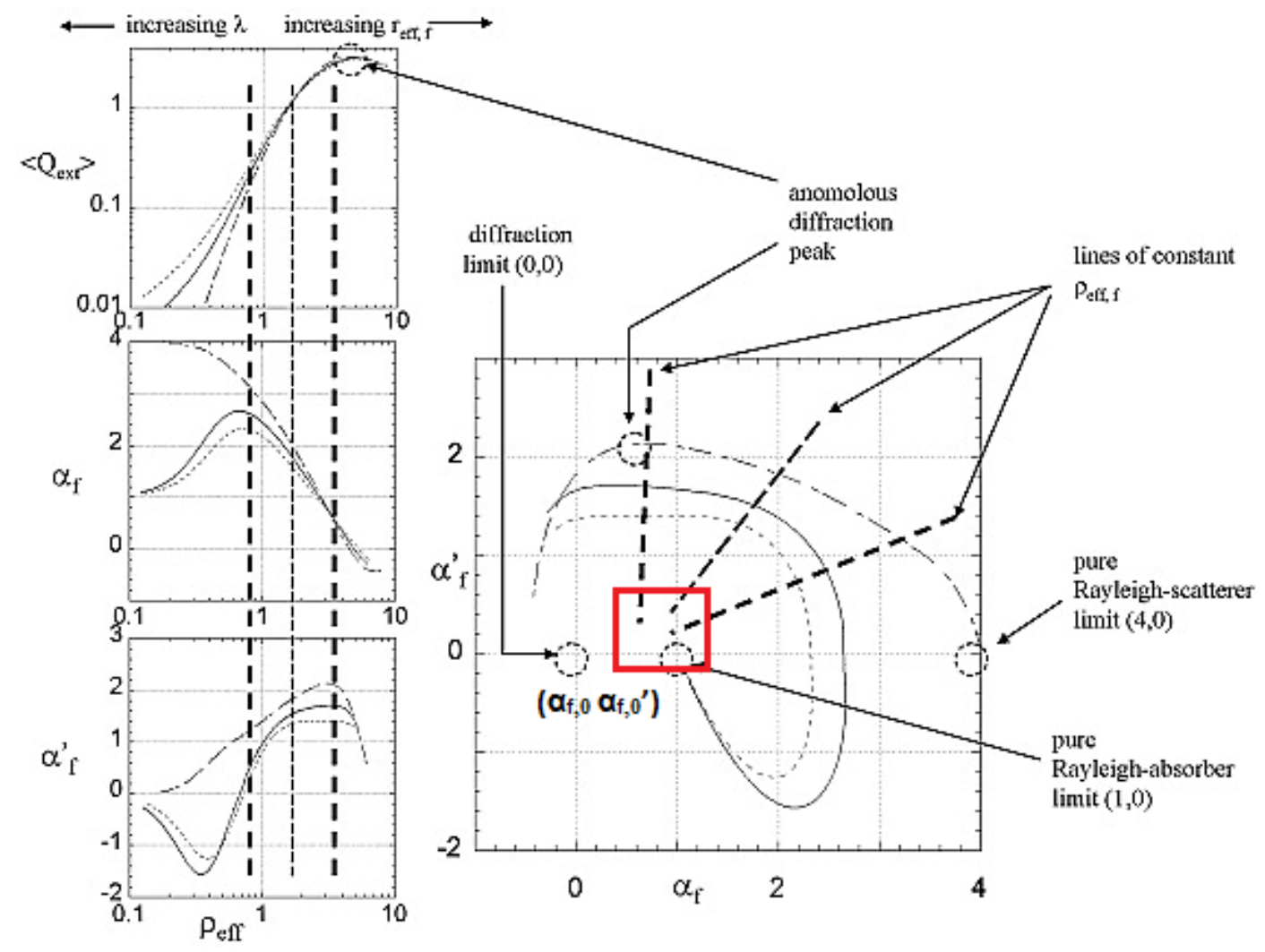

Figure 2-3: The parabolic equation $\alpha_{f}^{\prime}=a \alpha_{f}^{2}+b \alpha_{f}+c$ is used to generate the three curves in the figure; each curve represents a different case. (a). the dash-dot trace represents the non-absorbing homogeneous sphere with refractive index $\mathrm{m}=1.5+0 \mathrm{i}$ (b) solid trace represents the soot core that has refractive index $\mathrm{m}=1.8-0.6 \mathrm{i}$ surrounded by a non-absorbing shell of refractive index $\mathrm{m}=1.5-0 \mathrm{i}$ ( $6 \%$ core mass with volume weight effective refractive index $m_{\text {eff }}=1.514-0.029 \mathrm{i}$, Reid et al 1999) (c) dotted trace with 12\% core mass and volume weight effective refractive index $m_{\text {eff }}=1.529-0.058 \mathrm{i}$. The bold dashed lines roughly indicate the limit of fine mode $\rho_{\text {eff,f }}$ produced by the sunphotometric wavelength between $380 \mathrm{~nm}$ to $1020 \mathrm{~nm}$. With the reference wavelength of $500 \mathrm{~nm}$, the $\rho_{\text {eff,f }}$ yields values from 0.1 to 10 reflecting the $R_{\text {eff }}$ from 0.008 to $0.8 \mu \mathrm{m}$.(Borrowed O’Neil et al. 2005 Figure 1 ) 



Figure 2-4: The simulation plots of the (a, top) Angström exponent and (b, bottom) curvature for the monomodal lognormal aerosol size distributions with varying effective radii. The aerosol particles used in this simulation was an internal mixture with tuning volume ratio of water, ammonium sulfate and black carbon with the refractive index of $\mathrm{m}=1.37-0.003 \mathrm{i}$ at four wavelengths $(0.44,0.67,0.87$ and $1.02 \mu \mathrm{m}) . \sigma=0.38$ represents the fine particles with median radii $\mathrm{R}_{\mathrm{i}} \leq 0.6 \mu \mathrm{m}$, and $\sigma=0.75$ represents the particles in the coarse mode with median radii $\mathrm{R}_{\mathrm{i}} \geq 0.6 \mu \mathrm{m}$. (Figure 8 from Schuster et al. $2006^{31}$ )

The $\alpha_{\mathrm{f}}$ and $\alpha_{\mathrm{f}}$ ' were obtained from the SDA treatment of the HC-CRD extinction coefficients as described earlier in this section. Then $\alpha_{\mathrm{f}}$ and $\alpha_{\mathrm{f}}$ ' are combined to determine the angular displacement $\varphi$ in the two-dimensional ada space

$$
\tan \varphi=\frac{\alpha_{f}^{\prime}-\alpha_{f, 0}^{\prime}}{\alpha_{f}-\alpha_{f, 0}}=\frac{\alpha_{f}^{\prime}-0.2}{\alpha_{f}-0.5}
$$

where $\varphi$ is in radians (O'Neil et al 2005). The $\varphi$ from Equation 2-10 is then used to produce the fine mode Van de Hulst phase shift parameter $\rho_{\text {eff,f. }}$ 


$$
\rho_{e f f, f}=0.31593+1.25050 \varphi+0.52859 \varphi^{2}
$$

where the coefficients in this relationship were derived from the polar fitting described earlier. Once the value of $\rho_{\text {eff, }}$ was determined, the effective radius of the fine particle distribution $\mathrm{R}_{\mathrm{eff}}$ can be found using

$$
\rho_{e f f, f}=2 \cdot\left(\frac{2 \pi R_{e f f}}{\lambda}\right) \cdot\left(m_{r}-1\right)
$$

where $\lambda$ is the reference wavelength $500 \mathrm{~nm}$, and $\mathrm{m}_{\mathrm{r}}$ is the refractive index. Depending on the relative humidity and thus water uptake by the particles, the refractive index used in Equation 2-12 needs to be readjusted. A discussion on the calculation of the refractive index using a mixing rule is introduced in the next section.

The SDA-FMC algorithm was implemented in a MATLAB program provided by Dr. O'Neill and was shown to be able to process the extinction data obtained from the HC$\mathrm{CRD}$ and obtain reasonable values for the effective radius of laboratory-generated aerosols.

\subsection{Mixing Rule}

The aerosol direct effect is the result of the interaction between the aerosol particles and radiation. The bulk refractive index of the material determines the fraction of scattering and absorption of light by pure materials. However atmospheric aerosols are composed of external and internal mixtures of components with different refractive indices. The effective refractive indices of the mixed aerosol particles may depend upon the chemical 
composition, shape, and morphology, especially for internal mixtures (Freedman et al. 2009). In this work, the determination of the aerosol particle size ( $\left.\mathrm{R}_{\mathrm{eff}}\right)$ from HC-CRD using the SDA-FMC procedure required prior knowledge of the bulk refractive indices of the substrates and the effective refractive indices of the mixed aerosol particles. The mixing scenario that we assumed for the HC-CRD experiment was internal mixing with homogenous morphology.

A number of methods for calculating the refractive index of mixed composition aerosols are used and described in detail elsewhere (Freedman et al. 2009). These "mixing rules" include (1) molar-weighted which obtains the total refraction of a mixture using the linear average of the refractions weighted by their molar volume (Jacobson et al. 2001, Born 1999, Abo Riziq et al. 2007, Stelson et al. 1990); (2) volume-weighted using the linear average of the indices of the components weighted by their volume fraction (Abo Riziq et al. 2007); (3) the Maxwell-Garnett rule; and (4) the dynamic effective medium approximation. The underlying assumption for all of these mixing rules was that it is possible to obtain the refractive index of complex aerosol particles through the knowledge of the properties (density, molecular weight, refractive index) of the individual constituents, and the way in which they were mixed. In all cases, the "wet" aerosols were a mixture of the aerosol substrate with water, but in some instances, the "dry" particles were themselves an internal mixture of different components. 
2.5.1 Determination of the effective refractive index for humidity controlled channels There were two distinct types of internal mixing to consider in the HC-CRD study. We start with the first mixing scenario which was the mixture of an aerosol substrate with water. The HC-CRD was equipped with two humidity controlled flow tubes that were used to modify the RHs including one humidified and one dehumidified flow resulting in particles with different (high and low) water content.

In the dehumidified flow, the relative humidity was well below the CRH (ERH) for the inorganic species used, so most of the aerosol particles were in their crystal/solid phases. The condition mentioned above is also applied to the deliquescent species that stay in the crystalline form until the surrounding relative humidities reach to the deliquescence relative humidity (DRH). In these cases, no mixing rule is needed for the dehumidified condition. Therefore the refractive index of the pure aerosol substrate (i.e., the bulk) was used for the refractive index of the single-component aerosols, which is also the foundation for determining the effective refractive indices for the other two RH conditions.

An iterative algorithm for the determination of the effective refractive index and effective radius of the mid and high RH conditions was developed as part of this work. The refractive index used is only the real part of the refractive index because the imaginary parts of the refractive indices for the substrates investigated to date is too small to be taken into consideration $(\mathrm{k} \sim 0)$. 


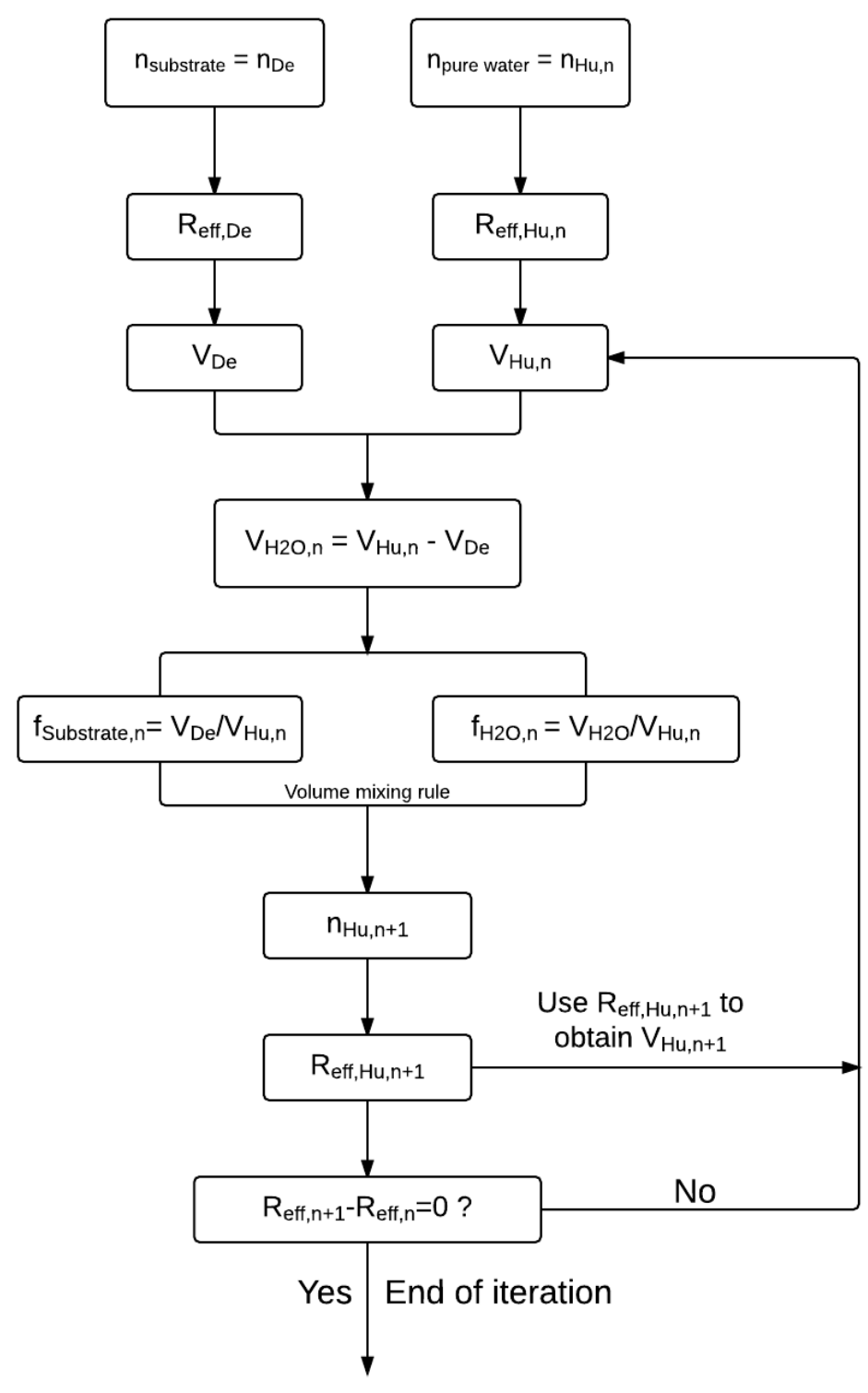

Figure 2-5: Schematic representation of the iterative algorithm for determination of the effective refractive index and radius of the aerosols in the moderate and high $\mathrm{RH}$ channels - subscript "De" refers to the dehumidified aerosol flow and "Hu" either of the humidified ones. 
Figure 2-5 illustrates the order of operations in this algorithm. The refractive indices of the substrate and pure water $(n=1.33)$ were required to start the algorithm. The refractive index of the pure aerosol substrate (i.e., the bulk) was used for the refractive index of the dehumidified (low $\mathrm{RH})$ condition, and the effective radius of the particles $\left(\mathrm{R}_{\text {eff,De }}\right)$ in the dehumidified flow was calculated from the SDA-FMC results obtained in the dehumidified flow tube and using Equation 2-12. The volume of the assumed dry particle is then calculated using Equation 2-13 and this is considered as the solute volume for the particles in all RH states

$$
V_{D e}=\frac{4}{3} \pi R_{e f f, D e}^{3}
$$

For the high RH aerosol, the refractive index of pure water is first used in equation 2-15 to yield a humidified particle size $\mathrm{R}_{\mathrm{eff}, \mathrm{Hu}, \mathrm{I}}$ and the volume of the particle can be then determined using Equation 2-14a

$$
\begin{array}{r}
V_{H u}=\frac{4}{3} \pi R_{e f f, H u, i}^{3} \\
V_{A m b}=\frac{4}{3} \pi R_{e f f, A m b, i}^{3}
\end{array}
$$

while for the mid RH channel, the refractive index of the dry particle was used as the starting value for the iterative procedure and the volume of the particle was calculated using Equation 2-14b. 
The growth in the volume of particles between the high or mid RH aerosols and the low $\mathrm{RH}$ particles corresponds to the water uptake during the particle hygroscopic growth, so the volume of water in the humidified particle may be obtained by difference

$$
V_{H 2 O}=V_{H u(A m b)}-V_{D e}
$$

where $A m b$ would refer to the mid or high RH state, or an actual ambient $\mathrm{RH}$ observed in field measurements. Once the volume of water in the particles was found; the volume fraction of the solute (salt/substrate) and water can be determined

$$
\begin{array}{r}
f_{H 2 O}=\frac{V_{H u(A m b)}-V_{D e}}{V_{H u(A m b)}} \\
f_{\text {salt }}=\frac{V_{D e}}{V_{H u(A m b)}}
\end{array}
$$

The volume mixing rule is then applied to determine a new refractive index based on the calculated volume fraction, $\mathrm{n}_{\mathrm{Hu}, \mathrm{i}+1}$ named thusly to differentiate it from the bulk refractive index used for the dehumidified flow

$$
n_{i+1}=f_{H 2 O} n_{H 20}+f_{\text {Substrate }} n_{\text {Substrate }}
$$

This $\mathrm{n}_{\mathrm{Hu}, \mathrm{n}+1}$ is then used to calculate a revised particle size for the test aerosol $\mathrm{R}_{\mathrm{eff}, \mathrm{Hu}, \mathrm{n}+1}$. The modification to the sizes from the procedure is obtained by difference

$$
\Delta R_{e f f}=R_{e f f, i}-R_{e f f, i+1}
$$


There are two values that can be used as indicators to end the iteration procedure. The first one is the size difference shown in Equation 2-18. If the $\Delta_{\text {Reff }}$ is above a critical value, the $\mathrm{R}_{\mathrm{eff}, \mathrm{Hu}, \mathrm{i}+1}$ will be used to calculate a new volume of dehumidified particles and pair of volume fractions. The newly calculated volume fraction pair is then used to obtain a new effective refractive index; and the new humidified particle size $\mathrm{R}_{\mathrm{eff}, \mathrm{i}+2}$ is compared with the $\mathrm{R}_{\mathrm{eff}, \mathrm{i}+1}$. These steps will be repeated until the $\Delta_{\mathrm{Reff}}$ approaches zero. Because the errors from measurement and calculation were propagated into the size calculation; the size differences sometimes have an oscillatory behavior when $\mathrm{R}_{\mathrm{eff}}$ approaches the true value, but the convergence is usually rapid and deterministic. Alternatively, the refractive index difference shown in Equation 2-19 can be used as an indicator of convergence.

$$
\Delta n_{H u(A m b)}=n_{i}-n_{i+1}
$$

\subsubsection{Mixing rule for multi-component substrates}

The second mixing scenario where mixed-composition particles are hydrated was more realistic in a sense; because the atmospheric aerosol particles are usually composed of mixtures of compounds. The volume mixing rule was applied to determine the effective refractive index of the low $\mathrm{RH}$ aerosol. The bulk refractive index of each component was found in the literature and the refractive index of the mixture was calculated by the linear average of the components weighted by their volume fractions:

$$
n_{\text {tot,2nd scenario }}=f_{1} n_{1}+f_{2} n_{2}
$$


Where $f_{i}$ is the volume fraction of the components. The "dry" size and refractive index was then used as it was for the single component aerosols to determing the refractive index and size of the particles after water uptake.

\subsection{Determination of $\gamma(\mathrm{RH})$ and $\kappa(\mathrm{RH})$}

The aerosol hygroscopic growth factor is the ratio of particle size at the relative humidity of interest to the size of particles at a reference relative humidity, usually taken as low enough that the particle is "dry". The aerosol particles rapidly grow in size once exposed to high $\mathrm{RH}$, and a value greater than unity indicates particle hygroscopicity. From the results of the SDA-FMC, i.e., the three-wavelength derived $\mathrm{R}_{\mathrm{eff}, \mathrm{f}}$ for two different $\mathrm{RH}$ conditions (i.e., two HC-CRD flows) the growth factor can be obtained

$$
g f(R H)=\frac{R_{e f f, w e t}}{R_{e f f, d r y}}
$$

The aerosol hygroscopicity parameter $\kappa$ can then derived from the HC-CRD measurements according to its dependence on the growth factor (gf), as given by Petters and Kreidenweis et al. in their seminal 2007 paper (Petters et al. 2007,2009)

$$
\begin{gathered}
\kappa=\left(G f_{R H^{3}}-1\right)(1 / a w-1) \\
a_{w}=\frac{\% R H}{100}
\end{gathered}
$$

where the water activity is equal to the $\mathrm{RH}$ if the Kelvin effect is omitted, usually a safe assumption for particles above $100 \mathrm{~nm}$ in diameter. In the results section, $\kappa$ determined in 
this way is compared to published results using other methods/instruments to validate the new approach described here.

A water uptake parameter ("WUP") that describes the size increase with humidification in a log-log space was also developed. It is obtained using the power law relation between the $\mathrm{R}_{\mathrm{eff}}$ and the corresponding $\% \mathrm{RH}$.

$$
W U P=\frac{\log \frac{R_{e f f, H u R H}}{R_{e f f, D e, R H}}}{\log \frac{100-\% R H_{D e}}{100-\% R H_{H u}}}
$$

Alternatively, the size distribution and composition can be obtained from other instruments (usually a scanning particle mobility spectrometer and an aerosol mass spectrometer) and the optical properties can be calculated using Mie theory. The modeled optical properties can then be compared to the measurements, usually using the single term parameter, $\gamma(\mathrm{RH})$, that describes the aerosol optical hygroscopicity. This parameter can be obtained from the power law relation between the extinction coefficient and the corresponding \%RH. Because HC-CRD was able to synchronously measure the extinction and $\% \mathrm{RH}$ at three $\% \mathrm{RH}$ conditions; three different pairs of $\gamma(\% \mathrm{RH})$ can be found using the equation shown below

$$
\gamma_{H u / A m b}=\frac{\log \frac{b_{\text {ext,HuRH}}}{b_{\text {ext,Amb,RH }}}}{\log \frac{100-\% R H_{H u}}{100-\% R H_{A m b}}}
$$




$$
\gamma_{A m b / D e}=\frac{\log \frac{b_{\text {ext }, A m b R H}}{b_{\text {ext }, D e, R H}}}{\log \frac{100-\% R H_{A m b}}{100-\% R H_{D e}}}
$$

Where the subscript "De" represents the dehumidified channel, the subscript "Hu" represents the humidified channel and "Amb" represents the ambient channel. In the modeling approach, the kappa values can be adjusted for species whose hygroscopicity is not well-known to allow for agreement with the measurements of gamma. 


\section{Results and Discussion}

Aerosols generated from two distinct types of chemical mixtures were investigated, including two inorganic mixture systems and six organic/inorganic mixture systems. The extinction coefficients that were directly obtained from HC-CRD measurement of different mixture systems along with the optical hygroscopicity descriptions (parameters: $\mathrm{f}(\mathrm{RH})$ and $\gamma(\mathrm{RH}))$ derived from the extinction coefficients are presented in this section. The particle size and growth parameters that are then calculated from the SDA/FMC method will also be presented and discussed

\subsection{Extinction coefficients, $\mathrm{f}(\mathrm{RH})$ and $\gamma(\mathrm{RH})$}

\subsubsection{Inorganic mixture systems}

Results obtained from two sets of inorganic mixtures are described in this section. The inorganic aerosols were used to investigate the hypothesis that the simple changes in the $b_{\text {ext }}$ with $\mathrm{RH}$ expressed as the pair-wise calculations of $\mathrm{f}(\mathrm{RH})$ or $\gamma(\mathrm{RH})$ could be used to infer composition. Although the results of this investigation are not promising, they do help to establish the context for the method in the next section and are included for completeness. Both chemical systems highlighted in this section have the same anions: $\mathrm{SO}_{4}{ }^{2-}$ and $\mathrm{HSO}_{4}{ }^{-}$but different cations: $\mathrm{Na}^{+}$and $\mathrm{NH}_{4}{ }^{+}$. Each mixture system is bounded by the two pure salts (sulfate or bisulfate) with five sulfate/bisulfate mixtures with mass mixing ratios of $2: 8,4: 6,5: 5,6: 4$, and $8: 2$ comprising the rest of the set. All of these substrates are considered inorganic and the aerosols produced from them are hygroscopic with hysteresis in their RH behavior. The DRHs and CRHs of the pure salts are listed in Table 3-1. Because each of the salts has a unique $\mathrm{DRH}$ and $\mathrm{CRH}$, the mixing ratio (i.e., 
chemical composition) can affect the hygroscopic growth and alter the DRH of the mixture substrates. It is thus expected that the extinction coefficients are functions of the chemical compositions in the mixtures system (i.e., the mixing ratio of sulfate and bisulfate).

Table 3-1: DRH and CRH for the substrates of sulfate and bisulfate system

\begin{tabular}{ccccc}
\hline & $\left.\mathbf{( N H}_{4}\right)_{2} \mathbf{S O}_{4}{ }^{\mathbf{a}}$ & $\mathbf{N H}_{4} \mathrm{HSO}_{4}{ }^{\mathbf{a}}$ & $\mathbf{N a}_{2} \mathrm{SO}_{4}{ }^{\mathbf{a}}$ & NaHSO$_{4}$ \\
\hline DRH, $\%$ & 80 & 40 & 84 & 52 \\
Solubility, wt $\%$ & 43.3 & 76 & 38.5 & 28.5 \\
CRH, $\%$ & $40-37$ & $22-0.05$ & $59-57$ & $<5$ \\
a. Tang. Et al. 1996 & & & & \\
\hline
\end{tabular}

Tables 3-2 and table 3-3 below list the extinction coefficients at $532 \mathrm{~nm}$ and the $\mathrm{f}(\mathrm{RH})$ and $\gamma(\mathrm{RH})$ obtained from experiments on the $\left(\mathrm{NH}_{4}\right)_{2} \mathrm{SO}_{4}-\left(\mathrm{NH}_{4}\right) \mathrm{HSO}_{4}$ system and the $\mathrm{Na}_{2} \mathrm{SO}_{4}-\mathrm{NaHSO}_{4}$ system respectively. Because all of the substrates used are hygroscopic with hysteresis, we expect to obtain different $\mathrm{f}(\mathrm{RH})$ and $\gamma(\mathrm{RH})$ values for each pair-wise combination of $b_{\text {ext }}(\mathrm{RH})$ measurements, reflecting the differences in the rate of change of the scattering coefficient as the particles undergo discontinuous hygroscopic growth. The subscripts "Amb/De" represent a pairing of the $b_{\text {ect }}$ values from the dehumidified condition with those from the ambient condition (the "ambient" reference comes from our use of this instrument in the field; in this context, it simply means the RH is not intentionally altered). Although the percentage relative humidity values change from experiment to experiment, this pairing is typically $\mathrm{RH}<20 \%$ and $\mathrm{RH} \approx 50 \%$. The "Hu/De" refers to pairings of dehumidified with humidified conditioning with $\mathrm{RH}<20 \%$ 
and $\mathrm{RH}>80 \%$ while "Hu/Amb" describes a pairing of measurments at ambient and humidified RHs of about $50 \%$ and $80 \%$.

Table 3-2: The extinction coefficients at three different humidity conditions for the $\left(\mathrm{NH}_{4}\right)_{2} \mathrm{SO}_{4}-\left(\mathrm{NH}_{4}\right) \mathrm{HSO}_{4}$ mixture system

\begin{tabular}{|c|c|c|c|c|c|}
\hline \multicolumn{2}{|c|}{ Mass Mixing Ratio } & \multirow{2}{*}{$\begin{array}{c}\mathrm{NH}_{4}{ }^{+} \mathrm{SO}_{4}{ }^{2+} \\
\text { ratio }\end{array}$} & \multirow{2}{*}{$\begin{array}{l}\text { Humidity } \\
\text { Condition }\end{array}$} & \multirow{2}{*}{$\%$ RH } & \multirow{2}{*}{$\begin{array}{c}\text { Ext } \\
\text { Coeff. }\end{array}$} \\
\hline$\left(\mathrm{NH}_{4}\right)_{2} \mathrm{SO}_{4}$ & $\mathrm{NH}_{4} \mathrm{HSO}_{4}$ & & & & \\
\hline \multirow{3}{*}{0} & \multirow{3}{*}{10} & \multirow{3}{*}{$1.0: 1$} & Dehumidified & 15 & 355.1 \\
\hline & & & Ambient & 50 & 522.8 \\
\hline & & & Humidified & 86 & 1031.7 \\
\hline \multirow{3}{*}{2} & \multirow{3}{*}{8} & \multirow{3}{*}{$1.2: 1$} & Dehumidified & 16 & 212.4 \\
\hline & & & Ambient & 50 & 379.5 \\
\hline & & & Humidified & 86 & 712.4 \\
\hline \multirow{3}{*}{4} & \multirow{3}{*}{6} & \multirow{3}{*}{ 1.4:1 } & Dehumidified & 18 & 130.2 \\
\hline & & & Ambient & 51 & 175.1 \\
\hline & & & Humidified & 86 & 326.8 \\
\hline \multirow{3}{*}{5} & \multirow{3}{*}{5} & \multirow{3}{*}{$1.5: 1$} & Dehumidified & 17 & 235.4 \\
\hline & & & Ambient & 51 & 382.5 \\
\hline & & & Humidified & 86 & 707.9 \\
\hline \multirow{3}{*}{6} & \multirow{3}{*}{4} & \multirow{3}{*}{$1.6: 1$} & Dehumidified & 20 & 221.5 \\
\hline & & & Ambient & 52 & 395.2 \\
\hline & & & Humidified & 87 & 697.7 \\
\hline \multirow{3}{*}{8} & \multirow{3}{*}{2} & \multirow{3}{*}{$1.8: 1$} & Dehumidified & 22 & 210.1 \\
\hline & & & Ambient & 52 & 349.2 \\
\hline & & & Humidified & 86 & 619 \\
\hline \multirow{3}{*}{10} & \multirow{3}{*}{0} & \multirow{3}{*}{$2.0: 1$} & Dehumidified & 18 & 217.9 \\
\hline & & & Ambient & 51 & 340.4 \\
\hline & & & Humidified & 86 & 659.8 \\
\hline
\end{tabular}


Table 3-3: $\mathrm{f}(\mathrm{RH})$ and gammas at three different humidity conditions for the $\left(\mathrm{NH}_{4}\right)_{2} \mathrm{SO}_{4}$ $\left(\mathrm{NH}_{4}\right) \mathrm{HSO}_{4}$ mixture system

\begin{tabular}{|ccccccc|}
\hline $\begin{array}{c}\text { Mixture } \\
\text { Number }\end{array}$ & \multicolumn{2}{c}{ Mass Mixing Ratio } & \multicolumn{2}{c}{$\mathbf{f}(\mathbf{R H})$} & \multicolumn{2}{c|}{$\gamma(\mathbf{R H})$} \\
& $\left.\mathbf{( N H}_{\mathbf{4}}\right)_{\mathbf{2}} \mathbf{S O}_{\mathbf{4}}$ & $\mathbf{N H}_{\mathbf{4}} \mathbf{H S O}_{\mathbf{4}}$ & $\mathbf{A m b} / \mathbf{D e}$ & $\mathbf{H u} / \mathbf{A m b}$ & $\mathbf{A m b} / \mathbf{D e}$ & $\mathbf{H u} / \mathbf{A m b}$ \\
\hline 1 & 0 & 10 & 1.47 & 2.91 & 0.72 & 0.53 \\
2 & 2 & 8 & 1.79 & 3.35 & 1.11 & 0.5 \\
3 & 4 & 6 & 1.34 & 2.51 & 0.57 & 0.5 \\
4 & 5 & 5 & 1.62 & 3.01 & 0.95 & 0.5 \\
5 & 6 & 4 & 1.78 & 3.15 & 1.16 & 0.44 \\
6 & 8 & 2 & 1.66 & 2.95 & 1.06 & 0.46 \\
7 & 10 & 0 & 1.56 & 3.03 & 0.87 & 0.51 \\
\hline
\end{tabular}

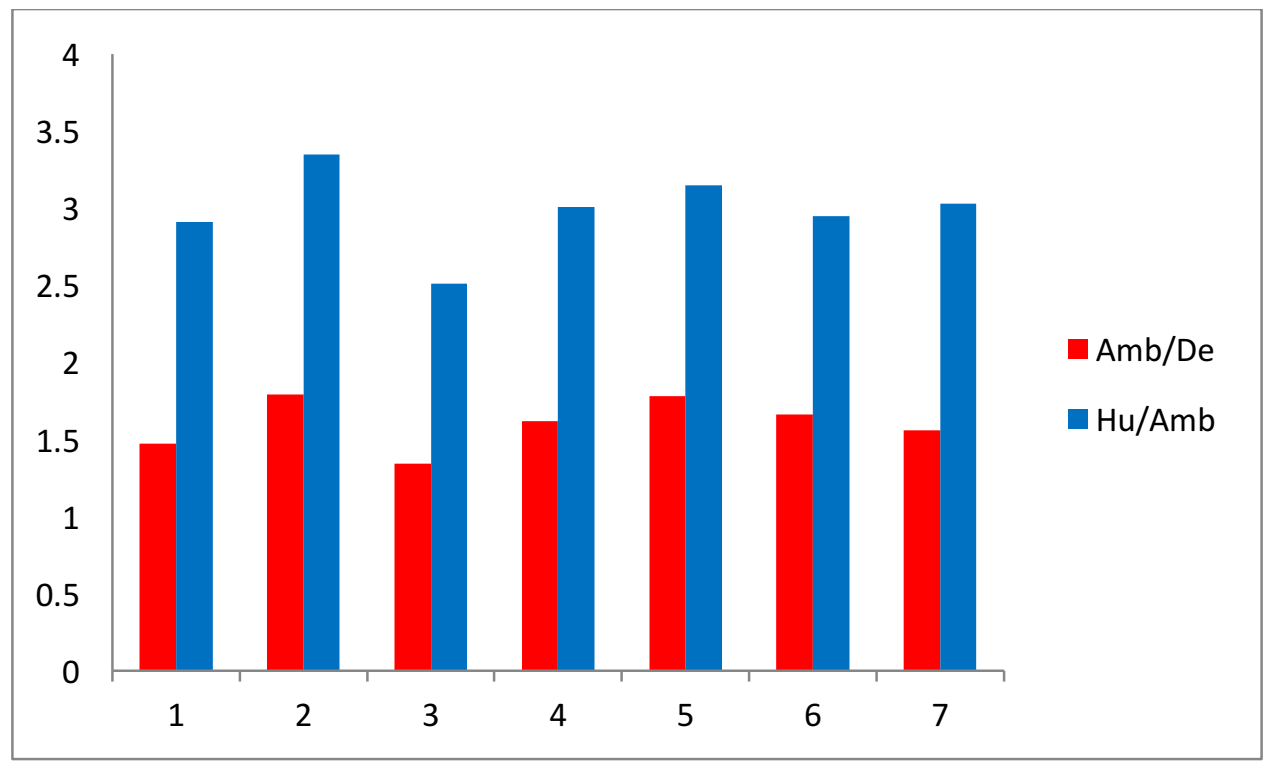

Figure 3-1: $\mathrm{f}(\mathrm{RH})$ at three different humidity conditions for the $\left(\mathrm{NH}_{4}\right)_{2} \mathrm{SO}_{4}-\left(\mathrm{NH}_{4}\right) \mathrm{HSO}_{4}$ mixture system 


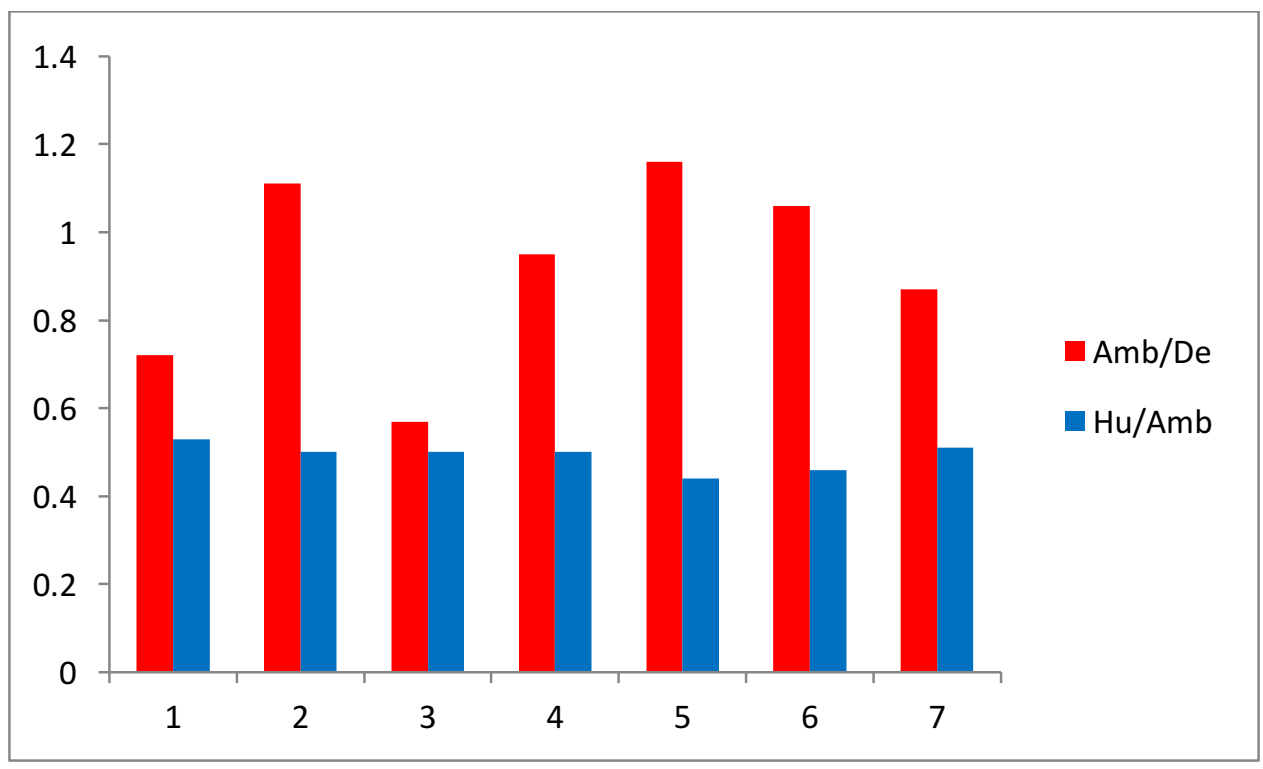

Figure 3-2: $\gamma(\mathrm{RH})$ (Gammas) at three different humidity conditions for the $\left(\mathrm{NH}_{4}\right)_{2} \mathrm{SO}_{4}$ $\left(\mathrm{NH}_{4}\right) \mathrm{HSO}_{4}$ mixture system

It was hypothesized that the change in extinction due to the hygroscopic growth could be used to infer the chemical composition of the substrate. For the aerosols produced from neat $\left(\mathrm{NH}_{4}\right)_{2} \mathrm{SO}_{4}$ and $\left(\mathrm{NH}_{4}\right) \mathrm{HSO}_{4}$ solutions there is some evidence of the expected "hygroscopic with hysteresis" growth curve, since the $\mathrm{f}(\mathrm{RH})$ in the high $\mathrm{RH}$ region is nearly twice that in the low $\mathrm{RH}$ range and there is a difference between the two $\gamma(\mathrm{RH})$ values, especially for the neat ammonium sulfate. This is promising, since it implies that salts could be distinguished from organic aerosols that take up water more continuously across the whole RH range. To further test the hypothesis, the five intermediate mixtures with different mixing ratios of sulfate and bisulfate were examined. All of the mixtures show extinction coefficients that increase with increasing relative humidity (indicating 
hygroscopic growth) and some evidence of the same discontinuous growth at high vs. low RH characteristic of salts.

Santarpia, et al. 2005 found from studies of atmospheric aerosols that the hygroscopic behavior of ammonium and sulfate ion-containing aerosol mixtures are determined by the ionic ratio of ammonium versus sulfate instead of the individual chemical constituents (ammonium sulfate vs. ammonium bisulfate). It was found that the ratio of ammonium to sulfate varies over a continuum in the atmosphere from zero (sulfuric acid) to two (ammonium sulfate) and that the ratio determines the occurrence of the hysteretic behavior. When this ratio is less than 1:1, the hygroscopic behavior will resemble that of sulfuric acid, with little or no hysteresis. When the ammonium to sulfate ratio is increased to $1: 1$, the hygroscopic growth is similar to that of ammonium bisulfate where they note that many experiments have difficulty observing the hysteresis behavior of ammonium bisulfate under typical atmospheric conditions. As the ratio further increased into the range where this ratio is similar to letovicite $(3: 2$, tri-ammonium sulfate hydrogensulfate $\left.\left(\mathrm{NH}_{4}\right)_{3} \mathrm{H}\left(\mathrm{SO}_{4}\right)_{2}\right)$ or ammonium sulfate (2:1), hysteresis will be observed. The approximate ratios for the five mixtures of $\left(\mathrm{NH}_{4}\right)_{2} \mathrm{SO}_{4}$ and $\left(\mathrm{NH}_{4}\right) \mathrm{HSO}_{4}$ are shown in Table 3.2. We then use the ratio and the pair of gamma values for each mixture to examine the hygroscopic behavior of each substrate. For the pure $\left(\mathrm{NH}_{4}\right) \mathrm{HSO}_{4}$, where the literature suggests no hysteresis behavior can be easily observed, the pair of gamma values are similar to one another and both less than one, an indication that the particles displayed no hysteretic behavior (no strong discontinuous changes in their growth). At the other extreme $\left(2: 1\right.$, neat $\left.\left(\mathrm{NH}_{4}\right)_{2} \mathrm{SO}_{4}\right)$ the two $\gamma(\mathrm{RH})$ values are more dissimilar, but 
not to as great an extent as might have been expected. The $\gamma(\mathrm{RH})$ pairs for the mixed aerosols are even less clearly interpretable, most showing greater differences (indications of discontinuous growth) and larger values (indicating rapid growth during the high RH part of the range) than were observed for ammonium sulfate. The literature does not indicate that intermediate mixture particles would show stronger hysteretic behavior, so these results seem puzzling.

The values of $\mathrm{f}(\mathrm{RH})$ for the two RH modifications (i.e., Amb/De and Hu/Amb) also do not establish a clear trend associated with the change in mixing ratio. It was expected that the 2:8 $\left(\mathrm{NH}_{4}\right)_{2} \mathrm{SO}_{4}: \mathrm{NH}_{4} \mathrm{HSO}_{4}$ would exhibit a similar growth pattern to the neat $\mathrm{NH}_{4} \mathrm{HSO}_{4}$ while the 8:2 $\left(\mathrm{NH}_{4}\right)_{2} \mathrm{SO}_{4}: \mathrm{NH}_{4} \mathrm{HSO}_{4}$ mixture would be more similar to neat $\left(\mathrm{NH}_{4}\right)_{2} \mathrm{SO}_{4}$, but only the latter is observed in the $\mathrm{f}(\mathrm{RH})$ values. The next mixing ratio $(4: 6)$ in the series produced an even more puzzling result and these experiments were repeated multiple times to confirm this odd behavior. It appears that the change in $\mathrm{f}(\mathrm{RH})$ cannot be used as the indicator of the chemical composition (mixing ratio) even in a well-controlled chemical system. The pair-wise combinations of gamma values also fail to establish a monotonic relationship with respect to the change in mixing ratio. Therefore neither $f(R H)$ nor $\gamma(\mathrm{RH})$ values can be used to reflect the change in mixing ratio of the investigated $\left(\mathrm{NH}_{4}\right)_{2} \mathrm{SO}_{4}-\left(\mathrm{NH}_{4}\right) \mathrm{HSO}_{4}$ mixtures.

Table 3-4 and table 3-5 list the extinction coefficients and pair-wise $\mathrm{f}(\mathrm{RH})$ and $\gamma(\mathrm{RH})$ values obtained for the $\mathrm{Na}_{2} \mathrm{SO}_{4}-\mathrm{NaHSO}_{4}$ mixture system, again bounded by the neat $\mathrm{Na}_{2} \mathrm{SO}_{4}$ and $\mathrm{NaHSO}_{4}$ solutions and containing the five mixtures with varied mass mixing 
ratios as shown. Both $\mathrm{Na}_{2} \mathrm{SO}_{4}$ and $\mathrm{NaHSO}_{4}$ are inorganic aerosols that will show "hygroscopic with hysteresis" type growth curves. Again all mixtures (and the aerosols from the neat solutions) show the predicted increase in the extinction coefficient with humidification and evidence of non-continuous changes in the slope of that relationship.

Table 3-4: The extinction coefficients, $\mathrm{f}(\mathrm{RH})$ and gammas at three different humidity conditions for the $\mathrm{Na}_{2} \mathrm{SO}_{4}-\mathrm{NaHSO}_{4}$ mixtures system

\begin{tabular}{|c|c|c|c|c|}
\hline \multicolumn{2}{|c|}{$\begin{array}{c}\text { Mass Mixing } \\
\text { Ratio }\end{array}$} & \multirow{2}{*}{$\begin{array}{l}\text { Humidity } \\
\text { Condition }\end{array}$} & \multirow[t]{2}{*}{$\%$ RH } & \multirow{2}{*}{$\begin{array}{c}\text { Ext } \\
\text { Coeff. }\end{array}$} \\
\hline $\mathrm{Na}_{2} \mathrm{SO}_{4}$ & $\mathrm{NaHSO}_{4}$ & & & \\
\hline \multirow{3}{*}{0} & \multirow{3}{*}{10} & Dehumidified & 16 & 179.3 \\
\hline & & Ambient & 52 & 319.2 \\
\hline & & Humidified & 87 & 716.6 \\
\hline \multirow{3}{*}{2} & \multirow{3}{*}{8} & Dehumidified & 23 & 188 \\
\hline & & Ambient & 49 & 408.8 \\
\hline & & Humidified & 86 & 932.4 \\
\hline \multirow{3}{*}{4} & \multirow{3}{*}{6} & Dehumidified & 21 & 226.8 \\
\hline & & Ambient & 50 & 525.2 \\
\hline & & Humidified & 86 & 1166.1 \\
\hline \multirow{3}{*}{5} & \multirow{3}{*}{5} & Dehumidified & 18 & 130.2 \\
\hline & & Ambient & 50 & 300.3 \\
\hline & & Humidified & 85 & 593 \\
\hline \multirow{3}{*}{6} & \multirow{3}{*}{4} & Dehumidified & 20 & 175.6 \\
\hline & & Ambient & 50 & 348.6 \\
\hline & & Humidified & 86 & 869.7 \\
\hline \multirow{3}{*}{8} & \multirow{3}{*}{2} & Dehumidified & 19 & 195.4 \\
\hline & & Ambient & 53 & 388.3 \\
\hline & & Humidified & 87 & 1081.8 \\
\hline \multirow{3}{*}{10} & \multirow{3}{*}{0} & Dehumidified & 19 & 177.9 \\
\hline & & Ambient & 50 & 240.7 \\
\hline & & Humidified & 86 & 1074.1 \\
\hline
\end{tabular}


Table 3-5: $\mathrm{f}(\mathrm{RH})$ and gammas at three different humidity conditions for the $\mathrm{Na}_{2} \mathrm{SO}_{4}$ $\mathrm{NaHSO}_{4}$ mixtures system

\begin{tabular}{|ccccccc|}
\hline $\begin{array}{c}\text { Mixture } \\
\text { Number }\end{array}$ & \multicolumn{2}{c}{$\begin{array}{c}\text { Mass Mixing } \\
\text { Ratio }\end{array}$} & \multicolumn{2}{c|}{$\mathbf{f}(\mathbf{R H})$} & \multicolumn{2}{c|}{$\gamma(\mathbf{R H})$} \\
& $\mathbf{N a}_{\mathbf{2}} \mathbf{S O}_{\mathbf{4}}$ & $\mathbf{N a H S O} \mathbf{4}_{\mathbf{4}}$ & $\mathbf{A m b} / \mathbf{D e}$ & $\mathbf{H u} / \mathbf{A m b}$ & $\mathbf{A m b} / \mathbf{D e}$ & Hu/Amb \\
\hline 1 & 0 & 10 & 1.78 & 4 & 1.06 & 0.61 \\
2 & 2 & 8 & 2.17 & 4.96 & 1.87 & 0.63 \\
3 & 4 & 6 & 2.32 & 5.14 & 1.82 & 0.62 \\
4 & 5 & 5 & 2.31 & 4.55 & 1.69 & 0.55 \\
5 & 6 & 4 & 1.99 & 4.95 & 1.47 & 0.7 \\
6 & 8 & 2 & 1.99 & 5.54 & 1.27 & 0.82 \\
7 & 10 & 0 & 1.35 & 6.04 & 0.61 & 1.16 \\
\hline
\end{tabular}

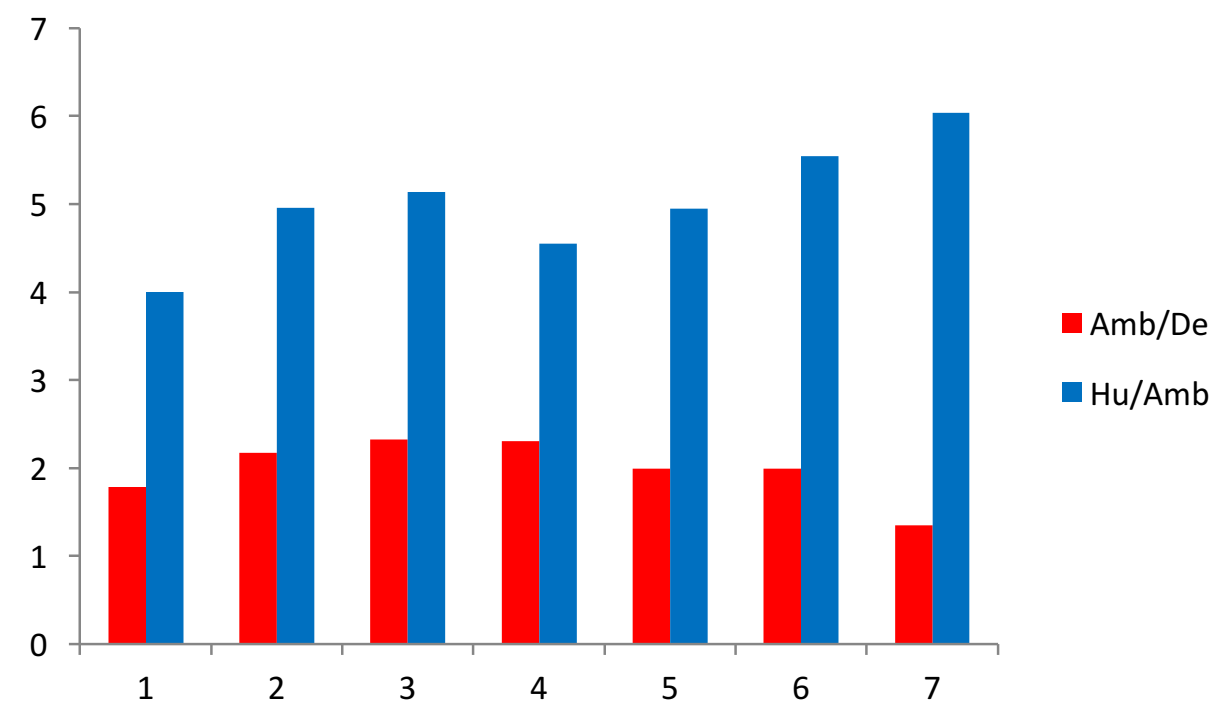

Figure 3-3: $\mathrm{f}(\mathrm{RH})$ at three different humidity conditions for the $\mathrm{Na}_{2} \mathrm{SO}_{4}-\mathrm{NaHSO}_{4}$ mixtures system 


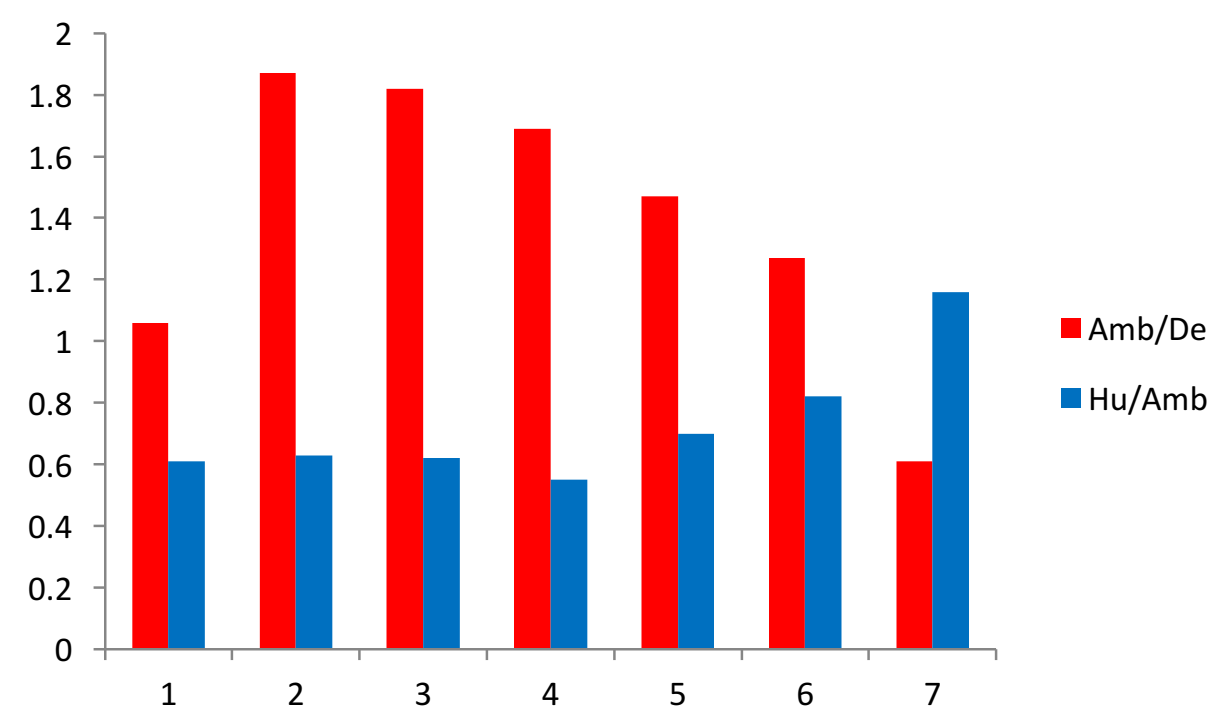

Figure 3-4: $\gamma(\mathrm{RH})$ (gammas) at three different humidity conditions for $\mathrm{Na}_{2} \mathrm{SO}_{4}-\mathrm{NaHSO}_{4}$ mixtures system

As indicated in Table 3-1, pure $\mathrm{NaHSO}_{4}$ aerosols have lower DRH than those formed from $\mathrm{Na}_{2} \mathrm{SO}_{4}$, so it is expected that $\mathrm{NaHSO}_{4}$ particles will start growing at a lower $\mathrm{RH}$ (near that of the ambient $\mathrm{RH}$ measurement). The $\mathrm{NaHSO}_{4}$ particles in the ambient $\mathrm{RH}$ flow thus may start to grow producing a value of $\gamma(\mathrm{Amb} / \mathrm{De})$ greater than one while $\gamma(\mathrm{Hu} / \mathrm{Amb})$ is less than one. In contrast to the pure $\mathrm{NaHSO}_{4}$, the pure $\mathrm{Na}_{2} \mathrm{SO}_{4}$ particles have a higher DRH (84\%) and at the ambient channel relative humidity of $50 \%$ which is lower than its DRH, the growth cannot be activated at this relative humidity. Because the $\mathrm{RH}$ of the humidified flow is close to the $\mathrm{DRH}$ of pure $\mathrm{Na}_{2} \mathrm{SO}_{4}$, it is possible that only some of the particles started experiencing the hygroscopic growth. This may give rise to a $\gamma(\mathrm{Amb} / \mathrm{De})$ less than one and a $\gamma(\mathrm{Hu} / \mathrm{Amb})$ only slightly greater than one as observed.

Again, it was hypothesized that the $2: 8 \mathrm{Na}_{2} \mathrm{SO}_{4}: \mathrm{NaHSO}_{4}$ mixture would resemble the behavior of pure $\mathrm{NaHSO}_{4}$ while the $8: 2 \mathrm{Na}_{2} \mathrm{SO}_{4}: \mathrm{NaHSO}_{4}$ mixture would behave similarly 
to the pure $\mathrm{Na}_{2} \mathrm{SO}_{4}$ aerosols. In this case, neither mixture provides $\gamma$ values near the ends of the range, but increasing $\mathrm{Na}_{2} \mathrm{SO}_{4}$ mixing ratios are correlated with higher values of $\gamma(\mathrm{Hu} / \mathrm{Amb})$, except for the 5:5 mixture. The $\gamma(\mathrm{Amb} / \mathrm{De})$ values do not show monotonic dependence with respect to the mixing ratio across the whole range; but after a large increase in the $\gamma(\mathrm{Amb} / \mathrm{De})$ value upon adding $\mathrm{Na}_{2} \mathrm{SO}_{4}$ into the mixture, the values decreased with increasing $\mathrm{Na}_{2} \mathrm{SO}_{4}$. We hypothesize that the $\mathrm{pH}$ of the substrate solution may affect the particles' hygroscopic growth. The pure $\mathrm{Na}_{2} \mathrm{SO}_{4}$ is a nearly neutral salt that forms an aqueous solution with $\mathrm{pH} \approx 7$. Neat $\mathrm{NaHSO}_{4}$ is a very potent weak acid $\left(\mathrm{K}_{\mathrm{a}}\right.$ $=1.02 \times 10^{-2}$ ) and the solution $\mathrm{pH}$ is 1 for a $1 \mathrm{M}$ solution. Adding a small amount of $\mathrm{Na}_{2} \mathrm{SO}_{4}$ into the mixture creates a buffer, altering the $\mathrm{pH}$ of the substrate solution. The buffer is much less acidic causing the hygroscopic behavior to rapidly deviate from the pure $\mathrm{NaHSO}_{4}$. The variations in $\gamma(\mathrm{Amb} / \mathrm{De})$ that are observed probably reflect $\mathrm{pH}-$ induced changes in the water uptake or particle formation or both.

The pure $\mathrm{Na}_{2} \mathrm{SO}_{4}$ has the highest $\mathrm{f}(\mathrm{RH})(\mathrm{Hu} / \mathrm{De})$ value among the seven substrates while the pure $\mathrm{NaHSO}_{4}$ has the lowest $\mathrm{f}(\mathrm{RH})(\mathrm{Hu} / \mathrm{De})$ value of 4 and the value increases upon mixing with $\mathrm{Na}_{2} \mathrm{SO}_{4}$ (all greater than 4.5). However, none of the pair-wise $\mathrm{f}(\mathrm{RH}) \mathrm{s}$ establish a monotonic trend with respect to the mixing ratio and again we find that $\mathrm{f}(\mathrm{RH})$ cannot establish a relationship with mixing ratio and serve as an indicator for the chemical composition.

In summarizing the results obtained for the two inorganic sulfate-bisulfate systems, we find that all mixtures experience an increase in extinction coefficients with increasing RH. 
This behavior is consistent with hygroscopic substrates where the enhancements in the extinction coefficient are primarily due to the hygroscopic growth of the aerosol particles. Also both sulfate-bisulfate systems show evidence of the "hygroscopic growth with hysteresis" growth curve; and the mixing ratio in the sodium system seems to alter the position of the $\mathrm{DRH}$, moving it across the $\mathrm{RH}$ of the ambient flow in our instrument. The $\mathrm{f}(\mathrm{RH})(\mathrm{Hu} / \mathrm{De})$ values of this system range from 4 to 6 , much higher than in the ammonium system where the values range from 2 to 3.5 . This gross difference in $f(R H)$ could potentially serve as a rough diagnostic reference for the determination of chemical composition for the atmospheric aerosol. There was no clear and consistent correlation between the mixing ratio and the values of $\mathrm{f}(\mathrm{RH})$ or $\gamma(\mathrm{RH})$ for either chemical system so we find that neither parameter can be used to predict the mixing ratio (chemical composition) within the simple systems we investigated here. However the results for the simpler sodium bisulfate-sulfate system (sodium does not contribute to the acid-base behavior of the solutions) may indicate that the $\mathrm{pH}$ of the substrate solution can determine the hygroscopic behavior of the mixtures and more investigation of this point may be warranted. 


\subsubsection{Organic-inorganic Mixture Systems}

\subsubsection{Organic-inorganic Mixture Systems: $\mathrm{NaCl}$ vs Organic systems}

Tables 3-6 to 3-8 show the extinction coefficients of the organic/inorganic mixture systems described in this dissertation. Each system consists of aerosols produced from aqueous solutions containing variable mixing ratios (by mass) of one inorganic compound and one organic compound. There are two different groups within the organic/inorganic mixture system. As before, each system is bounded by aerosols made from solutions of the neat organic compound and the neat inorganic compound. The first group consists of the simple organic compounds sucrose, glycine, and D-glucose mixed with $\mathrm{NaCl}$ at mass mixing ratios of 1:2, 1:1, and 2:1. The second organic/inorganic mixture system combines a series of dicarboxylic acids with ammonium sulfate as the inorganic component. The selection of dicarboxylic acids includes malonic acid, adipic acid and azelaic acid, producing benchmarks that mimic the behavior a range of atmospheric aerosols from sea salt to biomass burning emissions.

Table 3-6 shows the extinction coefficients and pair-wise $\mathrm{f}(\mathrm{RH})$ and $\gamma(\mathrm{RH})$ values obtained for the sucrose- $\mathrm{NaCl}$ mixture system including the neat $\mathrm{NaCl}$, neat sucrose and three mixtures. Note that only the low to high $\mathrm{RH}$ combination is presented for $\mathrm{f}(\mathrm{RH})$. For all of the substrates, the extinction coefficient increases upon humidification as expected. For this system there is a clear trend in the $\mathrm{f}(\mathrm{RH})$ values from sucrose to $\mathrm{NaCl}$. Robinson et al. 2013 report $\mathrm{f}(\mathrm{RH})$ at $532 \mathrm{~nm}$ for pure sucrose aerosols of 1.11-1.24, which is close to our results. The distinct differences between the pair of gamma values indicates that hysteretic behavior occurs during the hygroscopic growth, but the 
differences generally decrease as the organic content increases, except for the pure sucrose aerosol. Overall higher sucrose fractions in the mixture inhibits the hygroscopic growth of $\mathrm{NaCl}$ as well as the occurrence of the hysteresis behavior, producing lower $\mathrm{f}(\mathrm{RH})$ and $\gamma(\mathrm{RH})$ values and smaller differences between the gamma values.

Table 3-6: The extinction coefficients, $\mathrm{f}(\mathrm{RH})$ and $\gamma(\mathrm{RH})$ at three different humidity conditions for mixed sucrose and $\mathrm{NaCl}$ mixture aerosols

\begin{tabular}{|c|c|c|c|c|c|c|c|}
\hline \multicolumn{2}{|c|}{ Mixing } & \multirow{2}{*}{$\begin{array}{l}\text { Humidity } \\
\text { Condition }\end{array}$} & \multirow{2}{*}{$\% \mathbf{R H}$} & \multirow{2}{*}{$\begin{array}{c}\text { Ext } \\
\text { Coeff. }\end{array}$} & \multirow{2}{*}{$\begin{array}{c}\mathbf{f}(\mathbf{R H}) \\
\text { Hu/De }\end{array}$} & \multicolumn{2}{|c|}{$\gamma(\mathbf{R H})$} \\
\hline Sucrose & $\mathrm{NaCl}$ & & & & & Amb/De & Hu/Amb \\
\hline \multirow[t]{3}{*}{0} & 1 & Dehumidified & 48 & 78.65 & 5.297 & 9.753 & 1.751 \\
\hline & & Ambient & 54 & 245.02 & & & \\
\hline & & Humidified & 66 & 416.55 & & & \\
\hline \multirow[t]{3}{*}{1} & 2 & Dehumidified & 25 & 141.48 & 4.646 & 0.743 & 1.798 \\
\hline & & Ambient & 50 & 191.27 & & & \\
\hline & & Humidified & 75 & 657.33 & & & \\
\hline \multirow[t]{3}{*}{1} & 1 & Dehumidified & 27 & 100.73 & 3.353 & 0.598 & 0.901 \\
\hline & & Ambient & 54 & 132.19 & & & \\
\hline & & Humidified & 84 & 337.70 & & & \\
\hline \multirow[t]{3}{*}{2} & 1 & Dehumidified & 30 & 120.19 & 2.946 & 0.861 & 0.771 \\
\hline & & Ambient & 58 & 184.43 & & & \\
\hline & & Humidified & 82 & 354.09 & & & \\
\hline \multirow[t]{3}{*}{1} & 0 & Dehumidified & 33 & 123.41 & 1.303 & 0.775 & 0.057 \\
\hline & & Ambient & 49 & 153.19 & & & \\
\hline & & Humidified & 78 & 160.79 & & & \\
\hline
\end{tabular}

glycine- $\mathrm{NaCl}$ mixtures bounded by neat $\mathrm{NaCl}$ and glycine. The $\mathrm{NaCl}$ growth data is the same as that presented in Table 3-4. The neat glycine solution produces aerosols that experience slightly greater increases in extinction coefficient in the humidified flow than were obtained for sucrose. Upon adding $\mathrm{NaCl}$ into the mixture, all three mixtures showed consistently higher increases in extinction coefficients, i.e, larger $\mathrm{f}(\mathrm{RH})$ than the pure 
glycine. In this case, the pairs of gamma values for the three mixtures indicate that they experienced little hysteretic behavior during their growth, but again neat glycine showed some indication that it did.

Table 3-7: The extinction coefficients, $\mathrm{f}(\mathrm{RH})$ and gammas at three different humidity conditions for glycine and $\mathrm{NaCl}$ mixtures system

\begin{tabular}{|c|c|c|c|c|c|c|c|}
\hline \multicolumn{2}{|c|}{ Mixing } & \multirow{2}{*}{$\begin{array}{l}\text { Humidity } \\
\text { Condition }\end{array}$} & \multirow{2}{*}{$\%$ RH } & \multirow{2}{*}{$\begin{array}{c}\text { Ext } \\
\text { Coeff }\end{array}$} & \multirow{2}{*}{$\begin{array}{l}\text { f(RH) } \\
\text { Hu/De }\end{array}$} & \multicolumn{2}{|c|}{$\gamma(\mathbf{R H})$} \\
\hline Glycine & $\mathrm{NaCl}$ & & & & & $\mathrm{Hu} / \mathbf{A m b}$ & $\mathrm{Amb} / \mathrm{De}$ \\
\hline \multirow[t]{3}{*}{0} & 1 & Dehumidified & 48 & 78.65 & 5.297 & 1.751 & 9.753 \\
\hline & & Ambient & 54 & 245.02 & & & \\
\hline & & Humidified & 66 & 416.55 & & & \\
\hline \multirow[t]{3}{*}{1} & 2 & Dehumidified & 37 & 92.20 & 4.652 & 1.491 & 1.433 \\
\hline & & Ambient & 53 & 141.15 & & & \\
\hline & & Humidified & 78 & 428.89 & & & \\
\hline \multirow[t]{3}{*}{1} & 1 & Dehumidified & 34 & 88.40 & 3.822 & 1.001 & 1.486 \\
\hline & & Ambient & 53 & 146.48 & & & \\
\hline & & Humidified & 79 & 337.84 & & & \\
\hline \multirow[t]{3}{*}{2} & 1 & Dehumidified & 34 & 161.67 & 2.544 & 0.689 & 1.081 \\
\hline & & Ambient & 56 & 251.05 & & & \\
\hline & & Humidified & 79 & 411.31 & & & \\
\hline \multirow[t]{3}{*}{1} & 0 & Dehumidified & 30 & 94.40 & 1.949 & 0.390 & 0.721 \\
\hline & & Ambient & 55 & 129.04 & & & \\
\hline & & Humidified & 82 & 183.95 & & & \\
\hline
\end{tabular}

Table 3-8 shows that similar results were obtained for the glucose- $\mathrm{NaCl}$ mixture system. The pure D-glucose particles experience minimal growth with $\mathrm{RH}$ as expected since it is not a very hygroscopic species similar to the other organic components in this work. The 1:2 D-glucose: $\mathrm{NaCl}$ mixture exhibits similar behavior to the pure $\mathrm{NaCl}$ with the highest increase among the mixtures and there is general downward trend with increasing organic character. The gamma values suggest that hysteresis may occur during the growth but that it also decreases with increasing D-glucose concentration. 
Table 3-8: The extinction coefficients, $\mathrm{f}(\mathrm{RH})$ and gammas at three different humidity conditions for glucose and $\mathrm{NaCl}$ mixtures system

\begin{tabular}{|c|c|c|c|c|c|c|c|}
\hline \multicolumn{2}{|c|}{ Mixing } & \multirow{2}{*}{$\begin{array}{l}\text { Humidity } \\
\text { Condition }\end{array}$} & \multirow[b]{2}{*}{$\%$ RH } & \multirow[b]{2}{*}{$\begin{array}{c}\text { Ext } \\
\text { Coeff }\end{array}$} & \multirow[b]{2}{*}{$\begin{array}{l}\text { f(RH) } \\
\text { Hu/De }\end{array}$} & \multicolumn{2}{|c|}{$\gamma(\mathrm{RH})$} \\
\hline Glucose & $\begin{array}{c}\mathrm{NaC} \\
\mathrm{l}\end{array}$ & & & & & $\begin{array}{c}\mathbf{A m b} / \mathbf{D} \\
\mathrm{e}\end{array}$ & $\begin{array}{c}\mathrm{Hu} / \mathrm{Am} \\
\mathrm{b}\end{array}$ \\
\hline \multirow[t]{3}{*}{0} & 1 & Dehumidified & 48 & 78.65 & 5.297 & 1.751 & 9.753 \\
\hline & & Ambient & 54 & 245.02 & & & \\
\hline & & Humidified & 66 & 416.55 & & & \\
\hline \multirow[t]{3}{*}{1} & 2 & Dehumidified & 32 & 68.09 & 4.469 & 1.055 & 1.654 \\
\hline & & Ambient & 52 & 123.12 & & & \\
\hline & & Humidified & 80 & 304.31 & & & \\
\hline \multirow[t]{3}{*}{1} & 1 & Dehumidified & 28 & 111.83 & 2.039 & 1.421 & 0.854 \\
\hline & & Ambient & 52 & 159.08 & & & \\
\hline & & Humidified & 63 & 228.07 & & & \\
\hline \multirow[t]{3}{*}{2} & 1 & Dehumidified & 31 & 106.82 & 2.425 & 0.926 & 0.770 \\
\hline & & Ambient & 55 & 147.28 & & & \\
\hline & & Humidified & 75 & 259.05 & & & \\
\hline \multirow[t]{3}{*}{1} & 0 & Dehumidified & 31 & 205.70 & 1.802 & 0.274 & 1.042 \\
\hline & & Ambient & 53 & 307.47 & & & \\
\hline & & Humidified & 76 & 370.61 & & & \\
\hline
\end{tabular}

3.1.2.2 Organic-inorganic Mixture Systems: Dicarboxylic acids

The second set of organic/inorganic mixture systems combines a series of aliphatic

dicarboxylic acids with ammonium sulfate as the inorganic component. The selection of dicarboxylic acids includes malonic acid (C3), adipic acid (C6) and azelaic acid (C9).

Dicarboxylic acids are one of the most abundant organic constituents in the ambient atmospheric particles (Rogge et al., 1993). Dicarboxylic acids are formed from gas phase photochemical reactions involving a wide range of anthropogenic and biogenic precursors. Smog chamber (laboratory reaction) experiments have been done and were able to identify dicarboxylic acids among the products of oxidation of cyclic olefins and 
aromatic hydrocarbons, fatty acids, and as break-down products from larger dicarboxylic acids (Ray et al., 2005).

Table 3-9: The extinction coefficients and pair-wise $\mathrm{f}(\mathrm{RH})$ and $\gamma(\mathrm{RH})$ at three different humidity conditions for malonic acid (MA) and ammonium sulfate (AS) mixtures

\begin{tabular}{|c|c|c|c|c|c|c|c|}
\hline \multicolumn{2}{|c|}{$\begin{array}{l}\text { Mass Mixing } \\
\text { Ratio }\end{array}$} & \multirow[t]{2}{*}{$\begin{array}{l}\text { Humidity } \\
\text { Condition }\end{array}$} & \multirow[t]{2}{*}{ \%RH } & \multirow{2}{*}{$\begin{array}{c}\text { Ext } \\
\text { Coeff } \\
\text { a.532n } \\
\text { m } \\
\end{array}$} & \multirow[t]{2}{*}{$\mathbf{f}(\mathbf{R H})$} & \multicolumn{2}{|c|}{$\gamma(\mathbf{R H})$} \\
\hline МА & $\mathbf{A S}$ & & & & & $\begin{array}{c}\mathrm{Amb} / \mathrm{D} \\
\mathrm{e}\end{array}$ & $\begin{array}{c}\text { Hu/Am } \\
\text { b }\end{array}$ \\
\hline 0 & 4 & $\begin{array}{c}\text { Dehumidifie } \\
\text { d } \\
\text { Ambient } \\
\text { Humidified }\end{array}$ & $\begin{array}{l}18.0 \\
51.0 \\
86.0\end{array}$ & $\begin{array}{l}217.9 \\
340.4 \\
659.8\end{array}$ & 3.028 & 0.866 & 0.528 \\
\hline 1 & 3 & $\begin{array}{l}\text { Dehumidifie } \\
\text { d } \\
\text { Ambient } \\
\text { Humidified }\end{array}$ & $\begin{array}{l}28.4 \\
34.9 \\
67.8\end{array}$ & $\begin{array}{l}240.9 \\
303.3 \\
442.0\end{array}$ & 1.835 & 2.397 & 0.535 \\
\hline 1 & 1 & $\begin{array}{l}\text { Dehumidifie } \\
\text { d } \\
\text { Ambient } \\
\text { Humidified }\end{array}$ & $\begin{array}{l}27.0 \\
35.6 \\
73.6\end{array}$ & $\begin{array}{l}165.3 \\
190.3 \\
275.4\end{array}$ & 1.666 & 1.121 & 0.414 \\
\hline 3 & 1 & $\begin{array}{c}\text { Dehumidifie } \\
\text { d } \\
\text { Ambient } \\
\text { Humidified }\end{array}$ & $\begin{array}{l}28.5 \\
36.6 \\
69.0\end{array}$ & $\begin{array}{l}174.6 \\
186.1 \\
241.8\end{array}$ & 1.385 & 0.529 & 0.366 \\
\hline 4 & 0 & $\begin{array}{c}\text { Dehumidifie } \\
\text { d } \\
\text { Ambient } \\
\text { Humidified }\end{array}$ & $\begin{array}{l}28.9 \\
36.0 \\
72.7\end{array}$ & $\begin{array}{l}52.4 \\
62.1 \\
76.0\end{array}$ & 1.45 & 1.612 & 0.237 \\
\hline
\end{tabular}

Table 3-9 shows the extinction coefficients, $\mathrm{f}(\mathrm{RH})$ and pairs of $\gamma(\mathrm{RH})$ s obtained for malonic acid (MA) and ammonium sulfate (AS) mixtures. The results for neat 
ammonium sulfate are as presented for the earlier experiments in Table 3.2. The $f(R H)$ values consistently decrease with the increasing fraction of malonic acid in the mixture and the $\gamma$ values of the humidified condition to the ambient condition exhibit the same trend. However, the pair-wise $\gamma$ value of the ambient RH condition to the dehumidified condition does not show an identifiable trend. This results in a lack of a trend in the differences between the $\gamma(\mathrm{RH})$ pairs, making it difficult to assess whether there is information as to the hysteretic behavior in the system.

Table 3-10 shows the extinction coefficients, $\mathrm{f}(\mathrm{RH})$ and pairs of $\gamma(\mathrm{RH})$ values obtained for adipic acid (AA) and ammonium sulfate (AS) mixtures. The $\mathrm{f}(\mathrm{RH})$ values generally decreases as the fraction of malonic acid in the mixture increases, but it does not exhibit linearity as observed for the malonic acid / ammonium sulfate mixtures. The $\gamma(\mathrm{RH})$ pairs again provide no clear picture regarding the presence of hysteresis among the mixtures. The two negative $\gamma(\mathrm{RH})$ values from AA:AS 1:3 and 3:1 indicates the presence of an "inverse Kelvin effect" which will be further discussed in the next section. Clearly little growth is experienced in these systems. 
Table 3-10: The extinction coefficients, $\mathrm{f}(\mathrm{RH})$ and $\gamma(\mathrm{RH})$ at three different humidity conditions for adipic acid (AA) and ammonium sulfate (AS) mixtures

\begin{tabular}{|c|c|c|c|c|c|c|c|}
\hline \multicolumn{2}{|c|}{$\begin{array}{c}\text { Mass Mixing } \\
\text { Ratio }\end{array}$} & \multirow[t]{2}{*}{$\begin{array}{l}\text { Humidity } \\
\text { Condition }\end{array}$} & \multirow[t]{2}{*}{$\%$ RH } & \multirow{2}{*}{$\begin{array}{c}\text { Ext } \\
\text { Coeff } \\
\text { @532nm }\end{array}$} & \multirow{2}{*}{$\begin{array}{c}\mathbf{f}(\mathbf{R H}) \\
\mathrm{Hu} / \mathrm{De}\end{array}$} & \multicolumn{2}{|c|}{$\gamma(\mathbf{R H})$} \\
\hline $\mathbf{A A}$ & $\mathbf{A S}$ & & & & & Amb/De & Hu/Amb \\
\hline \multirow{4}{*}{0} & \multirow{3}{*}{4} & Dehumidified & 18.0 & 217.9 & 3.028 & 0.866 & 0.528 \\
\hline & & Ambient & 51.0 & 340.4 & & & \\
\hline & & Humidified & 86.0 & 659.8 & & & \\
\hline & & Dehumidified & 23.8 & 157.8 & 1.591 & 5.2 & -0.122 \\
\hline \multirow[t]{3}{*}{1} & 3 & Ambient & 30.7 & 259.1 & & & \\
\hline & & Humidified & 46.3 & 251.2 & & & \\
\hline & & Dehumidified & 19.1 & 122.5 & 1.795 & 2.631 & 0.167 \\
\hline \multirow[t]{3}{*}{1} & 1 & Ambient & 32.0 & 193.8 & & & \\
\hline & & Humidified & 67.9 & 219.8 & & & \\
\hline & & Dehumidified & 28.8 & 159.5 & 1.958 & 2.729 & 0.275 \\
\hline \multirow[t]{3}{*}{3} & 1 & Ambient & 39.5 & 248.2 & & & \\
\hline & & Humidified & 73.7 & 312.2 & & & \\
\hline & & Dehumidified & 19.7 & 136.5 & 1.08 & 2.347 & -0.452 \\
\hline \multirow[t]{2}{*}{4} & 0 & Ambient & 32.4 & 204.5 & & & \\
\hline & & Humidified & 67.2 & 147.5 & & & \\
\hline \multicolumn{8}{|c|}{ for azelaic acid (AzA) and ammonium sulfate (AS) mixtures. The $f(R H)$ values decreases } \\
\hline \multicolumn{8}{|c|}{ linearly with the increase in the fraction of azelaic acid in the mixture. The gamma values } \\
\hline \multicolumn{8}{|c|}{ pair again failed to establish a trend with respect the variation between azelaic acid and } \\
\hline \multicolumn{8}{|c|}{ ammonium sulfate. However, it is believed that the "inverse Kelvin effect" exhibited in } \\
\hline \multicolumn{8}{|c|}{ the AA:AS system was the cause, and the further discussion on the inverse Kelvin effect } \\
\hline
\end{tabular}


Table 3-11: The extinction coefficients, $\mathrm{f}(\mathrm{RH})$ and $\gamma(\mathrm{RH})$ at three different humidity conditions for azelaic acid (AzA) and ammonium sulfate (AS) mixtures

\begin{tabular}{|c|c|c|c|c|c|c|c|}
\hline \multicolumn{2}{|c|}{$\begin{array}{c}\text { Mass Mixing } \\
\text { Ratio }\end{array}$} & \multirow[t]{2}{*}{$\begin{array}{l}\text { Humidity } \\
\text { Condition }\end{array}$} & \multirow[t]{2}{*}{$\%$ RH } & \multirow[t]{2}{*}{$\begin{array}{c}\text { Ext } \\
\text { Coeff } \\
@ 532 \mathrm{~nm}\end{array}$} & \multirow{2}{*}{$\begin{array}{l}\text { f(RH) } \\
\text { Hu/De }\end{array}$} & \multicolumn{2}{|c|}{ Gamma } \\
\hline$\overline{\mathbf{A z A}}$ & $\mathbf{A S}$ & & & & & Amb/De & Hu/Amb \\
\hline \multirow{3}{*}{0} & \multirow{3}{*}{4} & Dehumidified & 18 & 217.9 & 3.028 & 0.866 & 0.528 \\
\hline & & Ambient & 51 & 340.4 & & & \\
\hline & & Humidified & 86 & 659.8 & & & \\
\hline \multirow{3}{*}{1} & \multirow{3}{*}{3} & Dehumidified & 25.1 & 165.8 & 2.495 & 2.384 & 0.557 \\
\hline & & Ambient & 37.6 & 255.6 & & & \\
\hline & & Humidified & 73.7 & 413.6 & & & \\
\hline \multirow{3}{*}{1} & \multirow{3}{*}{1} & Dehumidified & 22.4 & 181 & 1.959 & 2.21 & 0.236 \\
\hline & & Ambient & 37.2 & 288.1 & & & \\
\hline & & Humidified & 73.9 & 354.6 & & & \\
\hline \multirow{3}{*}{3} & \multirow{3}{*}{1} & Dehumidified & 26.3 & 106.6 & 1.573 & 3.031 & -0.062 \\
\hline & & Ambient & 37.6 & 176.9 & & & \\
\hline & & Humidified & 73.9 & 167.7 & & & \\
\hline \multirow{3}{*}{4} & \multirow{3}{*}{0} & Dehumidified & 18.6 & 157.4 & 1.154 & 1.922 & -0.369 \\
\hline & & Ambient & 36.4 & 252.9 & & & \\
\hline & & Humidified & 74 & 181.6 & & & \\
\hline
\end{tabular}

3.2 Determination of the effective refractive indices and effective radius $\left(R_{\text {eff }}\right)$

The extinction coefficients from HC-CRD measurements are used in the SDA/FMC method that was described in the Methods section of this dissertation. The van de Hulst phase shift parameter can be then retrieved and used to determine the effective radii for the fine particle mode of each test aerosol at the three different $\mathrm{RH}$ conditions. For each particle substrate, the particle size of the dehumidified channel is determined before the rest of channels, using the bulk refractive index of the substrate for single component 
aerosols. The multi-component substrate's refractive index is calculated from the bulk refractive indices using the volume mixing rule described in the Methods section and the known relative concentrations in the nebulized liquid. The iterative algorithm for the determination of refractive indices for the ambient and the humidified channel was described in detail in the Methods section. At the end of the iterations, an effective refractive index and the corresponding effective radius are obtained. The growth factor (gf) value is obtained using the ratio of the effective radius of the humidified channel to the dehumidified channel, describing the overall growth from low RH to high RH. The $\kappa$ values are also obtained from the hygroscopic growth between the humidified channel and dehumidified channel.

3.2.1 The effective refractive indices, $\mathrm{R}_{\text {eff, }}$ growth factors $(\mathrm{gf}), \mathrm{k}(\mathrm{RH})$ and WUP values of inorganic mixtures

Table 3-12 and 3-13 present the refractive indices (RI) of the three RH conditions with the corresponding calculated effective radius ( $\left.\mathrm{R}_{\mathrm{eff}}\right)$; and the growth factors (gf) (eq 2-21), $\kappa(\mathrm{RH})($ eq 2-22), and WUP values (eq2-24) obtained from combinations of radii obtained at different RHs for the systems of $\left(\mathrm{NH}_{4}\right)_{2} \mathrm{SO}_{4}-\left(\mathrm{NH}_{4}\right) \mathrm{HSO}_{4}$ mixtures and $\mathrm{Na}_{2} \mathrm{SO}_{4}-\mathrm{NaHSO}_{4}$ mixtures. As the RH increases, the particle RI tends toward that of water (1.33). 
Table 3-12: The refractive index and effective radius for three different relative humidity conditions, and the derived growth factor, $\kappa(\mathrm{RH})$ and WUP for the $\left(\mathrm{NH}_{4}\right)_{2} \mathrm{SO}_{4}$ $\left(\mathrm{NH}_{4}\right) \mathrm{HSO}_{4}$ mixtures

\begin{tabular}{|c|c|c|c|c|c|}
\hline $\begin{array}{r}\text { Mass Mix } \\
\left(\mathrm{NH}_{4}\right)_{2} \mathrm{SO}_{4} \\
\end{array}$ & $\begin{array}{l}\text { ing Ratio } \\
\mathrm{NH}_{4} \mathrm{HSO}_{4} \\
\end{array}$ & $\begin{array}{c}\mathrm{NH}_{4}{ }^{+}: \mathrm{SO}_{4}{ }^{2+} \\
\text { ratio }\end{array}$ & RH(\%) & RI & $\begin{array}{l}\text { Reff } \\
(\mathrm{nm})\end{array}$ \\
\hline \multirow{3}{*}{0} & \multirow{3}{*}{10} & \multirow{3}{*}{$1: 01$} & 15 & 1.473 & 155 \\
\hline & & & 50 & 1.385 & 213 \\
\hline & & & 86 & 1.368 & 240 \\
\hline \multirow{3}{*}{2} & \multirow{3}{*}{8} & \multirow{3}{*}{$6: 05$} & 16 & 1.486 & 156 \\
\hline & & & 50 & 1.382 & 226 \\
\hline & & & 86 & 1.367 & 252 \\
\hline \multirow{3}{*}{4} & \multirow{3}{*}{6} & \multirow{3}{*}{$7: 05$} & 18 & 1.498 & 151 \\
\hline & & & 51 & 1.376 & 233 \\
\hline & & & 86 & 1.376 & 231 \\
\hline \multirow{3}{*}{5} & \multirow{3}{*}{5} & \multirow{3}{*}{$3: 02$} & 17 & 1.504 & 151 \\
\hline & & & 51 & 1.387 & 220 \\
\hline & & & 86 & 1.358 & 278 \\
\hline \multirow{3}{*}{6} & \multirow{3}{*}{4} & \multirow{3}{*}{$8: 05$} & 20 & 1.509 & 163 \\
\hline & & & 52 & 1.368 & 275 \\
\hline & & & 87 & 1.362 & 290 \\
\hline \multirow{3}{*}{8} & \multirow{3}{*}{2} & \multirow{3}{*}{$9: 05$} & 22 & 1.52 & 159 \\
\hline & & & 52 & 1.381 & 247 \\
\hline & & & 86 & 1.36 & 294 \\
\hline \multirow{3}{*}{10} & \multirow{3}{*}{0} & \multirow{3}{*}{$2: 01$} & 18 & 1.53 & 152 \\
\hline & & & 51 & 1.376 & 248 \\
\hline & & & 86 & 1.356 & 298 \\
\hline
\end{tabular}


Table 3-13: The derived growth factor, $\kappa(\mathrm{RH})$ and WUP for the $\left(\mathrm{NH}_{4}\right)_{2} \mathrm{SO}_{4}-\left(\mathrm{NH}_{4}\right) \mathrm{HSO}_{4}$ mixtures

\begin{tabular}{|c|c|c|c|c|c|}
\hline \multicolumn{2}{|c|}{ Mass Mixing Ratio } & \multirow{2}{*}{$\begin{array}{c}\mathrm{NH}_{4}{ }^{+}: \mathrm{SO}_{4}{ }^{2+} \\
\text { ratio }\end{array}$} & \multirow{2}{*}{$\begin{array}{c}\text { gf } \\
(\text { Hu/De) }\end{array}$} & \multirow{2}{*}{$\kappa(\mathbf{R H})$} & \multirow{2}{*}{ WUP } \\
\hline$\left(\mathrm{NH}_{4}\right)_{2} \mathrm{SO}_{4}$ & $\mathrm{NH}_{4} \mathrm{HSO}_{4}$ & & & & \\
\hline 0 & 10 & $1: 01$ & 1.55 & 0.433 & 0.24 \\
\hline 2 & 8 & $6: 05$ & 1.609 & 0.52 & 0.266 \\
\hline 4 & 6 & $7: 05$ & 1.535 & 0.423 & 0.242 \\
\hline 5 & 5 & $3: 02$ & 1.842 & 0.885 & 0.35 \\
\hline 6 & 4 & $8: 05$ & 1.774 & 0.713 & 0.322 \\
\hline 8 & 2 & 9:05 & 1.851 & 0.866 & 0.357 \\
\hline 10 & 0 & $2: 01$ & 1.964 & 1.027 & 0.375 \\
\hline
\end{tabular}

The neat $\left(\mathrm{NH}_{4}\right)_{2} \mathrm{SO}_{4}$ and $\mathrm{NH}_{4} \mathrm{HSO}_{4}$ and the five $(2: 8,4: 6,5: 5,6: 4,8: 2)$ mixtures show reasonably steady increases in radius with increasing relative humidity (except the 4:6 mixture, which is being re-investigated). This is consistent with the hygroscopicity of the two salts. The growth factor is calculated using the particle size of the humidified flow divided by that for the dehumidified flow condition. Tang et al. 1996 and Hegg et al. 1993 found that $\mathrm{NH}_{4}{ }^{+}$salt aerosols have growth factor values close to 1.5. Most of the growth factor values from the $\mathrm{NH}_{4}{ }^{+}$system are close to this value. The growth factors in this system did not show a clear monotonic trend with the varied mixing ratio, but did essentially increase from $\mathrm{NH}_{4} \mathrm{HSO}_{4}$ to $\left(\mathrm{NH}_{4}\right)_{2} \mathrm{SO}_{4}$.

The literature values for $\kappa(\mathrm{RH})$ are listed in Table 3-14. The literature gf derived $\kappa$ $(\mathrm{RH}=90 \%)$ for the pure $\left(\mathrm{NH}_{4}\right)_{2} \mathrm{SO}_{4}$ and pure $\left(\mathrm{NH}_{4}\right) \mathrm{HSO}_{4}$ are $0.33-0.72$ and 0.556 respectively. The $\kappa(\mathrm{RH})$ derived from the HC-CRD measurements are 1.027 for the pure $\left(\mathrm{NH}_{4}\right)_{2} \mathrm{SO}_{4}$ and 0.433 for pure $\left(\mathrm{NH}_{4}\right) \mathrm{HSO}_{4}$ respectively. Our $\left(\mathrm{NH}_{4}\right) \mathrm{HSO}_{4} \kappa(\mathrm{RH})$ is lower 
than the literature value while the $\left(\mathrm{NH}_{4}\right)_{2} \mathrm{SO}_{4}$ is higher than the reported values. The $\kappa(\mathrm{RH})$ of the five mixtures also did not establish a clear monotonic trend with varied mixing ratio although the general trend was an increase: the 5:5, 6:4 and 8:2 $\left(\mathrm{NH}_{4}\right)_{2} \mathrm{SO}_{4}$ : $\mathrm{NH}_{4} \mathrm{HSO}_{4}$ mixture are higher than the pure $\left(\mathrm{NH}_{4}\right) \mathrm{HSO}_{4}$ and close to the pure $\left(\mathrm{NH}_{4}\right)_{2} \mathrm{SO}_{4}$. This is consistent with the observation in section 3.1.1 that the ionic ratio of $\mathrm{NH}_{4}{ }^{+}$vs. $\mathrm{SO}_{4}{ }^{2-}$ in the mixture could determine the hygroscopic behavior. Additionally, the reported $\kappa(\mathrm{RH})$ of letovicite $\left(\left(\mathrm{NH}_{4}\right)_{3} \mathrm{H}\left(\mathrm{SO}_{4}\right)_{2}\right)$ has an average value of 0.58 where the $\kappa(\mathrm{RH})$ of pure $\left(\mathrm{NH}_{4}\right) \mathrm{HSO}_{4}$ with "dry" particle size of $100 \mathrm{~nm}$ is 0.556 indicating that letovicite is more hygroscopic than ammoium bisulfate. It is possible that the 5:5, 6:4 and 8:2 $\left(\mathrm{NH}_{4}\right)_{2} \mathrm{SO}_{4}: \mathrm{NH}_{4} \mathrm{HSO}_{4}$ mixtures should have higher $\kappa(\mathrm{RH})$, closer to $\left(\mathrm{NH}_{4}\right)_{2} \mathrm{SO}_{4}$.

Table 3-14: $\kappa(\mathrm{RH})$ values obtained from this work and the literature

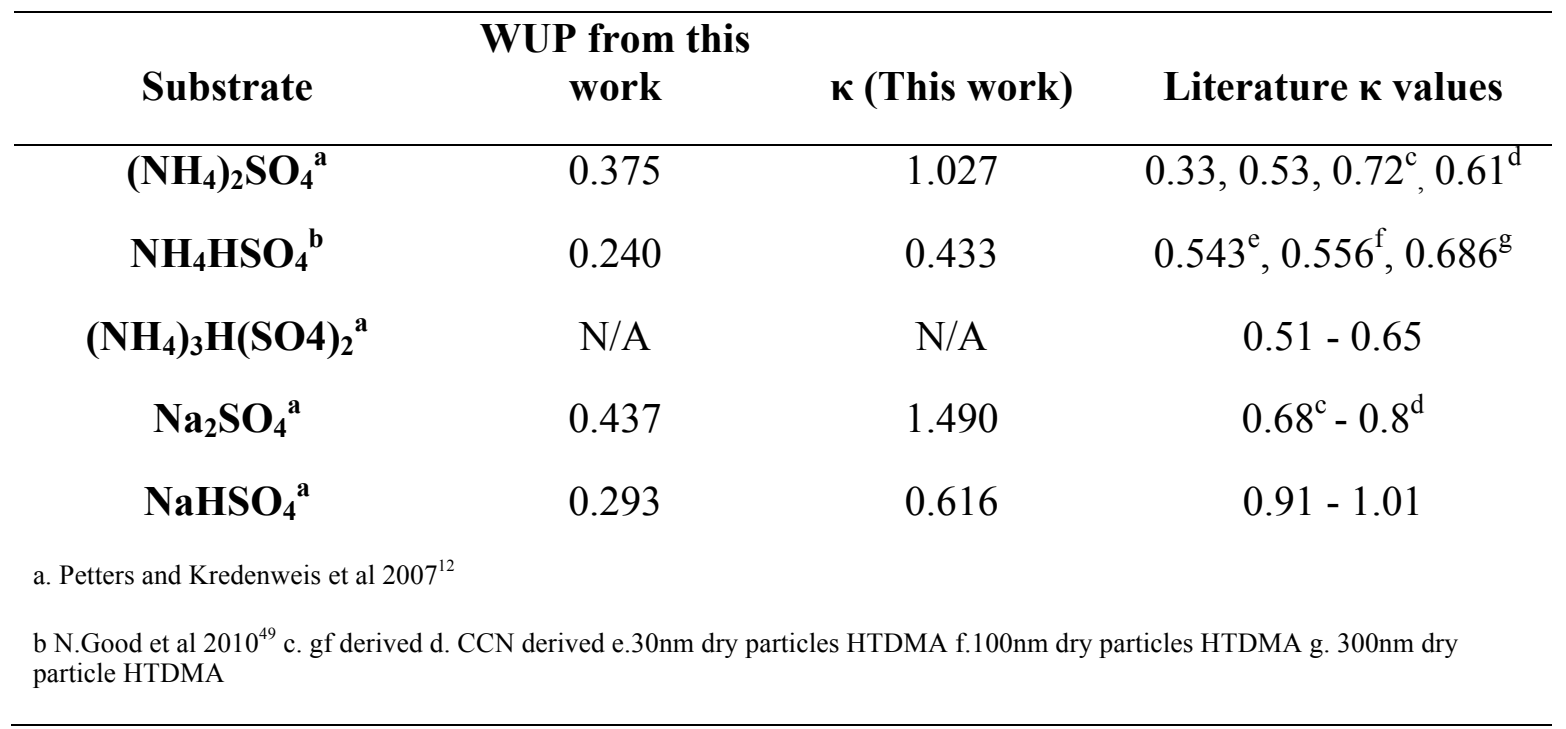

Table 3-14 includes the $\kappa(\mathrm{RH})$ values obtained from this work and the literature for the pure substrates in the inorganic systems considered. Half of the $\kappa(\mathrm{RH})$ values from this 
work are below the reported values, and the other half are above the reported values; but we note that most of the $\kappa(\mathrm{RH})$ values were obtained using HTDMA. This technique captures the growth of particles generated in very dry stage $(\sim 10 \% \mathrm{RH})$ and humidified up to $90 \% \mathrm{RH}$. In the HC-CRD, the relative humidity of aerosol particles after generation is about $\sim 40 \%$ and these particles can be either dehumidified to the dry form (if that happens) or humidified and grow into droplets with increased $\mathrm{RH}$ (up to $\sim 85 \%$ ). The $\kappa(\mathrm{RH}) \mathrm{s}$ determined in this work have different humidity history vs. the particles measured by HTDMA and this may account for the differences in values obtained for $g f$ and $\kappa(\mathrm{RH}) \mathrm{s}$ (i.e. humidity history dependence). We did introduce a new parameter WUP to describe hygroscopic growth as an alternative to $\kappa(\mathrm{RH})$, that uses a power law relationship to capture the change in $\mathrm{R}_{\text {eff, }}$ with $\mathrm{RH}$ in a log-log space. Calculated results for WUP are presented in this work, but there are no literature values to compare to, so the obtained values and utility of this parameter will need further investigation.

Table 3-15 and Table 3-16 list the refractive indices (RI) of the three RH channels with the corresponding calculated effective radius $\left(\mathrm{R}_{\mathrm{eff}}\right)$, the growth factors (gf) and $\kappa$ (kappa) values for the $\mathrm{Na}_{2} \mathrm{SO}_{4}-\mathrm{NaHSO}_{4}$ system. 
Table 3-15: The refractive index and effective radius at three different RH conditions, for the $\mathrm{Na}_{2} \mathrm{SO}_{4}-\mathrm{NaHSO}_{4}$ mixtures

\begin{tabular}{|c|c|c|c|c|}
\hline \multicolumn{2}{|c|}{ Mass Mixing Ratio } & \multirow{2}{*}{ RH(\%) } & \multirow{2}{*}{ RI } & \multirow{2}{*}{$\begin{array}{l}\text { Reff } \\
(\mathrm{nm})\end{array}$} \\
\hline $\mathrm{Na}_{2} \mathrm{SO}_{4}$ & $\mathrm{NaHSO}_{4}$ & & & \\
\hline \multirow{3}{*}{0} & \multirow{3}{*}{10} & 16 & 1.46 & 161 \\
\hline & & 52 & 1.361 & 260 \\
\hline & & 87 & 1.355 & 279 \\
\hline \multirow{3}{*}{2} & \multirow{3}{*}{8} & 23 & 1.464 & 145 \\
\hline & & 49 & 1.362 & 234 \\
\hline & & 86 & 1.349 & 276 \\
\hline \multirow{3}{*}{4} & \multirow{3}{*}{6} & 21 & 1.468 & 130 \\
\hline & & 50 & 1.381 & 181 \\
\hline & & 86 & 1.355 & 230 \\
\hline \multirow{3}{*}{5} & \multirow{3}{*}{5} & 18 & 1.471 & 152 \\
\hline & & 50 & 1.364 & 244 \\
\hline & & 85 & 1.357 & 263 \\
\hline \multirow{3}{*}{6} & \multirow{3}{*}{4} & 20 & 1.472 & 134 \\
\hline & & 50 & 1.356 & 234 \\
\hline & & 86 & 1.349 & 261 \\
\hline \multirow{3}{*}{8} & \multirow{3}{*}{2} & 19 & 1.476 & 124 \\
\hline & & 53 & 1.352 & 234 \\
\hline & & 87 & 1.356 & 221 \\
\hline \multirow{3}{*}{10} & \multirow{3}{*}{0} & 19 & 1.48 & 128 \\
\hline & & 50 & 1.364 & 210 \\
\hline & & 86 & 1.344 & 280 \\
\hline
\end{tabular}

Like the other mixed inorganic system, the particle size is a strong function of the relative humidity for the pure $\mathrm{Na}_{2} \mathrm{SO}_{4}$, pure $\mathrm{NaHSO}_{4}$, and five $(2: 8,4: 6,5: 5,6: 4,8: 2)$ $\mathrm{Na}_{2} \mathrm{SO}_{4}: \mathrm{NaHSO}_{4}$ mixtures. Literature values of the pure $\mathrm{Na}_{2} \mathrm{SO}_{4}$ and pure $\mathrm{NaHSO}_{4}$ suggest $\mathrm{NaHSO}_{4}$ is more hygroscopic than the pure $\mathrm{Na}_{2} \mathrm{SO}_{4}$. 
Table 3-16: The derived growth factor, $\kappa(\mathrm{RH})$ and WUP for the $\mathrm{Na}_{2} \mathrm{SO}_{4}-\mathrm{NaHSO}_{4}$ mixtures

\begin{tabular}{|c|c|c|c|c|}
\hline \multicolumn{2}{|c|}{$\begin{array}{c}\text { Mass Mixing } \\
\text { Ratio }\end{array}$} & \multirow{2}{*}{$\begin{array}{c}\text { gf } \\
(\text { Hu/De })\end{array}$} & \multirow{2}{*}{ к(RH) } & \multirow{2}{*}{ WUP } \\
\hline $\mathrm{Na}_{2} \mathrm{SO}_{4}$ & $\mathrm{NaHSO}_{4}$ & & & \\
\hline 0 & 10 & 1.73 & 0.616 & 0.293 \\
\hline 2 & 8 & 1.907 & 0.934 & 0.372 \\
\hline 4 & 6 & 1.768 & 0.723 & 0.326 \\
\hline 5 & 5 & 1.733 & 0.716 & 0.318 \\
\hline 6 & 4 & 1.955 & 1.023 & 0.379 \\
\hline 8 & 2 & 1.783 & 0.723 & 0.322 \\
\hline 10 & 0 & 2.188 & 1.49 & 0.437 \\
\hline
\end{tabular}

However comparing to the $\mathrm{NH}_{4}{ }^{+}$containing mixtures, the $\mathrm{Na}^{+}$system has larger gf values, consistent with previous findings from Tang et al.1996 that particles containing $\mathrm{Na}^{+}$ (except $\mathrm{NaCl}$ ) experienced more growth than particles containing $\mathrm{NH}_{4}{ }^{+}$at $80 \% \mathrm{RH}$. Again, there is no clear trend in gf values with mixing ratio. It is interesting to note that most of the mixtures in this system have greater increases in size within the lower $\mathrm{RH}$ branch except the pure $\mathrm{Na}_{2} \mathrm{SO}_{4}$, which implies the acidic nature of the mixture may affect the hygroscopic growth behavior. As for the $\kappa(\mathrm{RH})$ values, both the pure $\mathrm{Na}_{2} \mathrm{SO}_{4}$ and pure $\mathrm{NaHSO}_{4}$ are lower than the reported values in the literature (see Table 3-14).

The water uptake parameter exhibits a similar trend to that of $\kappa(\mathrm{RH})$. It is possible to use this parameter to capture the hysteresis growth behavior during the measurement, but it still needs further investigations. 
3.2.2 The effective refractive indices, $\mathrm{R}_{\text {eff, }}$ growth factors $(\mathrm{gf}), \mathrm{k}(\mathrm{RH})$ and WUP values of inorganic/organic mixtures

Tables 3-17 to 3-19 present the calculated refractive indices (RI) and the corresponding calculated effective radii ( $\mathrm{R}_{\mathrm{eff}}$ ) for the three $\mathrm{RH}$ conditions and the growth factors (gf), $\kappa(\mathrm{RH})$, and WUP values obtained from the three systems of inorganic-organic mixtures.

Table 3-17: The effective refractive index and effective radius at three different $\mathrm{RH}$ conditions, for the sucrose and $\mathrm{NaCl}$ mixtures

\begin{tabular}{|c|c|c|c|c|c|c|c|}
\hline \multicolumn{2}{|c|}{ Mixing } & \multirow{2}{*}{$\%$ RH } & \multirow{2}{*}{ RI } & \multirow{2}{*}{$\begin{array}{c}R_{\text {eff }} \\
(\mathbf{n m})\end{array}$} & \multirow{2}{*}{$\begin{array}{c}\text { gf } \\
(\text { Hu/De })\end{array}$} & \multirow{2}{*}{$\kappa(\mathbf{R H})$} & \multirow{2}{*}{ WUP } \\
\hline Sucrose & $\mathrm{NaCl}$ & & & & & & \\
\hline \multirow[t]{3}{*}{0} & 1 & 48 & 1.544 & 74 & 3.248 & 17.364 & 2.807 \\
\hline & & 54 & 1.344 & 183 & & & \\
\hline & & 66 & 1.336 & 239 & & & \\
\hline \multirow[t]{3}{*}{1} & 2 & 25 & 1.53 & 71 & 3.441 & 13.290 & 1.131 \\
\hline & & 50 & 1.355 & 143 & & & \\
\hline & & 75 & 1.335 & 245 & & & \\
\hline \multirow[t]{3}{*}{1} & 1 & 27 & 1.524 & 126 & 2.162 & 1.772 & 0.516 \\
\hline & & 54 & 1.38 & 198 & & & \\
\hline & & 84 & 1.349 & 272 & & & \\
\hline \multirow[t]{3}{*}{2} & 1 & 30 & 1.517 & 90 & 2.333 & 2.609 & 0.631 \\
\hline & & 58 & 1.389 & 133 & & & \\
\hline & & 82 & 1.345 & 211 & & & \\
\hline \multirow[t]{3}{*}{1} & 0 & 33 & 1.503 & 117 & 1.482 & 0.628 & 0.348 \\
\hline & & 49 & 1.463 & 127 & & & \\
\hline & & 78 & 1.383 & 173 & & & \\
\hline
\end{tabular}

Table 3-17 shows the effective refractive index, the effective radius $\mathrm{R}_{\text {eff }}(\mathrm{nm})$, the hygroscopic growth factors (gf), $\kappa(\mathrm{RH})$ and WUP for the $\mathrm{NaCl}$-sucrose mixtures. The pure $\mathrm{NaCl}$ exhibited the "hygroscopic with hysteresis" behavior: very little water uptake before deliquescence is observed at the ambient $\mathrm{RH}$ of $54 \%$ and a much higher 
magnitude increase in size as the $\mathrm{RH}$ increased to $66 \%$. The $\kappa(\mathrm{RH})$ obtained for the pure $\mathrm{NaCl}$ in this work is 2.8 , while Petters and Kreidenweis et al 2007 report 0.91-1.33 derived from H-TDMA measured growth factors at $90 \%$ relative humidity. Our value is higher than the reported values, but is likely to be in error, since the humidified $\mathrm{NaCl}$ aerosol particles produce so much scattering that we move outside of the linear dynamic range for the ring-down measurements.

The neat sucrose aerosols behave like most of organic species we have investigated; the growth in size is limited. Previous studies demonstrated that sucrose aerosols have continuous but limited water uptake with growth factors of 1.21 at $\mathrm{RH}=90 \%$ and a steeper increase as RH approaches $100 \%$. The growth factor obtained from this work is 1.48 at a relative humidity of $78 \%$, substantially greater than expected. The literature also suggests that there is a glass transition $\mathrm{RH}$ for sucrose aerosols ranging from $25 \%$ to $53 \%$ at room temperature. The particles have crystalline structures in their dry form; the dissolution of the crystal causes deliquescence, but the glassy particles have different ways of taking up and releasing water. Theoretically, water uptake by glassy particles should be the same as for the crystal; however, because the high viscosity of the glassy phase results in slow diffusion, particles only slowly take up or release water and equilibrium may not be reached. As the relative humidity increases, more water is taken up, resulting in a lower viscosity and faster diffusion which leads to a more rapid growth in the higher humidity region. The RH of the dehumidified and ambient channels fall into this glassy transition RH range for the pure sucrose resulting in smaller changes in particle size due to the kinetically limited growth. From the calculated $R_{\text {eff }}$ of the pure 
sucrose aerosol particles, the radii for dehumidified and ambient channels are $117 \mathrm{~nm}$ and $127 \mathrm{~nm}$ respectively. A $10 \mathrm{~nm}$ difference in size is measured indicating there is no significant growth during the low RH range, consistent with the glassy transition theory suggested by the literature.

The 2:1 NaCl: sucrose mixture shows a larger increase in size from relative humidity of $30 \%$ to $58 \%$. This range still mostly falls into the sucrose glassy transition RH range, so we expect little or no growth for pure sucrose. The $\mathrm{NaCl}$ in the mixture does take up water, consistent with the observed $42 \mathrm{~nm}$ growth. The 1:1 and 1:2 NaCl: sucrose mixtures grow more in size under the similar RH conditions. Robinson et al. 2013 found the growth factor monotonically decreases as the fraction of sucrose increased in ammonium sulfate (AS)-sucrose mixtures (i.e., AS: sucrose $=2: 1,1: 1$ and 1:2). In this work, the mixtures of $\mathrm{NaCl}$ and sucrose from 2:1 to 1:2 do show decreases from 3.441 to 2.333 , but the 1:1 mixture has a growth factor of 2.162 which is the lowest among the three mixtures. 
Table 3-18: The derived growth factor(gf), $\kappa(\mathrm{RH})$, and WUP for the glycine and $\mathrm{NaCl}$ mixtures

\begin{tabular}{|c|c|c|c|c|c|c|c|}
\hline \multicolumn{2}{|c|}{ Mixing } & \multirow{2}{*}{$\% \mathbf{R H}$} & \multirow{2}{*}{ RI } & \multirow{2}{*}{$\begin{array}{l}\text { Reff } \\
(\mathrm{nm})\end{array}$} & \multirow{2}{*}{$\begin{array}{c}\text { gf } \\
(\text { Hu/De) }\end{array}$} & \multirow{2}{*}{$\kappa(\mathbf{R H})$} & \multirow{2}{*}{ WUP } \\
\hline Glycine & $\mathrm{NaCl}$ & & & & & & \\
\hline \multirow[t]{3}{*}{0} & 1 & 48 & 1.544 & 74 & 3.248 & 17.364 & 2.807 \\
\hline & & 54 & 1.344 & 183 & & & \\
\hline & & 66 & 1.336 & 239 & & & \\
\hline \multirow[t]{3}{*}{1} & 2 & 37 & 1.516 & 75 & 2.608 & 4.790 & 0.920 \\
\hline & & 53 & 1.422 & 96 & & & \\
\hline & & 78 & 1.341 & 197 & & & \\
\hline \multirow[t]{3}{*}{1} & 1 & 34 & 1.502 & 83 & 2.517 & 3.857 & 0.786 \\
\hline & & 53 & 1.372 & 133 & & & \\
\hline & & 79 & 1.341 & 209 & & & \\
\hline \multirow[t]{3}{*}{2} & 1 & 34 & 1.488 & 101 & 2.086 & 2.201 & 0.654 \\
\hline & & 56 & 1.383 & 146 & & & \\
\hline & & 79 & 1.347 & 211 & & & \\
\hline \multirow[t]{3}{*}{1} & 0 & 30 & 1.46 & 132 & 1.423 & 0.422 & 0.263 \\
\hline & & 55 & 1.429 & 144 & & & \\
\hline & & 82 & 1.375 & 187 & & & \\
\hline
\end{tabular}

Table 3-18 shows the effective refractive index, the calculated effective radius $R_{\text {eff }}(n m)$, the hygroscopic growth factors (gf), $\kappa(\mathrm{RH})$ and WUP for a set of $\mathrm{NaCl} /$ glycine mixtures. The pure glycine does not experience as much growth as the $\mathrm{NaCl}$, as expected. The radius only increases $55 \mathrm{~nm}$ with a $40 \%$ relative humidity increase.

Unlike the hygroscopic compounds that could double in size at high relative humidity; the pure glycine only has a growth factor of 1.423. Garland et al. 2007 studied the hygroscopic growth of pure glycine using a cavity ring-down aerosol extinction spectrometer (CRD-AES) at 532nm, and the growth factor was found to be 1.30 at $\mathrm{RH}$ of 
$80 \%$ for a particle size range from $146 \mathrm{~nm}-627 \mathrm{~nm}$. Chan et al. 2005 obtained a growth factor of $1.25 .^{50,51}$ The growth factor of pure glycine obtained from this work is close to but higher that the literature values. The literature $\kappa$ value used in the Table $3-14$ is derived from the growth factor, so they are also higher than expected. Chan et al. 2005 reported growth factor values of 1.33 and 1.41 at $\mathrm{RH}$ of $85 \%$ and $90 \%$. The resulting $\kappa(85 \%)$ and $\kappa(90 \%)$ are 0.239 and 0.2 respectively using the equation described in the previous section. The $\kappa(\mathrm{RH})$ value of the glycine from this work is 0.422 .

All three mixtures of glycine: $\mathrm{NaCl}(2: 1,1: 1$ and 1:2) behave similarly in the low $\mathrm{RH}$ region; they experience little increase in size. In the higher RH region, the 2:1 mixture behaves similarly to pure glycine with limited size growth upon further humidification. Both the growth factor and the $\kappa(\mathrm{RH})$ value is higher than for pure glycine, consistent with the presence of $\mathrm{NaCl}$ in the mixture. The 1:2 and 1:1 mixtures behave similarly to neat $\mathrm{NaCl}$ aerosols with more growth in size at high relative humidity. Both the growth factors and $\kappa(\mathrm{RH}) \mathrm{s}$ increase as the fraction of $\mathrm{NaCl}$ increases in the mixtures, as the particles become more hygroscopic. The growth factors and $\kappa(\mathrm{RH})$ values from $\mathrm{NaCl} / \mathrm{glycine}$ system exhibit monotonic increases as the fraction of $\mathrm{NaCl}$ increases in the mixtures, the expected trend. 
Table 3-19: The effective refractive index and effective radius at three different $\mathrm{RH}$ conditions, and the derived growth factor(gf), $\kappa(\mathrm{RH})$, and WUP for the glucose and $\mathrm{NaCl}$ mixtures

\begin{tabular}{|c|c|c|c|c|c|c|c|}
\hline \multicolumn{2}{|c|}{ Mixing } & \multirow{2}{*}{$\%$ RH } & \multirow{2}{*}{ RI } & \multirow{2}{*}{$\begin{array}{c}R_{\text {eff }} \\
(n m)\end{array}$} & \multirow{2}{*}{$\begin{array}{c}\text { gf } \\
\text { (Hu/De) }\end{array}$} & \multirow{2}{*}{ к(RH) } & \multirow{2}{*}{ WUP } \\
\hline Glucose & $\mathrm{NaCl}$ & & & & & & \\
\hline \multirow[t]{3}{*}{0} & 1 & 48 & 1.544 & 74 & 3.248 & 17.364 & 2.807 \\
\hline & & 54 & 1.344 & 183 & & & \\
\hline & & 66 & 1.336 & 239 & & & \\
\hline \multirow[t]{3}{*}{1} & 2 & 32 & 1.554 & 91 & 2.518 & 3.788 & 0.759 \\
\hline & & 52 & 1.394 & 135 & & & \\
\hline & & 80 & 1.344 & 228 & & & \\
\hline \multirow[t]{3}{*}{1} & 1 & 28 & 1.559 & 56 & 2.747 & 11.683 & 1.518 \\
\hline & & 52 & 1.346 & 137 & & & \\
\hline & & 63 & 1.341 & 155 & & & \\
\hline \multirow[t]{3}{*}{2} & 1 & 31 & 1.563 & 104 & 1.881 & 1.854 & 0.615 \\
\hline & & 55 & 1.443 & 132 & & & \\
\hline & & 75 & 1.365 & 195 & & & \\
\hline \multirow[t]{3}{*}{1} & 0 & 31 & 1.573 & 77 & 3.347 & 11.348 & 1.133 \\
\hline & & 53 & 1.345 & 196 & & & \\
\hline & & 76 & 1.336 & 258 & & & \\
\hline
\end{tabular}

Table 3-19 presents the effective refractive index, the calculated effective radius $\left(\mathrm{R}_{\mathrm{eff}} \mathrm{nm}\right)$, the hygroscopic growth factors (Gf), $\kappa(\mathrm{RH})$ and WUP values for a set of $\mathrm{NaCl} / \mathrm{D}$-glucose mixtures. Glucose aerosols have previously reported growth factor values of $1.2-1.25$ at 80\% RH using a bulk method. Both Mochida and Kawamura, et al. 2004 and Peng, et al. $2001 \mathrm{~b}$ conducted bulk measurements and found the DRH of D-glucose is $89.1-90 \%{ }^{52,53}$ This indicates that pure glucose should exhibit some growth under the high relative humidity condition. From the dehumidified condition to ambient, the growth is limited as the radius increases less than $15 \mathrm{~nm}$. As the relative humidity increases our results indicate a substantial growth occurred before the reported DRH. One caveat about the 
literature values is that the measurements were made using the bulk method. The physiochemical properties of the substance may change from the bulk phase to the particle phase. Thus it is suspected that the pure glucose in the particle phase has a higher water affinity than the bulk phase, but this would need further investigation.

The 2:1 D-glucose: $\mathrm{NaCl}$ mixture behaves similarly to the other 2:1 organic-inorganic mixtures, especially under the lower RH condition. The calculated size difference between dehumidified and ambient channel is small (less than $30 \mathrm{~nm}$ ). Therefore, the 2:1 D-glucose: $\mathrm{NaCl}$ mixture has similar gf and $\kappa(\mathrm{RH})$ as other $2: 1$ organic $/ \mathrm{NaCl}$ mixtures in this work. The 1:2 and 1:1 D-glucose: $\mathrm{NaCl}$ mixture behaves very differently than the 2:1 mixture, but similar to each other. It seems that this organic seriously inhibits the hygroscopic growth of $\mathrm{NaCl}$. Because we suspect that the amount of scattering produced by $\mathrm{NaCl}$ may be above the HC-CRD limit of quantitation; it is necessary to revisit these mixtures with a new inorganic surrogate. 
Table 3-20: The effective refractive index and effective radius at three different $\mathrm{RH}$ conditions, and the derived growth factor(gf), $\kappa(\mathrm{RH})$, and WUP for malonic acid *(MA) and ammonium sulfate (AS) mixtures

\begin{tabular}{|c|c|c|c|c|c|c|c|}
\hline \multicolumn{2}{|c|}{$\begin{array}{c}\text { Mass Mixing } \\
\text { Ratio }\end{array}$} & \multirow[t]{2}{*}{$\%$ RH } & \multirow[t]{2}{*}{$\mathbf{R I}$} & \multirow[t]{2}{*}{$\begin{array}{l}\text { Reff } \\
(\mathbf{n m})\end{array}$} & \multirow[t]{2}{*}{$\begin{array}{c}\text { gf } \\
(\text { Hu/De })\end{array}$} & \multirow[t]{2}{*}{$\kappa(\mathbf{R H})$} & \multirow[t]{2}{*}{ WUP } \\
\hline MA & $\mathbf{A S}$ & & & & & & \\
\hline \multirow{3}{*}{0} & \multirow{3}{*}{4} & 18 & 1.480 & 152 & 1.961 & 1.064 & 0.407 \\
\hline & & 51 & 1.480 & 248 & & & \\
\hline & & 86 & 1.330 & 298 & & & \\
\hline \multirow{3}{*}{1} & \multirow{3}{*}{3} & 29 & 1.480 & 236 & 1.053 & 0.074 & 0.459 \\
\hline & & 35 & 1.480 & 244 & & & \\
\hline & & 69 & 1.401 & 249 & & & \\
\hline \multirow{3}{*}{1} & \multirow{3}{*}{1} & 27 & 1.480 & 241 & 1.166 & 0.210 & 0.422 \\
\hline & & 36 & 1.480 & 247 & & & \\
\hline & & 74 & 1.388 & 281 & & & \\
\hline \multirow{3}{*}{3} & \multirow{3}{*}{1} & 29 & 1.480 & 202 & 1.005 & 0.006 & 0.442 \\
\hline & & 37 & 1.480 & 198 & & & \\
\hline & & 69 & 1.408 & 203 & & & \\
\hline \multirow{3}{*}{4} & \multirow{3}{*}{0} & 29 & 1.480 & 235 & 1.006 & 0.007 & 0.384 \\
\hline & & 36 & 1.480 & 173 & & & \\
\hline & & 73 & 1.330 & 236 & & & \\
\hline
\end{tabular}

Table 3-20 presents the effective refractive index, the calculated effective radius $\left(\mathrm{R}_{\mathrm{eff}} \mathrm{nm}\right)$, the hygroscopic growth factors (Gf), $\kappa(\mathrm{RH})$ and WUP values for malonic acid *(MA) and ammonium sulfate (AS) mixtures system. The physical growth factor also established a similar trend to the other mixtures in this section: the growth in particle size decreases with the addition of malonic acid in the mixture. However, the equal mass ratio (MA: AS $=1: 1)$ aerosols display a gf value of 1.374 that is higher than the gf of 1.348 from the MA:AS=1:3 mixture. C.F. Braban et al. also observed that the ammonium sulfate displayed neither deliquescence nor crystallization at the 1:1 mixing ratio with malonic 99 
acid. It is suspected that the larger growth in size is due to the adsorption of malonic acid and ammonium sulfate without substantial water uptake. The growth factor derived kappa values decrease linearly with the increasing malonic acid portion; the kappa values of mixtures group (MA:AS=1:3,1:1 and 3:1) were 0.689,0.572 and 0.412. The literature reported gf derived kappa value of MA and AS were 0.53 and 0.44 respectively; the mixtures kappa values obtained from this experiment were relatively close to literature values.

Table 3-21 presents the effective refractive index, the calculated effective radius $\left(\mathrm{R}_{\mathrm{eff}} \mathrm{nm}\right)$, the hygroscopic growth factors (Gf), $\kappa(\mathrm{RH})$ and WUP values for adipic acid *(AA) and ammonium sulfate (AS) mixtures. Joutsensaari, Vaattovaara, Vesterinen, Hämeri,\& Laaksonen, 2001 and Sjogren et al., 2007 report that the pure adipic acid does not exhibit water uptake below 96\% RH and both HTDMA and EDB studies support the statement. The higher gfs for the AA:AS 1:1 and 3:1 mixtures compared to the 1:3 mixture may be due to the presence of the "inverse Kelvin effect." Sjogren et al., 2007 acquired SEM images of particles with $\mathrm{AA}: \mathrm{AS}=3: 1$ and found that the mixture consisted of a conglomerate of nanocrystals with irregular shapes filled with 20-100 nm cracks, pores and veins under dehumidified condition. Upon approaching the DRH of ammonium sulfate, it is believed that the aqueous ammonium sulfate is present in these veins and pores. Water diffusing to the open veins can be more easily absorbed to the concave wall in the vein or pore than to a flat surface. The enhancement largely depends on the inner diameter of the veins - i.e., the concavity of the liquid surface at the vein opening, which results in a Kelvin effect that is the inverse of that experienced at the surface of a convex 
liquid droplet. Kärcher\& Lohmann,2003; Weingartner, Burtscher, Baltenspergen,1997 \& Sjogren et al., 2007

Table 3-21: The effective refractive index and effective radius at three different $\mathrm{RH}$ conditions, and the derived growth factor(gf), $\kappa(\mathrm{RH})$, and WUP for adipic acid *(AA) and ammonium sulfate (AS) mixtures.

\begin{tabular}{|c|c|c|c|c|c|c|c|}
\hline \multicolumn{2}{|c|}{$\begin{array}{c}\text { Mass Mixing } \\
\text { Ratio }\end{array}$} & \multirow[t]{2}{*}{$\%$ RH } & \multirow[t]{2}{*}{ RI } & \multirow[t]{2}{*}{$\begin{array}{l}\text { Reff } \\
(\mathrm{nm})\end{array}$} & \multirow[t]{2}{*}{$\begin{array}{c}\text { gf } \\
(\text { Hu/De })\end{array}$} & \multirow[t]{2}{*}{$\kappa(\mathbf{R H})$} & \multirow[t]{2}{*}{ WUP } \\
\hline $\mathbf{A A}$ & AS & & & & & & \\
\hline \multirow{3}{*}{0} & \multirow{3}{*}{4} & 18.0 & 1.480 & 152 & 1.961 & 1.064 & 0.407 \\
\hline & & 51.0 & 1.480 & 248 & & & \\
\hline & & 86.0 & 1.330 & 298 & & & \\
\hline \multirow{3}{*}{1} & \multirow{3}{*}{3} & 23.8 & 1.470 & 185 & 1.01 & 0.037 & 0.822 \\
\hline & & 30.7 & 1.470 & 179 & & & \\
\hline & & 46.3 & 1.467 & 187 & & & \\
\hline \multirow{3}{*}{1} & \multirow{3}{*}{1} & 19.1 & 1.460 & 223 & 1.19 & 0.323 & 0.471 \\
\hline & & 32.0 & 1.460 & 215 & & & \\
\hline & & 67.9 & 1.407 & 265 & & & \\
\hline \multirow{3}{*}{3} & \multirow{3}{*}{1} & 28.8 & 1.480 & 243 & 1.04 & 0.045 & 0.380 \\
\hline & & 39.5 & 1.480 & 230 & & & \\
\hline & & 73.7 & 1.437 & 252 & & & \\
\hline \multirow{3}{*}{4} & \multirow{3}{*}{0} & 19.7 & 1.439 & 256 & 1.123 & 0.203 & 0.461 \\
\hline & & 32.4 & 1.439 & 252 & & & \\
\hline & & 67.2 & 1.407 & 288 & & & \\
\hline
\end{tabular}



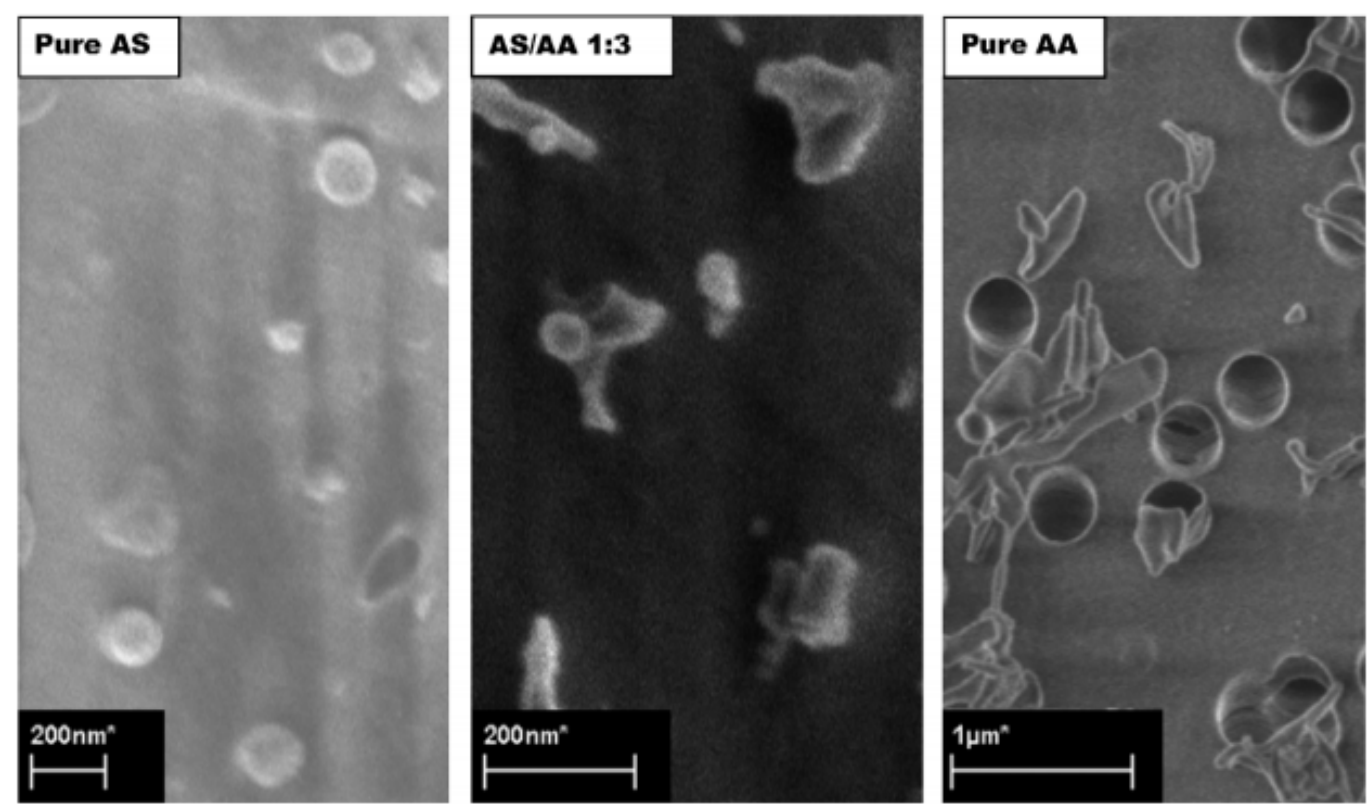

Figure 3-5:SEM images of spherical pure ammonium sulfate partiles, irregular particle of $\mathrm{AA}: \mathrm{AS}=3: 1$ mixture and pure adipic acid. The dark spherical features in the pure AA frame are the holes of the Nuclepore filter and not deposited particles. (Sjogren et al., 2007) 


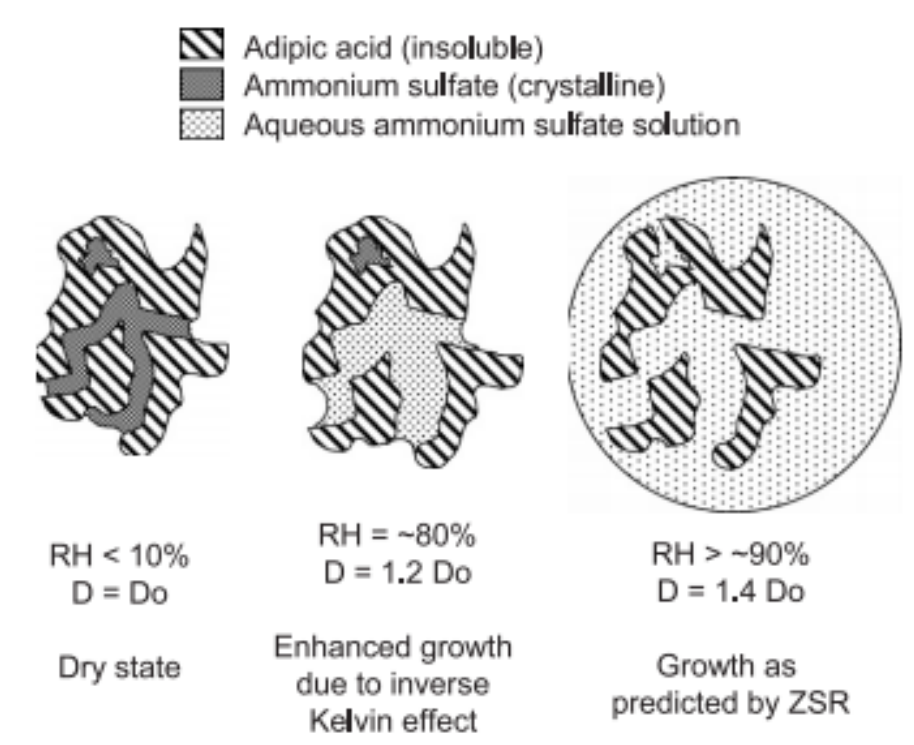

Figure 3-6: Schematic drawing of the process resulting in an inverse Kelvin effect. (Sjogren et al., 2007)

Table 3-22 presents the effective refractive index, the calculated effective radius $\left(\mathrm{R}_{\mathrm{eff}} \mathrm{nm}\right)$, the hygroscopic growth factors (Gf), $\kappa(\mathrm{RH})$ and WUP values for azelaic acid *(AzA) and ammonium sulfate (AS) mixtures. Both gf and $\kappa(\mathrm{RH})$ for the azelaic acid mixtures exhibit a clear trend where both decrease with the increasing ratio of the azelaic acid in the mixtures. At $293 \mathrm{~K}$, ammonium sulfate has an aqueous solubility of $43 \mathrm{~g}$ per $100 \mathrm{~g}$ of solution; in contrast, azelaic acid is sparingly soluble $0.24 \mathrm{~g}$ per $100 \mathrm{~g}$ aqueous solubility. We thus expect little or no hygroscopic growth for the azelaic acid aerosols. Upon addition of the ammonium sulfate, the mixture only experiences a slight increase in size growth. 
Table 3-22: The effective refractive index and effective radius at three different $\mathrm{RH}$ conditions, and the derived growth factor $(\mathrm{gf}), \kappa(\mathrm{RH})$, and WUP for azelaic acid *(AzA) and ammonium sulfate (AS) mixtures system

\begin{tabular}{|c|c|c|c|c|c|c|c|}
\hline \multicolumn{2}{|c|}{$\begin{array}{c}\text { Mass Mixing } \\
\text { Ratio }\end{array}$} & \multirow[t]{2}{*}{$\%$ RH } & \multirow[t]{2}{*}{ RI } & \multirow[t]{2}{*}{$\begin{array}{l}\text { Reff } \\
(\mathrm{nm})\end{array}$} & \multirow[t]{2}{*}{$\begin{array}{c}\text { gf } \\
\text { (Hu/De) }\end{array}$} & \multirow[t]{2}{*}{$\kappa(\mathrm{RH})$} & \multirow[t]{2}{*}{ WUP } \\
\hline $\mathbf{A z A}$ & $\mathbf{A S}$ & & & & & & \\
\hline \multirow{4}{*}{0} & \multirow{3}{*}{4} & 18 & 1.480 & 152 & 1.961 & 1.064 & 0.407 \\
\hline & & 51 & 1.480 & 248 & & & \\
\hline & & 86 & 1.330 & 298 & & & \\
\hline & \multirow{3}{*}{3} & 25.1 & 1.467 & 195.2 & 1.351 & 0.525 & 0.473 \\
\hline \multirow[t]{3}{*}{1} & & 37.6 & 1.467 & 200 & & & \\
\hline & & 73.7 & 1.385 & 263.8 & & & \\
\hline & & 22.4 & 1.454 & 210.5 & 1.051 & 0.057 & 0.346 \\
\hline \multirow[t]{3}{*}{1} & 1 & 37.2 & 1.454 & 204.4 & & & \\
\hline & & 73.9 & 1.438 & 221.2 & & & \\
\hline & & 26.3 & 1.441 & 229 & 1.05 & 0.055 & 0.367 \\
\hline \multirow[t]{3}{*}{3} & 1 & 37.6 & 1.441 & 224 & & & \\
\hline & & 73.9 & 1.426 & 240.4 & & & \\
\hline & & 18.6 & 1.428 & 249.7 & 1.002 & 0.002 & 0.306 \\
\hline \multirow[t]{2}{*}{4} & 0 & 36.4 & 1.428 & 248.3 & & & \\
\hline & & 74 & 1.428 & 250.2 & & & \\
\hline
\end{tabular}


Table 3-23: summarizes the $\kappa(\mathrm{RH})$ values for single substrates obtained from this work and compares them to literature values.

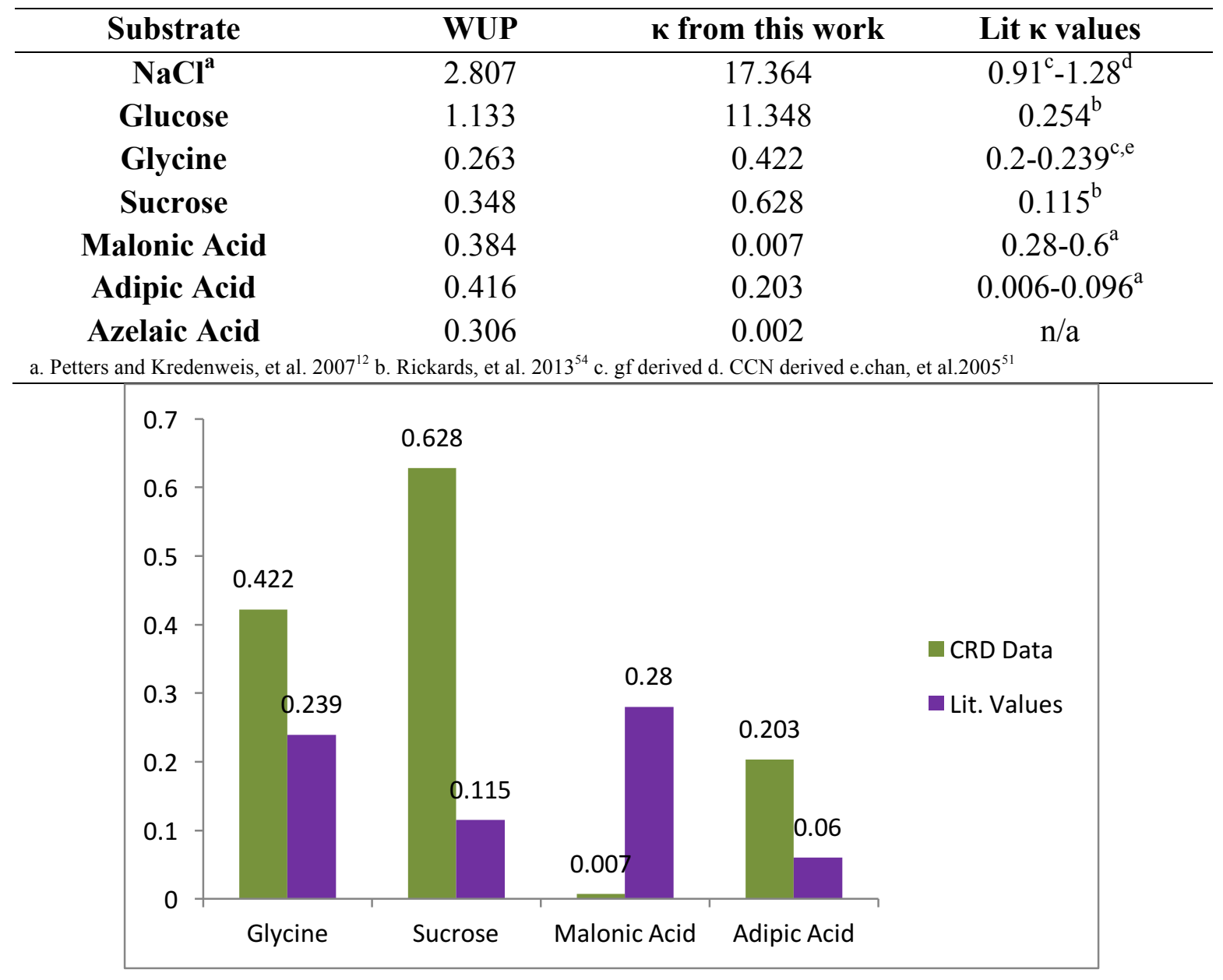

Figure 3-7 Some comparison between literature $\kappa(\mathrm{RH})$ values of the organic surrogates and the $\kappa(\mathrm{RH})$ values obtained from HC-CRD measurement

Table 3-23 summarizes the WUP and $\kappa(\mathrm{RH})$ values for single substrates obtained from this work and with respect to the available literature values. Figure 3-7 demonstrate the organic surrogate compounds such as sucrose, glycine and the series of dicarboxylic acids show reasonable agreement with the reported values, while $\mathrm{NaCl}$ and $\mathrm{D}$-glucose are well above the reported values. It is believed that the capacity of HC-CRD measurement cannot well capture the growth of highly hygroscopic spices. However, it is proved that 
the HC-CRD is capable of measuring the growth of the mixture of slightly hygroscopic species and hydrophobic species which is the chemical composition of the atmospheric aerosols. Therefore, HC-CRD is suitable instrument for the field study.

As discussed in the Methods section, there are many methods to obtain $\kappa(\mathrm{RH})$ including HTDMA, CCN counter and bulk methods like EDB. The range of $\kappa(\mathrm{RH})$ can vary slightly based on the instrumentation used. Some hygroscopic species have humidification history dependence (i.e., the volume fraction of the particle before the humidity modification), which also produces some variations in $\kappa(\mathrm{RH})$ values. Thirdly, the physico-chemical properties of aerosol particles have size dependence, the measurements that were conducted in the bulk phase may not well represent the behavior of the particle phase; therefore the deviation between bulk method and HC-CRD can be expected.

The water uptake parameter (WUP) is a new parameter we are exploring to capture the growth of particles while considering the particle's humidification history. The water uptake parameter has similar behavior across the mixtures as $\kappa(\mathrm{RH})$. The ultimate goal is that the parameters will better describe the hygroscopic behavior without large variation. 


\section{Conclusions and Future Direction}

The HC-CRD has been shown to have the capability of measuring aerosol particle's RH dependent extinction coefficients at three different wavelengths. As expected the growth of the particles caused by water uptake results in larger extinction at higher RH for nearly all of the aerosols investigated. The SDA-FMC procedure has also been shown to be capable of estimating the fine mode particle size. The challenge of using the SDA-FMC procedure is the assignment of proper effective refractive index for each of the humidity conditions, since composition changes with water uptake. For the laboratory measurements in the work, we were able to properly determine the effective refractive indices for each $\mathrm{RH}$ based on the chemical composition of the substrates. The calculated effective radius and the derived hygroscopic parameters for the inorganic systems need to further investigated because the large extinctions produced during the humidification process made some measurements questionable.

The HC-CRD and particle generation and conditioning system were optimized for the measurement of atmospherically relevant laboratory-generated aerosols. RH dependent extinction coefficients of hygroscopic species were measured and the $\mathrm{f}(\mathrm{RH})$ values and pairs of $\gamma(\mathrm{RH})$ values were able to capture the "hygroscopic growth with hysteresis" type behavior expected for inorganic mixture systems. The $\mathrm{f}(\mathrm{RH})$ values in the organicinorganic mixture system is found to be a function of the composition. The pairs of $\gamma(\mathrm{RH})$ values are able to capture some of the weaker hygroscopic growth with hysteresis in some of the organic mixtures near the inorganic limit. 
The $\mathrm{R}_{\text {eff, }} \mathrm{gf}$, and $\kappa(\mathrm{RH})$ values obtained from the SDA-FMC treatment of the organic mixture systems obtained some level of agreement with literature values. Ammonium sulfate (AS) was found to be a useful inorganic surrogate particle substrate that does not produce untenably large extinction at high relative humidity. The measurements using ammonium sulfate as the inorganic constituent for the dicarboxylic acid mixtures demonstrated that the optimized HC-CRD might be capable of analyzing the chemical composition (ratio of inorganic aerosol vs. organic aerosol) in the atmosphere. This important issue will obviously require more investigation and validation. Eventually this method could be used as a rapid diagnostic method for determining composition in atmospheric aerosol measurements.

We also posit that the instrument could be used in urban pollution aerosol testing. Beginning in 2015, pair of Google Street View cars, equipped with high-tech "mobile labs" developed by San Francisco-based startup Aclima was tested on the streets of West Oakland, CA taking second-by-second samples of the area's air. Species analyzed included nitrogen dioxide, black carbon, and nitric oxide, all produced by automobiles. The cars can be driven on every stretch of pavement, from tiny cul-de-sacs to truckchoked Peralta Street, multiple times per day, taking a large number of measurements. 


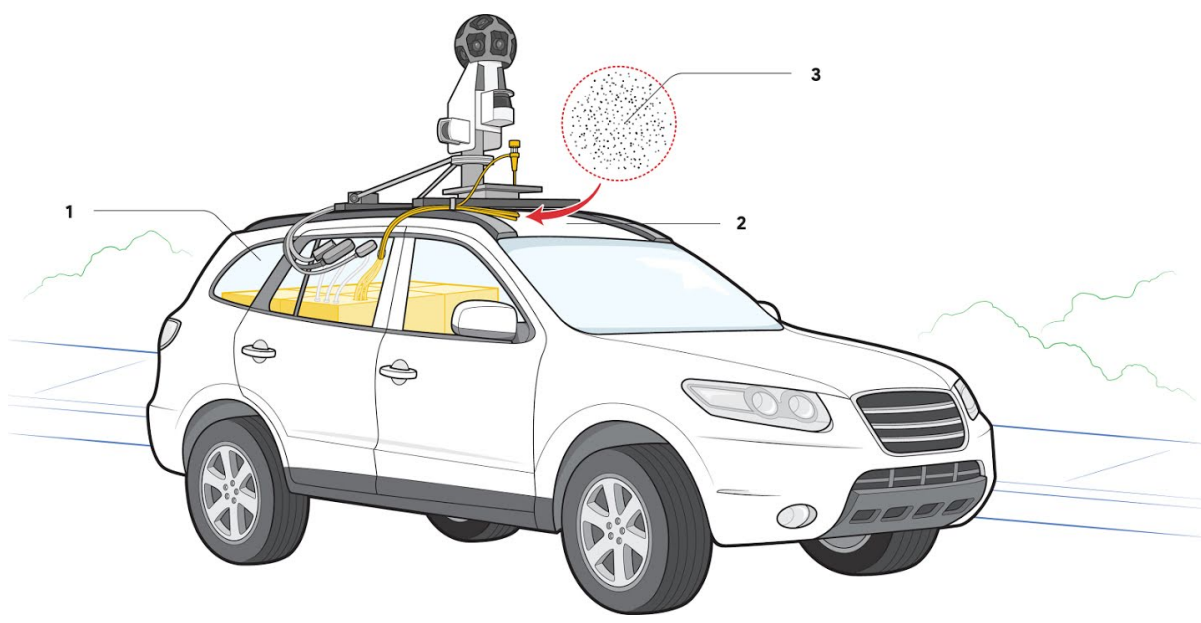

Figure 4-1: Anatomy of a mobile air pollution detection lab (photo credit: https://www.google.com/intl/en/about/stories/future-of-anti-pollutiontech/index.html)

There are only three stationary air pollution monitors for all of Oakland, CA that are supposed to reveal the city's air quality as a whole. But the Street View cars are able to measure air quality on spatial scales down to a single block for a truly hi-resolution view of the problem. This could result in one of the largest and most granular data sets of urban air pollution assembled in the world.

Aclima's mobile platform shown in the Figure 5-1 was built onto Google's existing Street View cars and was able to use their elaborate GPS tracking and 360-degree cameras. Air was sampled through an inlet on top of the car and pumped into a pollutionmonitoring system in the back, where black carbon, nitric oxide, and nitrogen dioxide were measured by sensors. Spatially encoded data on pollution concentrations were stored on the Google Cloud Platform and made available via Google Maps and Google Earth. 
The HC-CRD instrument was designed to be field deployable. It is relatively compact and is able to fit into the mobile platform. The air flow system can be adapted into the mobile measurements. With the exponentially increasing technological advances, intelligent systems will be able to accurately forecast air pollution in real time based on a multitude of factors, from traffic patterns to that day's weather to pollution-emitting businesses. On a personal scale, individuals may be able to use an app on their smartphone to see whether they are likely to be affected by the air quality on their way to work or the grocery store and adjust their travel plans or patterns. For cities, the hyperlocal maps will be served and used in decision/policy making such as the city planning and transportation design. The ultimate goal is to use the science and technology to understand how to better protect public health and well-being. 


\section{References}

(1) Abo Riziq, A.; Erlick, C.; Dinar, E.; Rudich, Y. Atmos. Chem. Phys. 2007, 7, 15231536.

(2) Abo Riziq, A.; Erlick, C.; Dinar, E.; Rudich, Y. Atmos. Chem. Phys. 2007, 7, 15231536.

(3) Atkinson, D. B.; Massoli, P.; O’Neill, N. T.; Quinn, P. K.; Brooks, S. D.; Lefer, B. Atmos. Chem. Phys. 2010, 10, 51-61.

(4) Atkinson, D. B. Analyst 2003, 128, 117-125.

(5) Berden, G.; Peeters, R.; Meijer, G. Int. Rev. Phys. Chem. 2000, 19, 565-607.

(6) Born, M.; Wolf, E. Principles of Optics: Electromagnetic Theory of Propagation, Interference and Diffraction of Light; 1999

(7) Carrico, C. M.; Petters, M. D.; Kreidenweis, S. M.; Collett, J. L.; Engling, G.; Malm, W. C. J. Geophys. Res. 2008, 113, D08206.

(8) Chan, M. N.; Choi, M. Y.; Ng, N. L.; Chan, C. K. Environ. Sci. Technol. 2005, 39, 1555-1562.

(9) Eck, T. F.; Holben, B. N.; Reid, J. S.; Dubovik, O.; Smirnov, A.; O’Neill, N. T.; Slutsker, I.; Kinne, S. J. Geophys. Res. 1999, 104, 31333.

(10) Fifth Assessment Report - Climate Change 2013 http://www.ipcc.ch/report/ar5/wg1/ (accessed May 24, 2014).

(11) Fierz-Schmidhauser, R.; Zieger, P.; Wehrle, G.; Jefferson, A.; Ogren, J. A.; Baltensperger, U.; Weingartner, E. Atmos. Meas. Tech. 2010, 3, 39-50.

(12) Fuzzi, S.; Andreae, M. O.; Huebert, B. J.; Kulmala, M.; Bond, T. C.; Boy, M.; Doherty, S. J.; Guenther, A.; Kanakidou, M.; Kawamura, K.; Kerminen, V.-M.; Lohmann, U.; Russell, L. M.; Pöschl, U. Atmos. Chem. Phys. 2006, 6, 2017-2038.

(13)Garland, R. M.; Ravishankara, A. R.; Lovejoy, E. R.; Tolbert, M. A.; Baynard, T. J. Geophys. Res. 2007, 112, D19303.

(14) Gobbi, G. P.; Kaufman, Y. J.; Koren, I.; Eck, T. F. Atmos. Chem. Phys. 2007, 7, 453-458.

(15) Hänel, G. Adv. Geophys. 1976, 19.

(16) Hansen, J. E.; Travis, L. D. Space Sci. Rev. 1974, 16, 527-610.

(17) Hegg, D.; Larson, T.; Yuen, P.-F. J. Geophys. Res. 1993, 98, 18435. 
(18) Hewitt, C. N.; Jackson, A. V. Atmospheric Science for Environmental Scientists; John Wiley \& Sons, 2009.

(19) Kohler, H. Trans. Faraday Soc. 1936, 32, 1152-1161.

(20) Kotchenruther, R. A.; Hobbs, P. V.; Hegg, D. A. J. Geophys. Res. 1999, 104, 2239.

(21) Mahowald, N.; Ward, D. S.; Kloster, S.; Flanner, M. G.; Heald, C. L.; Heavens, N. G.; Hess, P. G.; Lamarque, J.-F.; Chuang, P. Y. Annu. Rev. Environ. Resour. 2011, 36, $45-74$.

(22) McInnes, L.; Bergin, M.; Ogren, J.; Schwartz, S. Geophys. Res. Lett. 1998, 25, $513-$ 516.

(23) Menon, S. Annu. Rev. Environ. Resour. 2004.

(24) Mie, G. Ann. Phys. 1908, 330, 377-445.

(25) O’Neill, N. T.; Dubovik, O.; Eck, T. F. Appl. Opt. 2001, 40, 2368.

(26) O’Neill, N. T.; Eck, T. F.; Holben, B. N.; Smirnov, A.; Dubovik, O.; Royer, A. J. Geophys. Res. Atmos. 2001, 106, 9787-9806.

(27) O’Neill, N. T. J. Geophys. Res. 2003, 108, 4559.

(28) O’Neill, N. T. J. Geophys. Res. 2005, 110, D11207.

(29) Peng, C.; Chow, A. H. L.; Chan, C. K. Aerosol Sci. Technol. 2001, 35, 753-758.

(30) Petters, M. D.; Kreidenweis, S. M. Atmos. Chem. Phys. 2007, 7, 1961-1971.

(14) PM NAAQS | US EPA.

(31) Pöschl, U. Angew. Chem. Int. Ed. Engl. 2005, 44, 7520-7540.

(32) Quaas, J.; Ming, Y.; Menon, S.; Takemura, T.; Wang, M.; Penner, J. E.; Gettelman, A.; Lohmann, U.; Bellouin, N.; Boucher, O.; Sayer, A. M.; Thomas, G. E.; McComiskey, A.; Feingold, G.; Hoose, C.; Kristjánsson, J. E.; Liu, X.; Balkanski, Y.; Donner, L. J.; Ginoux, P. A.; Stier, P.; Grandey, B.; Feichter, J.; Sednev, I.; Bauer, S. E.; Koch, D.; Grainger, R. G.; Kirkevåg, A.; Iversen, T.; Seland, Ø.; Easter, R.; Ghan, S. J.; Rasch, P. J.; Morrison, H.; Lamarque, J.-F.; Iacono, M. J.; Kinne, S.; Schulz, M. Atmos. Chem. Phys. 2009, 9, 8697-8717.

(33) Rickards, A. M. J.; Miles, R. E. H.; Davies, J. F.; Marshall, F. H.; Reid, J. P. J. Phys. Chem. A 2013, 117, 14120-14131.

(34) Santarpia, J. L. J. Geophys. Res. 2005, 110, D03206. 
(35) Schuster, G. L.; Dubovik, O.; Holben, B. N. J. Geophys. Res. 2006, 111, D07207.

(36) Stelson, A. W. Environ. Sci. Technol. 1990, 24, 1676-1679.

(38) Tang, I. N.; Munkelwitz, H. R. Atmos. Environ. Part A. Gen. Top. 1993, 27, 467473.

(39) Tang, I. N. J. Geophys. Res. 1996, 101, 19245.

(40) Twomey, S. Atmos. Environ. 1974, 8, 1251-1256.

(41) US EPA, OAR, O. of A. Q. P. and S. Six Common Air Pollutants | Air \& Radiation | US EPA.

(42) Van de Hulst, H. C. Light scattering by small particles; John Wiley and Sons: New York, 1957.

(42) Zieger, P.; Fierz-Schmidhauser, R.; Weingartner, E.; Baltensperger, U. Atmos. Chem. Phys. 2013, 13, 10609-10631.

(43) Zieger, P.; Fierz-Schmidhauser, R.; Gysel, M.; Ström, J.; Henne, S.; Yttri, K. E.; Baltensperger, U.; Weingartner, E. Atmos. Chem. Phys. 2010, 10, 3875-3890. 